EXPLORATORY INVESTIGATION OF ORGANIZATION POWER, AND

ITS IMPACT ON STRATEGY IMPLEMENTATION AND FIRM

PERFORMANCE: A STUDY OF THE HOSPITALITY

FRANCHISE SYSTEMS

\author{
by \\ Haragopal Parsa \\ Dissertation submitted to the Faculty of the \\ Virginia Polytechnic Institute \& State University \\ in partial fulfillment of the requirements for the degree of \\ Doctor of Philosophy
}

in

Hospitality and Tourism Management

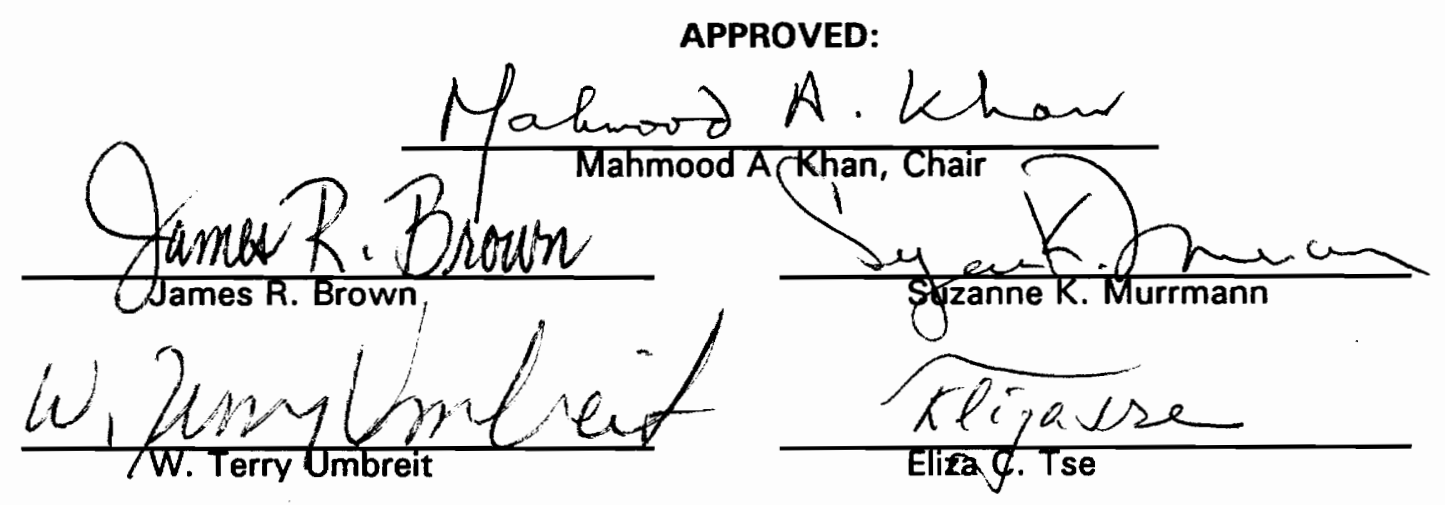

January, 1994

Blacksburg, Virginia 
总 


\title{
EXPLORATORY INVESTIGATION OF ORGANIZATION POWER, AND \\ ITS IMPACT ON STRATEGY IMPLEMENTATION AND FIRM \\ PERFORMANCE: A STUDY OF THE HOSPITALITY \\ FRANCHISE SYSTEMS
}

\author{
by \\ Haragopal Parsa \\ Mahmood A. Khan, Chair \\ Department of Hospitality and Tourism Management
}

\begin{abstract}
Franchising is the primary force in the growth and survival of the hospitality industry. Franchise systems contain legally independent, economically interdependent, and politically affective franchise organizations. Strategic management in hospitality franchise systems with emphasis on implementation methods is investigated in the present study. Impact of sources of power (economic and noneconomic), held by the franchisors, on franchisees' strategy implementation process and eventual performance are also included in this study. Single unit Quick Service Restaurant (QSR) franchisees from six different concepts have participated in this study. A total of ten research hypotheses are empirically tested using various statistical procedures.
\end{abstract}

The current study demonstrates that implementation plays an important role in determining performance (satisfaction) of an organization. It also shows that sources of power impact organizational performance (satisfaction) whether measured as revenues or profits. The QSR franchisees' satisfaction with franchise arrangements is affected by the nature power sources. The results indicate that some implementation models are more effective than others, and different performance objectives demand different implementation models. The "match" between the outcome objectives and the implementation model is essential to achieve the 
desired performance. Different sources of power (coercive, legitimate, referent, and information) have varying effects on organizational performance, financial or nonfinancial.

Originality of the instrument is one of the major methodological contributions of the study. Positive and statistically significant results achieved in the current study offer empirical validity to the instrument. Another major contribution is the confirmation of earlier studies by several authors on relation between power and satisfaction, and power and performance using the hospitality industry setting. The results also indicate that for long term survival, the OSR franchisees must consider different implementation models and their congruence with the nature of power present in the franchise system. 
S would like to dedicate this manuscript to my late father and loving mother.

iv 


\section{ACKNOWLEDGEMENT}

In search of Akshara Moksha I crossed five seas and four continents only to learn that the doctor of philosophy is only a first step in a thousand mile walk. I would like to take an opportunity to recognize the people who helped me in taking this first step.

This project could not have been realized without the continuous support and encouragement of Prof. Mahmood A. Khan, my doctoral advisor. I cannot thank him enough for the innumerable number of hours he spent in discussing, teaching, advising, coaching, counselling, and finally demanding excellence in academic pursuit. $\mathrm{He}$ is the best guide and a mentor a doctoral student can ask for.

Quality of this project is enhanced manyfold with the valuable conceptual, theoretical and methodological input from Dr. James R. Brown. He was always there to answer my questions and provide the support needed. I take pride to state that I always came out of his office little wiser than before. I most sincerely thank him for his commitment to this project in spite of the personal tragedy. It is truly a learning experience to work with Dr. Brown, a walking reference in marketing channels literature.

I cannot appreciate enough the support and encouragement I received from Dr. Suzanne K. Murrmann through the past few years. She was very patient with my mistakes all through the graduate studies and especially this project. Dr. Murrmann is a wonderful teacher and a colleague. Her valuable suggestions in methodology and theory building are sincerely appreciated. 
Appreciation is extended to Dr. Eliza C. Tse for her helpful suggestions, for her attention to details in preparing the manuscript, and innumerable class discussions. I would like to thank Prof. W. Terry Umbreit for his continued support, encouragement and personal interest in the research topic.

Several teachers were instrumental in developing many of the theoretical concepts and research methods presented in this project. Especially I would like to thank Prof. Tom Mentzer, Prof. Pamela A. Weaver, Prof. Kent Monroe and Dr. Noreen Klein.

I would like to thank Francis A. Kwansa and Mohan Rao Balmoori for their support and encouragement through the challenging times of graduate school; and Dr. Chekitan Dev, for his comments and suggestions.

Sincere thanks are extended to Dr. Dennis K. Ponton, Head, Department of Nutrition and Food Science, SUNYC-Buffalo, for his continued support and encouragement. Acknowledgement is extended to Dr. R. Karen O'Quin and Ms. Barbara Metivier of SUNYCBuffalo for their generous assistance in statistical analyses. I cannot thank enough Ms. Christine M. Szymanski at SUNYC-Buffalo for her assistance in preparing figures, tables, and the final document. Partial support for this project is provided by the State University of New York College at Buffalo which is gratefully acknowledged.

Finally, I am grateful to my family for their support through the ordeal of graduate work which culminated in this manuscript. I am indebted to my family for their cooperation, love, encouragement, patience, and support through the past few years in completing this task. According to them, I spent more hours with the computer than with the children. 
Above all, I am ever grateful to Mrs. G. Satyakumari and Dr. G.S. Murthy, eldest sister and brother-in-law, for their love and dedication to my family, and selfless support and infinite encouragement they provided us through the years. 


\section{TABLE OF CONTENTS}

Chapter 1 INTRODUCTION AND OVERVIEW $\ldots \ldots \ldots \ldots \ldots \ldots \ldots$

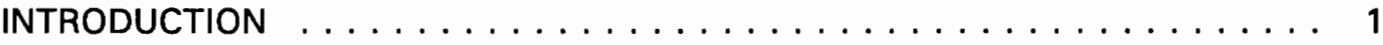

FRANCHISING IN THE ECONOMY $\ldots \ldots \ldots \ldots \ldots \ldots \ldots \ldots$

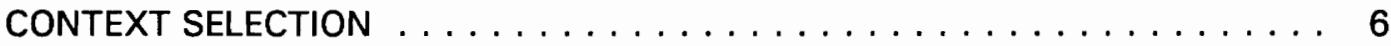

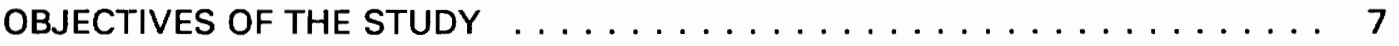

OVERVIEW OF THE CHAPTERS $\ldots \ldots \ldots \ldots \ldots \ldots \ldots$

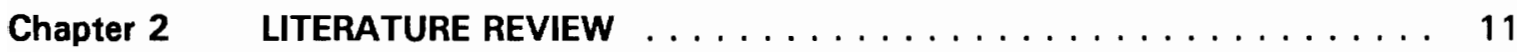

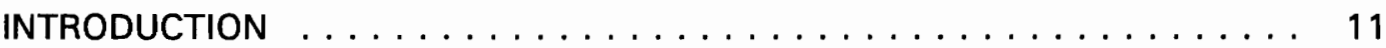

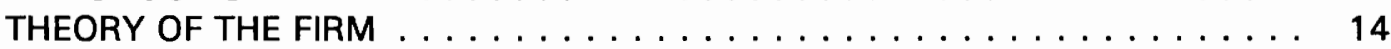

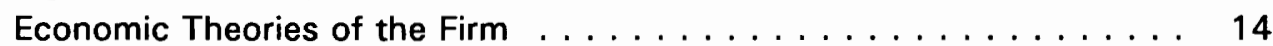

Behavioral Theories of the Firm . . . . . . . . . . . . . 17

Political Economy Perspective . . . . . . . . . . . . . . . . . . 20

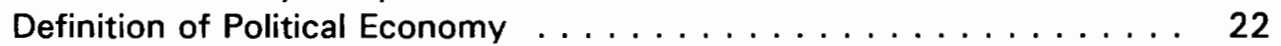

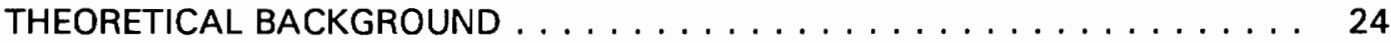

The Concept of Power . . . . . . . . . . . . . . . . 27

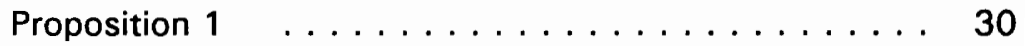

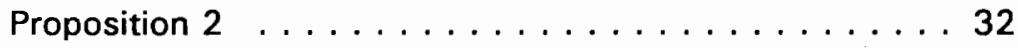

Strategy Implementation Process . . . . . . . . . . . . . . . 32

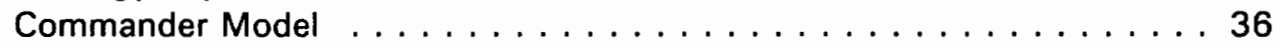

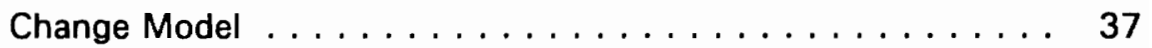

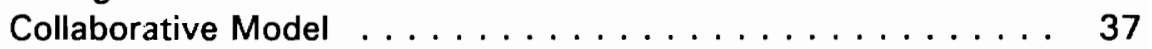

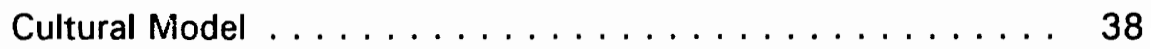

Crescive Model ..................... 39

Proposition $3 \ldots \ldots \ldots \ldots \ldots \ldots$

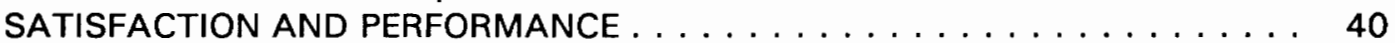

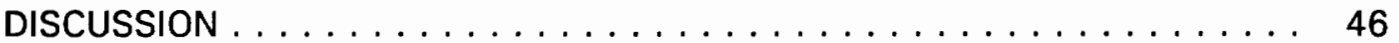

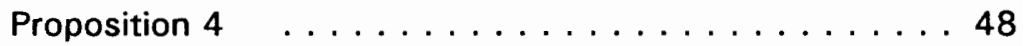

SUMMARY ........................... 50

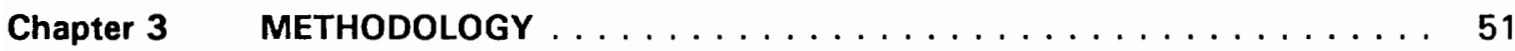

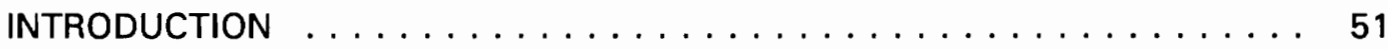

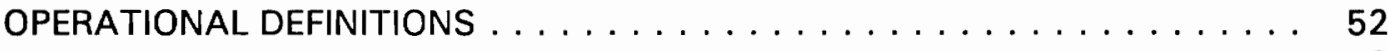

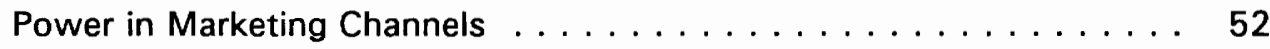

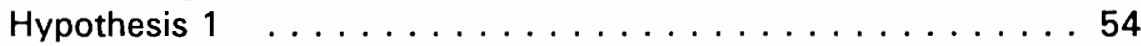

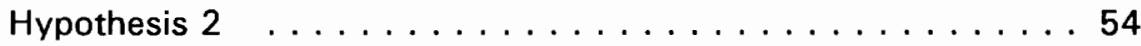

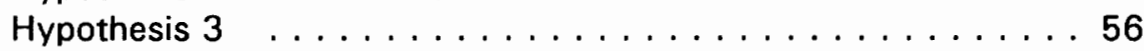

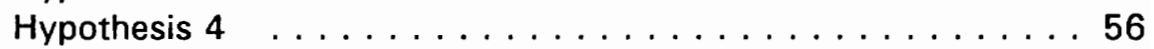

Strategy Implementation Process . . . . . . . . . . . . . 59

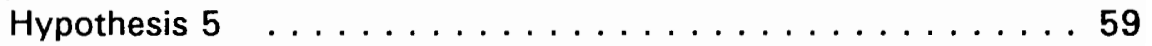

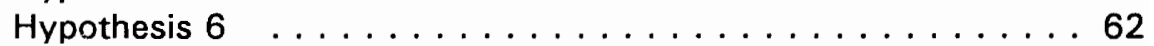


Power and Strategy Implementation . . . . . . . . . . . . . 62

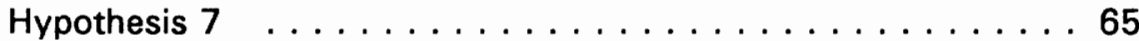

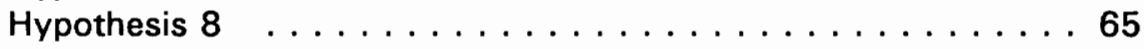

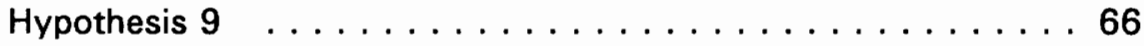

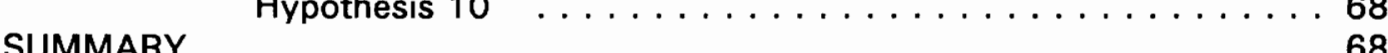

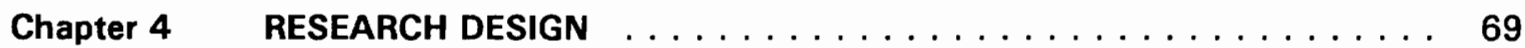

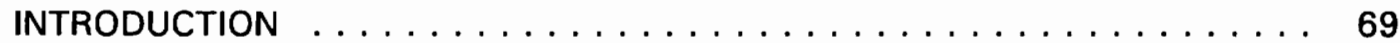

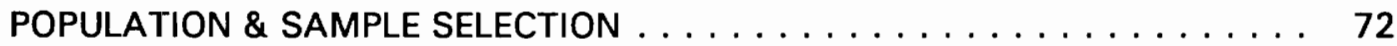

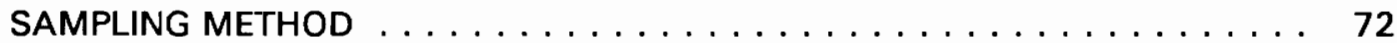

SAMPLE SIZE SELECTION $\ldots \ldots \ldots \ldots \ldots \ldots \ldots \ldots \ldots \ldots \ldots$

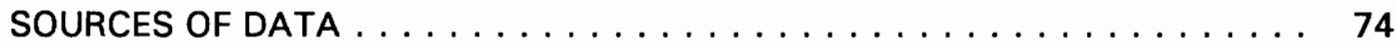

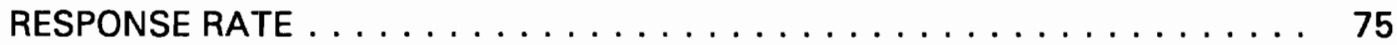

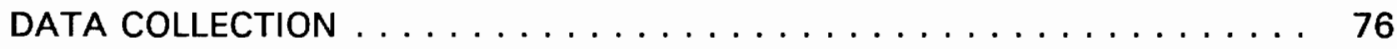

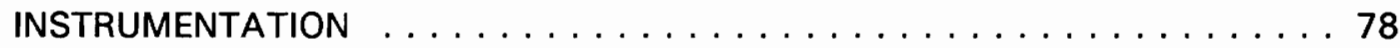

VALIDITY AND RELIABILITY $\ldots \ldots \ldots \ldots \ldots \ldots \ldots \ldots \ldots$

PRE-TESTING METHODS $\ldots \ldots \ldots \ldots \ldots \ldots \ldots \ldots \ldots \ldots$

SURVEY INSTRUMENT $\ldots \ldots \ldots \ldots \ldots \ldots \ldots \ldots \ldots \ldots \ldots \ldots$

INSTRUMENT SCALE $\ldots \ldots \ldots \ldots \ldots \ldots \ldots \ldots \ldots \ldots \ldots \ldots$

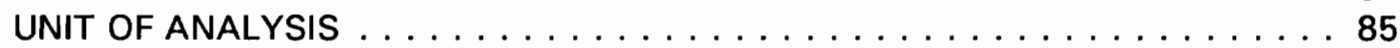

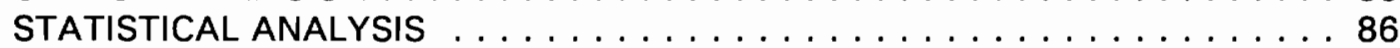

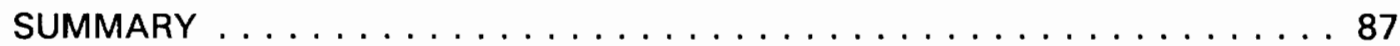

Chapter $5 \quad$ RESULTS AND ANALYSIS $\ldots \ldots \ldots \ldots \ldots \ldots \ldots$

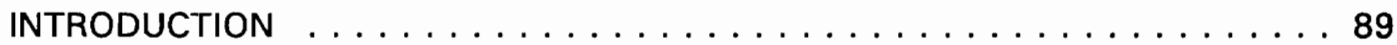

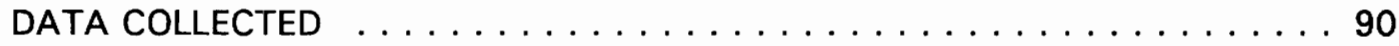

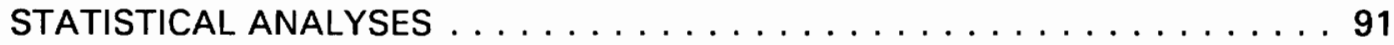

PROFILE OF PARTICIPATING OSR FRANCHISEES $\ldots \ldots \ldots \ldots \ldots \ldots$

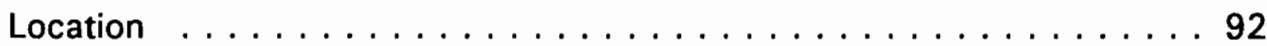

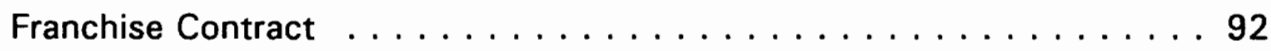

Demographic Data . . . . . . . . . . . . . . . . . . 96

Tenure with the Current Franchisor . . . . . . . . . . 103

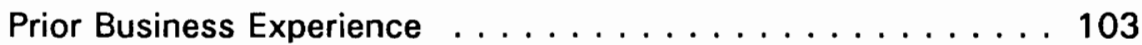

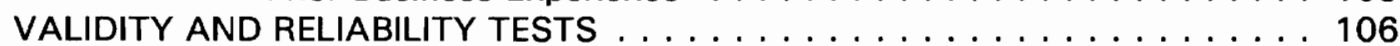

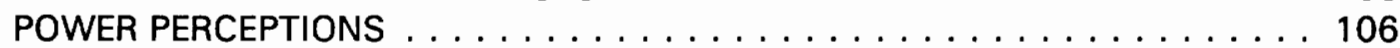

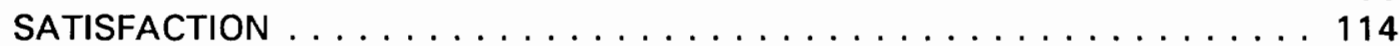

FINANCIAL PERFORMANCE $\ldots \ldots \ldots \ldots \ldots \ldots \ldots \ldots \ldots$

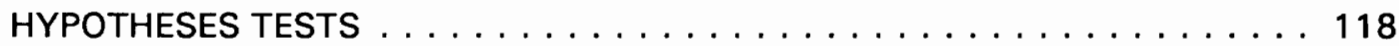

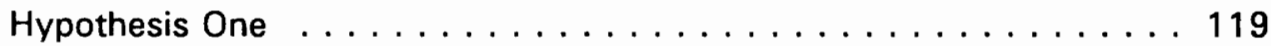

Hypothesis Two . . . . . . . . . . . . . . . . . . . 120

Hypothesis Three . . . . . . . . . . . . . . . . . 123

Hypothesis Four . . . . . . . . . . . . . . . . . 126

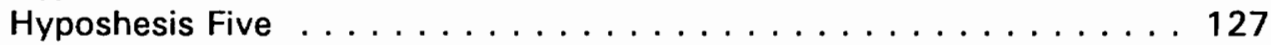

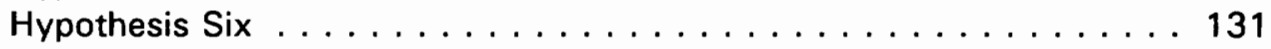

Hypothesis Seven . . . . . . . . . . . . . . . . 137

Hypothesis Eight . . . . . . . . . . . . . . . . . . 142 
Hypothesis Nine . . . . . . . . . . . . . . . . . . . . . . 144

Hypothesis Ten . . . . . . . . . . . . . . . . . . . . 147

RESULTS FROM MULTIPLE REGRESSION ANALYSIS . . . . . . . . . . . 150

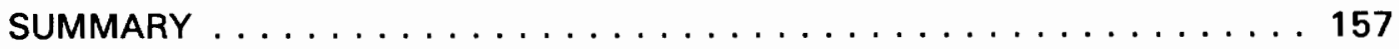

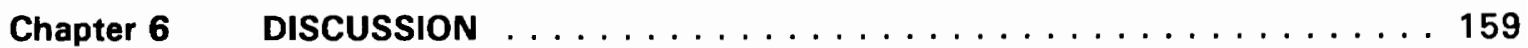

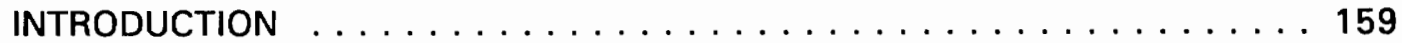

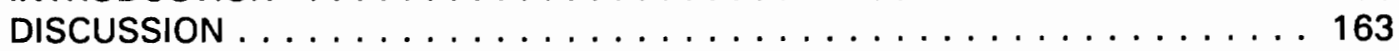

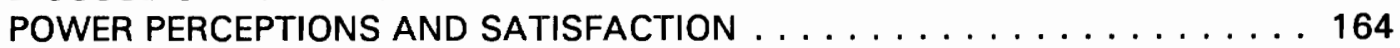

POWER PERCEPTIONS AND FINANCIAL PERFORMANCE $\ldots \ldots \ldots \ldots \ldots \ldots$

STRATEGY IMPLEMENTATION $\ldots \ldots \ldots \ldots \ldots \ldots \ldots \ldots$

POWER, IMPLEMENTATION, AND PERFORMANCE

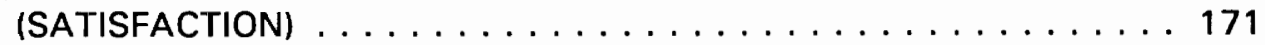

ECONOMIC POWER AND IMPLEMENTATION . . . . . . . . . . . . . . . . 172

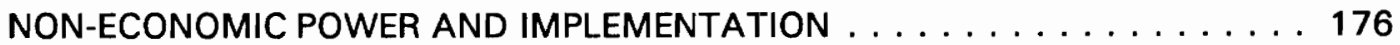

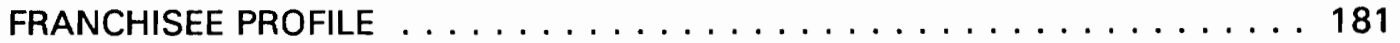

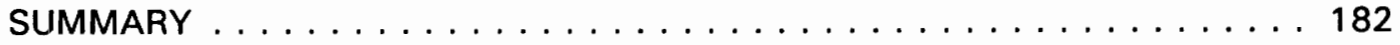

Chapter $7 \quad$ CONCLUSIONS $\ldots \ldots \ldots \ldots \ldots \ldots \ldots \ldots$

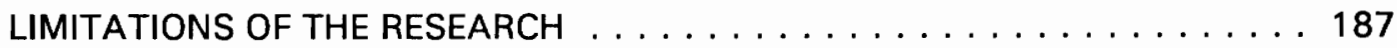

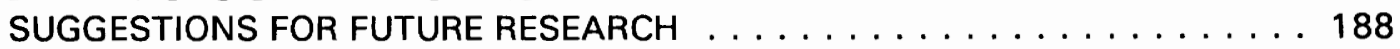

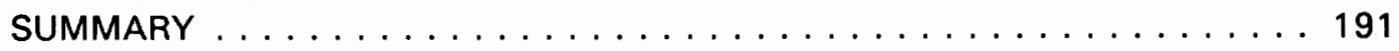

\section{REFERENCES}

\section{APPENDIX}

APPENDIX I APPENDIX II APPENDIX III -

APPENDIX IV APPENDIX $V$ APPENDIX VI APPENDIX VII APPENDIX VIII APPENDIX IX -
Definitions of Key Concepts in the Political Economy Framework Integrative Review of Political Economy Literature Integrative Review of Power in Marketing Channel Literature List of Theoretical Propositions (Research) List of Hypotheses List of Participating OSR Franchises Cover Letter Survey Instrument Research Summary Table 


\section{LIST OF ILLUSTRATIONS}

Figure 1

Figure 2

Figure 3

Figure 4

Figure 5

Figure 6

Figure 7 


\section{LIST OF TABLES}

Table 1 Profile of the Participating QSR Franchisees: Classification of Franchisor . ...................... 93

Table 2 Profile of the Participating QSR Franchisees: Classification by Location . . . . . . . . . . . . . . . . . . . . . . . 94

Table 3 Profile of the Participating QSR Franchisees: Classification by Franchise Contract . . . . . . . . . . . . . . . . . . 95

Table 4 Demographic Profile of the Participating QSR Franchisees:

Classification by Gender . . . . . . . . . . . . . . . . . 98

Table 5 Demographic Profile of the Participating OSR Franchisees:

Classification by Age . . . . . . . . . . . . . . . . . . . . 99

Table 6 Demographic Profile of the Participating OSR Franchisees:

Classification by Level of Education . . . . . . . . . . . . . . . . . 100

Table 7 Demographic Profile of the Participating QSR Franchisees:

Classification by Annual Salary . . . . . . . . . . . . . . . . . . 101

Table 8 Demographic Profile of the participating QSR Franchisees:

Classification by Income from Other Sources . . . . . . . . . . . 102

Table 9 Demographic Profile of the Participating OSR Franchisees:

Classification by Tenure with the Current Franchisor . . . . . . . . . . 104

Table 10 Demographic Profile of the Participating OSR Franchisees:

Classification by Years of Prior Business Experience . . . . . . . . . . 105

Table 11 Demographic Profile of the Participating QSR Franchisees:

Classification by the Nature of Prior Business Experience . . . . . . . 107

Table 12 Reliability Values for Multi-Item Research Constructs . . . . . . . . 108

Table 13a Factor Analysis of Sources of Power $\ldots \ldots \ldots \ldots \ldots \ldots \ldots \ldots$

Table $13 b \quad$ Factor Loadings for Sources of Power $\ldots \ldots \ldots \ldots \ldots \ldots \ldots$

Table $14 \quad$ Factor Correlation Matrix $\ldots \ldots \ldots \ldots \ldots \ldots \ldots \ldots \ldots$

Table 15 Factor Analysis: Eigen Values and Other Statistics $\ldots \ldots \ldots \ldots$

Table 16 Correclational Coefficient Values Between the Economic and Noneconomic Power Sources and Satisfaction . . . . . . . . . . . 121 
Table 18 Correlational Coefficient Values Between the Economic and Noneconomic Power Sources and Financial Performance . . . . . . . . 125

Table 19a One-way Analysis of Variance: Strategy Implementation and Financial Performance (IBFC) with All Five Implementation Groups Included

Table 19b One-Way Analysis of Variance: Test for Homogeneity Strategy Implementation and Financial Performance (Sales per Year) . . . . . . . 132

Table 20 One Way Analysis of Variance: Four Implementation Models and Performance (Sales per Year) . . . . . . . . . . . . . . 133

Table 21 One Way Analysis and Variance: Four Implementation Models and Performance (IBFC) . . . . . . . . . . . . . . . . . . . . . 134

Table 22 One Way Analysis: Four Implementation Models and Satisfaction ......................... 136

Table 23 Results of Multiple Discriminant Analysis: Economic Power, Financial Performance (IBFC and Sales per Year) and Satisfaction . . . . . . . . 141

Table 24 Results of Multiple Discriminant Analyses: Non-Economic Power, Financial Performance (IBFC and Sales per Year) and Satisfaction . . . 146

Table 25a Results of Multiple Regression: Sources of Power, Implementation and Satisfaction . . . . . . . . . . . . . . . . . . . . . 152

Table 25b Results of Multiple Regression: Sources of Power, Implementation, and Income Before Fixed Charges . . . . . . . . . . . . . . . . . 153

Table 25c Results of Multiple Regression: Sources of Power, Implementation, and Sales per Year . . . . . . . . . . . . . . . . . . . . 154

Table 26 Multiple Discriminant Analysis: Discriminant loadings for Economic Sources of Power, Implementation, Satisfaction and Performance . . . 175

Table 27 Multiple Discriminant Analysis: Discriminant loadings for Noneconomic Sources of Power, Implementation, Satisfaction, and Performance . . . 177 


\section{Chapter - 1}

\section{INTRODUCTION AND OVERVIEW}

\section{INTRODUCTION}

Franchise systems can be described as systems of interdependent organizations that, through negotiation and exchange, are involved in the process of making a product or service available to the consumer (adapted from Murray 1987). Carman and Klein (1986) described franchise systems as the most important type of contractually linked vertical marketing systems. These contractual arrangements occupy middle ground between highly integrated lall company-owned) systems and atomistic or decentralized entrepreneurial markets. Nature of these contractual arrangements could be as varied as the number of contracts written.

Early research in the field of franchising was predominantly economic in nature. During the past two decades, a significant stream of research has developed which expanded the research interest in franchising beyond economics into the behavioral and political-economic aspects. Behavioral scientists preferred to measure effectiveness of a franchise system in terms of conflict resolutions, interorganizational cooperation, balance of power, and participating 
member satisfaction. Eventually, research in behavioral aspects of franchising have dominated the field while political-economy perspective received little attention. This obvious lack of research interest in political-economy perspective was corrected later by the contributions of Stern and Reve (1980); Arndt (1983); Achrol et al. (1983) and others.

Conceptually rich political-economy framework is integrative in nature, and presents good potential to explain various phenomena in franchising. It offers a unifying, pragmatic framework by encompassing major economic and sociopolitical constructs. It also overcomes some of the limitations of economic and behavioral perspectives. Hence, political-economy framework is considered for the current research to study the hospitality franchise systems.

In franchise systems, participating member make series of decisions to achieve set objectives, behavioral, economic, and/or political. Study of organizations' decision content and process has evolved into a discipline under the rubric of Strategic Planning (Chandler 1962; Thompson 1967; Mintzberg 1978; Miles and Snow 1978; Ansoff 1980; Porter 1980). The process of accomplishing strategic objectives is referred to as Strategy Implementation (Galbraith and Nathanson 1978; Quinn 1980; Nutt 1983; Bourgeois and Brodwin 1984). Together strategic planning and implementation are referred to as Strategic Management (Thompson and Strickland 1991, p3). It is argued that nature of strategy content and methods of implementation chosen by a firm affects its ability to achieve desired objectives.

In the case of franchise systems, very limited information is available on how franchise system participants conduct their strategic management (development of strategy content and implementation of strategic plans) to achieve their desired objectives. Therefore, in the current study, an attempt has been made to understand the impact of various implementation methods 
on franchise system participants' goal achievement. Because of various limitations such as administrative constraints, monetary resources and time, the strategy content is not considered at present.

Franchise systems consist of interdependent, symbiotic, individual members or organizations. That means, members of a franchise system, franchisors or franchisees, depend on each other's objectives and performance to accomplish their individual goals. According to Justis and Judd (1989), the nature of this unique phenomenon of interdependence in franchise systems, exists in three forms: business form; legal form; and agreement form to honor each others' independence.

In franchise systems, because of inherent interdependence of the participants, a franchise member's performance could be significantly affected by the level of performance of the other members. Therefore, inclusion of research constructs that are very relevant in understanding franchise systems such as interdependence, conflict, power, and cooperation is essential in evaluating performance determinants of a franchise member. To fulfill this need, and to understand performance variance among franchise participants, the behavioral construct of power leconomic and noneconomicl, along with the strategic construct (implementation method) are considered in the current study. 


\section{FRANCHISING IN THE ECONOMY}

Franchising, in the current form, is an American phenomena that evolved into an unique business format with worldwide acceptance. Roots of franchising may be traced back to the Middle Ages. The term franchise originated from a French word, meaning "free from servitude" (Khan 1991 p3). In United States, McCormick Harvesting Company is credited for commissioning 'exclusive local agents' to sell its farm machinery, the earliest indication of franchising (Justis and Judd 1989). Later, the automobile industry used franchise format extensively to distribute its products. Dramatic growth of the U.S. hospitality industry during the 1960 s through the early 1980 s is attributed to franchising (Parsa and Khan 1992).

Franchising has contributed over one third $(34$ percent) of all retail sales in the United States. Franchise restaurants have contributed approximately $\$ 77$ billion to U.S. economy which is 12 percent of total franchise sales. Sales for franchised restaurants are expected to grow by 9.8 percent to $\$ 85.5$ billion in 1991 . Franchised restaurants have traditionally been classified as business-format franchises. In U.S.A., business-format franchise establishments have increased over 50 percent from 1980 to 1990 while their sales increased 150 percent reaching during the same period (International Franchise Association 1990). Franchising is projected to be the dominant form of business format in the 21 st century.

In the U.S. restaurant industry, earliest practice of franchising is credited to A \& W Root Beer restaurants (Khan 1991). Later, Howard Johnson's Restaurants, Ray Krock of McDonalds, and Colonel Sanders of Kentucky Fried Chicken popularized the concept of franchising. Many restaurant firms extended the franchising concept to the international markets with varying 
degrees of success. In this country, the largest concentration of franchised restaurants is in Texas, Ohio, California and Florida (International Franchise Association 1990).

According to Emerson (1990 p61), during the 1980s, many restaurant firms have returned to franchising as a major vehicle of growth. This renewed attention to franchising is followed by increasing number of franchise litigations. The Committee on Small Business of the 101 st U.S. Congress clearly recognized the importance of behavioral aspects of franchising and recommended a review of franchisor-franchisee relationships involving franchisee abuses (LaFalce 1991). The Committee recommendations relevant to franchisor-franchisee relations include :

* Creation of federal right of action for franchisees and potential franchisees who sustain loss or injury as a result of violation of federal requirements and to the conduct of franchise relationships.

* Development of federal standards of good cause relating to franchise terminations, renewals, and transfers of franchises.

* Restriction on the use of procedural devices in franchise agreements that seek to shield franchisors from legal liability or inhibit the exercise of legal rights by franchisees.

Franchise related conflicts in the restaurant industry may be due to differences in interpretation of legal contracts (Pizza Hut and PMI Corp. of San Antonio, Texas); menu pricing policies (Taco Bell's Value Menu); menu expansions (Wendy's breakfast program and its franchisees); strategic direction of the franchise system (Burger King and its franchisees); 
compliance with the quality standards (McDonalds Corp. and its franchisee in Paris, France); market share loss and territorial encroachment (Little Caesars' Pizza Inc. and its franchisees); building renovation requirements; and others. To avoid expensive legal battles and to promote positive franchise relations, franchisors often develop franchisee advisory councils. Though franchisee advisory councils are often effective, they are not 'cure alls' for franchise related problems. Management of franchise relations and their impact on franchisee satisfaction and performance deserve further understanding.

In light of increasing importance of franchising in U.S. economy in general and hospitality industry in particular, the proposed study attempts to evaluate performance variance among the franchise restaurant firms.

\section{CONTEXT SELECTION}

Franchising has been the backbone of the growth of the restaurant industry. Majority of the franchise restaurant firms belong to the Quick Service Restaurant (QSR) segment of the hospitality industry. According to the Nation's Restaurant News (NRN) (1991) eight of the top ten restaurant firms are in the OSR segment. McDonalds is the world's largest restaurant firm when measured by sales, while PepsiCo has the largest number of restaurant units in the world. The ratio between the franchisee-owned restaurants and franchisor-owned restaurants is usually three to one. That means there are three times more franchised restaurants than companyowned restaurants. Significant number of franchised restaurants fall under Quick Service Restaurant (QSR) segment. Eight of the top ten multi unit restaurant chains, according to NRN 
(1991), are in the OSR segment. Hence, for the current study, OSR segment is selected to test the research hypotheses on franchising.

\section{OBJECTIVES OF THE STUDY}

The primary objective of the study is to investigate the relation between organization power, strategy content, implementation process, and firm performance in hospitality franchise systems. In this study it is also intended to explore the indirect effects of chosen constructs on firm performance. As mentioned earlier, franchising has been the backbone of the Quick Service Restaurant industry (OSR) (Parsa and Khan 1991). Approximately seventy percent of all the QSR units are franchised (Nation's Restaurant News 1991). During the past decade, there were numerous reported conflicts between QSR franchisors and franchisees with potential impact on long term business performance. Hence, the current study is limited to QSR franchise systems. Major objectives of the current study include:

1. To investigate the relationship between sources of power and firm performance (satisfaction) in OSR franchise systems.

2. To determine if there are significant differences in the level of performance (satisfaction) of OSR franchises grouped according to the strategy implementation models. 
3. To determine, if there are any significant differences in the level of performance (satisfaction) of those QSR franchises that achieve a "match" between strategy implementation method and the sources of power, and those that do not.

Theoretical relations among the research constructs, power, implementation process, and performance (satisfaction) are presented later. Nature of the research constructs; and direction and magnitude of their interrelationships will be discussed in the next section.

\section{OVERVIEW OF THE CHAPTERS}

The primary purpose of Chapter One, Introduction and Overview, is to introduce the concept of franchising and its importance to the hospitality industry. It also describes the importance of franchising in the U.S. economy. This chapter also includes criteria for context selection and overview of the research design.

The second chapter, Literature Review, is concerned with an overall review and conceptualization. Only relevant literature is reviewed so as to develop a theoretical rationale for the proposed study, and from the existing body of knowledge research propositions are developed. This is accomplished by integrating three different streams of research (marketing channels; strategic management; and hospitality literature) connected by the common thread of franchising. 
The literature review is organized into four sections: Theory of the Firm; Theoretical Background; Satisfaction and Performance; and Discussion. The first section, Theory of the Firm, discusses the fundamental question of the nature of firm, which has not yet been addressed in the hospitality literature. It also introduces the political economy framework as an integrative framework. The second section, Theoretical Background, discusses the interrelationships between the behavioral and strategic constructs and their relation to performance (satisfaction). Theoretical propositions are presented. The third section, Satisfaction and Performance, discusses the rationale for selecting two dependent measures, satisfaction and performance. The last section, Discussion, includes discussion of relations among the individual research constructs and propositions. There are four propositions in total.

The third chapter, Methodology, is concerned with operational definitions, research design, methodology, development of research hypotheses, and data collection methods. It is divided into two major sections: objectives of the study; and operational definitions. Objectives of the study include broad outlines. The second section, Operational Definitions, includes development of research hypotheses relating research constructs power, implementation process, and performance (satisfaction). In total ten hypotheses are presented.

The fourth chapter, Research Design, consists of various methodological issues such as population selection; sample size; response rate; validity and reliability; instrument development and pretesting; analysis of responses and comments from the research subjects. Proposed statistical methods include descriptive statistics, correlational studies, factor analysis, multiple discriminant analysis, and multiple regression. 
The fifth chapter, Results and Analysis, includes tabulation of results, explanation of the research outcomes, explanation of error terms, confirmation or disconfirmation of research hypotheses, and interpretation of statistical analyses. It also includes profile of the respondents. Discussion of validity and reliability of the obtained results are also included.

The sixth chapter, Discussion, includes discussion of research results, explanation of anomalies, extension of research results, implications for the hospitality industry, contribution of the study to the hospitality, marketing channels and strategy management literatures.

The seventh chapter, Conclusions and Suggestions, consists of methodological and theoretical limitations of the current study and suggestions for future research. It extends the research results into the hospitality industry. It also includes propositions for future studies. 


\section{Chapter 2}

\section{LITERATURE REVIEW}

\section{INTRODUCTION}

For many years both researchers and practitioners have attempted to learn why some organizations achieve higher levels of performance than other organizations. To enhance their understanding of differences in performance, researchers first preferred to consider the nature of a firm. Over the years, this general area of enquiry on the nature of a firm has fallen under the rubric of "theory of firm." Many attempts have been made to describe a typical firm from different perspectives. There are two main streams of research that try to explain why and how firms emerge, succeed, survive, and decline: the economic perspective and the behavioral perspective. They are not mutually exclusive, but have rarely been pursued simultaneously.

Arndt (1983) attempted to study economic and behavioral perspectives together in a political economy framework. This framework was based upon the dimensions presented earlier by Stern and Reve (1980). In the current study, an attempt was made to extend political 
economy framework to strategy management and present alternative explanations for the observed differences in organizational performance. Presented propositions will be tested in the hospitality industry franchise systems.

Arndt (1983), with his model, attempted to broaden the theory of a firm to include external economic and social forces, and their interaction with the internal structure and process. According to Arndt (1983), an organization is better defined as a social unit attempting to optimize its resource utilization, considering the constraints placed on it by its external environment. The goals and objectives selected by a firm are the result of analysis of internal resources and external opportunities. Therefore, the purpose of a firm is not necessarily a single phenomenon of profit maximization or shareholders' wealth maximization as commonly advocated by economists, but also resource optimization and maximization of constituent satisfaction as argued by social scientists.

This brings back to the original question of differences in performance. Since all firms do not have the same basic purposes, goals, and objectives, a thorough understanding of the process of organization goal formulation and implementation is essential in determining the causes of differences in organizational performance. The goal setting process is not a static element but a necessary and recurring dynamic process (Thompson and McEwen 1958). The tools used by top management in developing a firm's goals and objectives, in order to optimize their resource utilization, is called strategy (Hofer and Schendel 1978).

Chandler (1962), in his seminal work, tried to explain the impact of strategy on organization performance with strategy-structure-performance paradigm. In exploring the possible sources of variance in firm performance, Miles and Snow (1978) and later Porter 
(1985), have presented different strategic typologies. Strategic typologies state that, in brief, variances in performance among different firms is contingent upon the firm's ability to achieve congruence between its preferred strategy content and its environment.

Interestingly, most of the strategy management literature (process and content) tries to explain differences in organizational performance by considering variations in strategy content (Chandler 1962; Rumelt 1974; Buzzell, Gale, and Sultan 1975; Miles and Snow 1978; Porter 1985; Hambrick 1983). The probable underlying assumptions in relating strategy content directly to the firm performance are that the behavioral aspects and strategy implementation processes are constant or irrelevant across the firms under consideration. Such assumptions repudiate the behavioral dynamics and their importance in strategy implementation process and consequential firm performance.

Organizations are not static entities but are dynamic and goal setting social entities. All organizations are in continuous change whether from the subtle process of environmental infusion, or by the intentional design of the powerful role players from within management, or by the collective will of organizational participants whose destiny is linked in some way to the changes (Achrol et al. 1983). Hence, the strategy outcomes, measured by firm performance, are contingent upon the firm's ability to successfully implement the agreed upon strategic goals.

Strategy implementation process and consequent performance of a firm are often affected by various organizational dynamics. Behavioral aspects of a firm, such as intrafirm conflict resolution, functional area interdependence, power and politics within the top management, and management of human resources tend to impact the implementation process 
and affect the probability of performance outcomes. By either considering constant or ignoring the behavioral aspects of a firm, the strategy content literature is limiting its potential to explain performance variance. Therefore, in the current study an attempt has been made to understand the impact of behavioral variables and implementation process on organization performance. The current study focusses on organization power and its effect on strategy implementation process and organization performance.

\section{THEORY OF THE FIRM}

To comprehend the process and content of goal formation and objective selection of a firm it is imperative to understand its nature. Nature of the firm is explored by various researchers from different fields such as sociology, economics, political science, law, marketing, finance and organization behavior. Relevant literature on nature of the firm is often classified under the category of 'theory of the firm'. The theory of the firm researchers, depending upon their choice of perspective, consider the firms as economic, behavioral, or politico-economic entities in nature. A review and analysis of relevant theories of the firm and the underlying assumptions are included here.

\section{ECONOMIC THEORIES OF THE FIRM}

Economists are the earliest social scientists to investigate the nature of a firm. According to Hawkins (1973), "The theory of the firm is one of the cardinal elements of economics because of the variety of uses it serves throughout the whole of economic analysis." 
Knowledge of the way in which organizations behave is essential in understanding organizational goals and objectives. Some of the economic theories of the firm include utility maximization, revenue (output) maximization, market value model and agency cost theory.

The commonly accepted profit-maximization theory of the firm is derived from the neoclassical models. Profit maximization theory is one of the earliest explanations of nature of the firm. Its origin can be traced to the classical works in economics by Smith (1776), Marshall (1890), Robinson (1933), and Chamberlin (1953). Early economists assumed that, over the long run, competitive forces would cause natural and market prices to coincide. Another assumption is that, under perfect competition, the cost of production, and supply and demand factors determine the profit levels of a firm. Under these conditions the owner's decision will be to set output at the point where marginal costs will equal marginal revenues (Anderson 1982). Hence, the objective of a firm would be single period profit maximization.

Some of the limitations of the profit maximization theory include: 1) it may not reflect the reality since it is based on a static model of perfect competition. Firms are too complex and dynamic to fit in a academic and theoretical model such as perfect competition; 2) Perfect competition is neither ideal (Robinson 1933) nor desired; 3) The profit maximization model suffers from an inability to consider risk differences among investment alternatives (Fama and Miller 1972).

Many financial economists have abandoned this theory in favor of more refined models. Profit maximization assumption, in spite of its limitations, is predominant in marketing management (Anderson 1982) and strategic management literature. Some of the most 
commonly used measures of firm performance in the strategy literature are the profitability indicators such as return on sales (ROS) and earnings before interest and tax (EBIT).

To overcome some of the limitations of profit maximization theory numerous alternate explanations were presented. According to Papandreou (1952), the objective of a firm would come about as a result of internal and external pressures and would be some kind of amalgam of the preferences of the various sections of the organization. This led to the development of utility maximization theory (Hawkins 1973). Revenue maximization theory was popularized by Roberts (1959), Baumol (1958) and McGuire (1962). In marketing literature, Buzell, Gale and Sultan's (1974) argument for increase in market share as the major objective of a firm is partially based on revenue maximization theory. In spite of theoretical refinement, these arguments also suffer from many limitations attached to their predecessor, the profit maximization theory.

Later theories of the firm, from economic perspective, include the market value model (Fama and Miller 1972) and the agency cost theory (Jensen and Meckling 1976). According to the market value model the major objective of a firm is to maximize present market value of the firm. In other words, all major decisions are treated as investments. Major assumptions of this theory include: 1 ) the management has same objective as the shareholders; 2) all shareholders have similar goals; and 3) shareholders have enough control over the management to achieve market value maximization.

Jenson and Meckling (1976) proposed the agency cost theory to address some of the inherent limitations in the market value model. Separation of ownership and control in modern corporations gives rise to an agency relationship between the stockholders and managers of the 
firm (Anderson 1982). An agency relationship may be defined as "a contract under which one or more persons (the principal(s) engage another person (the agent) to perform some service on their behalf which involves delegating some decision making authority to the agent" (Jensen and Meckling 1976, p.308). Major contribution of this theory is the explicit separation of principal owner(s) from the management. In other words, owner(s) that is (are) responsible for defining a firm's mission is separate from management that is responsible for developing and implementing organization strategies. The agency cost theory offers more realistic alternative to the earlier theories of the firm.

In brief, economic theories of the firm are based on the assumptions of perfect competition and rational decision making by management to accomplish shareholders' objectives. Economic theories are dominated by normative approach and quantitative methodology. Among economic theories of the firm, profit maximization and agency cost theories are most commonly accepted.

\section{BEHAVIORAL THEORIES OF THE FIRM}

Behavioral Theories are among the most dramatic of the new approaches to the theory of the firm. To state in broader terms, behavioral theories of the firm often stress coalitional nature of organizations, and emphasize the role of behavioral rather than economic factors in explaining the activities of a firm. Hawkins (1973), states that "behavioral theories dispense with the assumption that firms aim to maximize anything - even utility." Instead of hypothesizing about how rational people respond to various situations or saying how should 
they respond (normative approach), behavioral approaches attempt to study how firms, in reality, take decisions in practice (descriptive approach).

Simon (1955, 1964), basing on psychological theories, argued that people normally strive to satisfice than maximize. In support of his argument, Simon (1959) showed that when performance falls short of the aspiration level, a search begins for alternate ways to achieve it and at the same time, aspirational levels are adjusted down. In other words, when profit maximization is not a realistic goal firms would lower their expectations and strive for goal satisfaction. That means broader goal satisfaction of a firm takes precedence over the narrow objective of economic gains. Hence, a firm's behavior may be more accurately described as satisficing rather than maximizing (Simon 1959, 1964).

Cyert and March (1963) developed a duopoly model where firms estimate demand and production costs and choose their output level. When the preferred output level is not feasible, firms search for ways to reduce costs and may even adjust their profit targets to reflect realized changes in the state of the firm. Thus emergence of firm goals is a result of compromise between expectations and realizations. This model was empirically supported from their studies with American Canning Company and Continental Canning Company. Baumol and Steward (1964) presented further support to this model. (Refer to Cohen and Cyert (1965) for additional explanation and empirical evidence.)

Cyert and March (1963, p27) view a business firm as a coalition of individuals. The coalition members include managers, workers, stockholders, suppliers, lawyers, tax collectors, regulatory agencies, etc. Hence, they consider goal determination as a process of quasiresolution of conflicts among various coalition groups. This view of a business firm is consistent 
with Simon's (1959) and Cohen and Cyert's (1965) statement on firm behavior concerning goals as satisfying rather than maximizing.

Pfeffer and Salancik (1978) also consider a firm as a coalition of individuals with divergent objectives, a view similar to their predecessor in behavioral perspective. While developing the resource dependence model, Pfeffer and Salancik (1978) placed greater emphasis on external coalitions (environment) than on internal coalitions. External coalition may include suppliers, regulatory bodies, stockholders, public interest groups, consumers, labor, etc. According to this model firms select their objectives within the constraints placed upon them by the external environment. A firm's survival depends on its ability to obtain resources and support from its external coalitions. Pfeffer and Salancik (1978) implicitly assume that survival is the ultimate goal of the organization.

Constituency-based theory of the firm was presented by Anderson (1982). In contrast to Pfeffer and Salancik (1978) where emphasis is on external coalition, Anderson (1982) emphasizes internal coalitions with functional areas as units of analysis. Internal coalition strives to satisfy the needs and wants of the external coalition. Hence, the goals of a firm can be described as a best possible compromise evolved from differing objectives of various functional areas.

Coase (1937) wrote his seminal paper "The Nature of the Firm" when he was in USA on a travelling scholarship. He was about twenty years old when he first wrote the article in 1931. Coase's central thesis is that the differences in the costs of operating institutions (transaction costs) lead to the emergence of a firm to supersede a market. Hence, maximization in transaction cost efficiency is essential for a firm to survive and grow. Later, Williamson 
$(1975,1979,1985)$ advanced the theory of transaction costs to explain nature of the firms. Empirical support is provided by various authors (Rueker, Walker and Roering 1985; Dwyer and Oh 1987; Hill and Kim 1988; Heide and John 1988). The transaction cost perspective emphasizes comparative analysis of relative efficiency of internal coalitions versus external coalitions.

Behavioral theories of the firm are not without limitations. Some of the critics state that behavioral theories of the firm affect the magnitude but not the direction of the outcomes. According to Machlup (1967) assumptions underlying the economic theories of the firm may not be realistic compared to the behavioral theories, but the conclusions are not significantly different from that of the behavioral theories. Hawkins (1973) compared the behavioral theories to "...using a sledgehammer to crack a walnut."

In brief, the behavioral theories prefer to follow descriptive approach in understanding the nature of the firm. They consider firms as coalitions of individuals with divergent goals and objectives. Major objective of a firm is to survive and grow by maintaining positive balance between the internal and external coalitions.

\section{POLITICAL ECONOMY PERSPECTIVE}

The term political economy was introduced in the 17th century to explain why some social systems flourish over others. Economists are the earliest social scientists to study institutions to understand the nature of the firm. To enhance their explanatory power, economists introduced land, labor, and capital as units of analysis. In the economic perspective, 
an organization's labor component is considered as a single entity with a common economic goal identified with that of the firm. In reality that may not be the case because an employee may have personal goals that are different or even contrary, to the organizational goals (Thomas 1976). Assumption of congruence between an employee's personal goals and the organizational needs might enhance explanatory power of a perspective, but it compromises on existential realism (Brinberg and McGrath 1985).

To compensate for the lack of existential realism, behavioral scientists explored more realistic alternative explanations. Behavioral scientists view organizations more as dynamic, complex social entities and describe decisions of an organization as the 'best possible compromise' among the concerned groups. In other words, the organizational decision making process is influenced by the nature and needs of the participants, and the level of conflict and cooperation within and between the groups. The interest groups often act to acquire, maintain and defend critical resources (Anderson, 1982; Pfeffer and Salancik, 1978). Therefore, one could say that performance outcome of a firm is impacted not only by the scope of its economic objectives but also the behavioral realities. Hence, to explain and predict the level of performance of an organization it is essential to understand economic as well as behavioristic nature of firm. To accomplish this task of integrating economic and behavioral nature of the firm in understanding and predicting firm performance, the political economy framework was advanced. Zald (1971) used political economy framework to study the nature and development of social organizations. Stern and Reve's (1980) conceptual paper on political economy framework is partially based on Zald's (1971) work. Stern and Reve's (1980) model considers economic as well as behavioral aspects of a firm (Appendix - I, II). 


\section{DEFINITION OF POLITICAL ECONOMY}

According to Buchanan (1964), political economy, in its most generic sense, is the study of the interplay of power, the goals of power wielders, and productive exchange systems. Zald (1971), one of the earliest proponents of political economy framework as a tool to study organizations, stated that the term economy refers to the allocation of internal resources and acquisition of external resources. The polity focusses on ends of decisions that are made, the channels to utilize influence, the characteristics of influence of influence-holders, and the distribution of power. Where the economy is the productive system of an organization, the polity is the power-and-control systems of an organization (Zald $1971 \mathrm{p} 230$ ).

Stern and Reve (1980) define political economy framework as an approach which views a "social system as comprising interacting sets of major economic and socio-political forces which affect collective behavior and performance." Many later researchers in marketing channels have adopted this definition (Achrol et al. 1983; Arndt 1983; Dwyer and Welsh 1983; Hutt, Mokwa and Shapiro 1986). Throughout this proposed research following specific definitions, adopted from Wamsley and Zald (1973, p18-19), of the terms economic and political will be used.

Political refers to matters of legitimacy and distribution of power as they affect: the propriety of an agency's existence; its functional niche; its collective institutional goals; the goals of the dominant elite faction; major parameters of economy; and in some instances its means of task accomplishment. 
Economy refers to the combination of factors of production; the arrangement of division of labor; allocation of resources for task accomplishment; and maximization of efficiency.

Essentially, politics refer to the structure and processes that affect definition of goals and objectives, and economy includes means of production and resource distribution.

The political economy framework utilizes constructs from organization theory, political science, management, organization behavior, and sociology. Particularly, central notions come from the areas of social exchange, behavioral theories of the firm, and transaction cost economics (Arndt 1983). Basic dimensions of the political economy framework include polityeconomy; external-internal coalitions; and substructure-superstructures (Zald 1971; Benson 1975; Stern and Reve 1980; Morgan 1986). The direction of relations among these dimensions vary with the context of research.

In political economy framework, the external-internal considerations refer to the processes and structures both socio-political and economic that affect the functioning of an organization (Hunt, Ray, and Wood 1985). Achrol et al., (1983) related the task and macro environments to the political economy framework and put forth ten propositions. Hutt et al., (1986) extended the political economy framework to explain the nature of parallel political market place and firm performance.

In sum, contrary to the earlier perspectives (economic and behavioral), the political economy framework takes descriptive as well as normative view of a firm. This framework accommodates consideration of behavioral realities when selecting economic objectives of a firm. Thus, it enables researchers to better explain why and how a firm chooses its objectives 
and the consequent performance differential. Therefore, in the current study hospitality franchise firms are defined as politico-economic entities, and outcome objectives of a firm are considered to be both economic and behavioral. Selection of political-economy framework is only fitting considering the predominantly economic nature of strategy content and behavioral nature of strategy implementation (Figure 1).

In understanding the nature of organizations and their performance, marketing channel researchers often investigate constructs such as power, interdependence and inter- and intraorganization conflict (Figure 2). Review of marketing channel literature indicates that these three constructs have dominated the channel literature during the past two decades. Research on behavioral constructs is extremely limited in the hospitality literature. Hence, in this study, an attempt has been made to relate one of these constructs, power, to firm performance in light of emerging literature on strategy implementation. Resource limitations restricted the research study to one behavioral construct. Therefore, organization power is selected as an independent variable for its conceptual richness and its relevance in strategy implementation.

\section{THEORETICAL BACKGROUND}

In the following section theoretical backgrounds of the research constructs, organization power, strategy implementation process, and outcome measure (performance and satisfaction) will be discussed. This section also presents research propositions describing theoretical relationships between the research constructs. The direction and magnitude of the relations among the constructs will be presented in chapter III in the form of testable research hypotheses. 

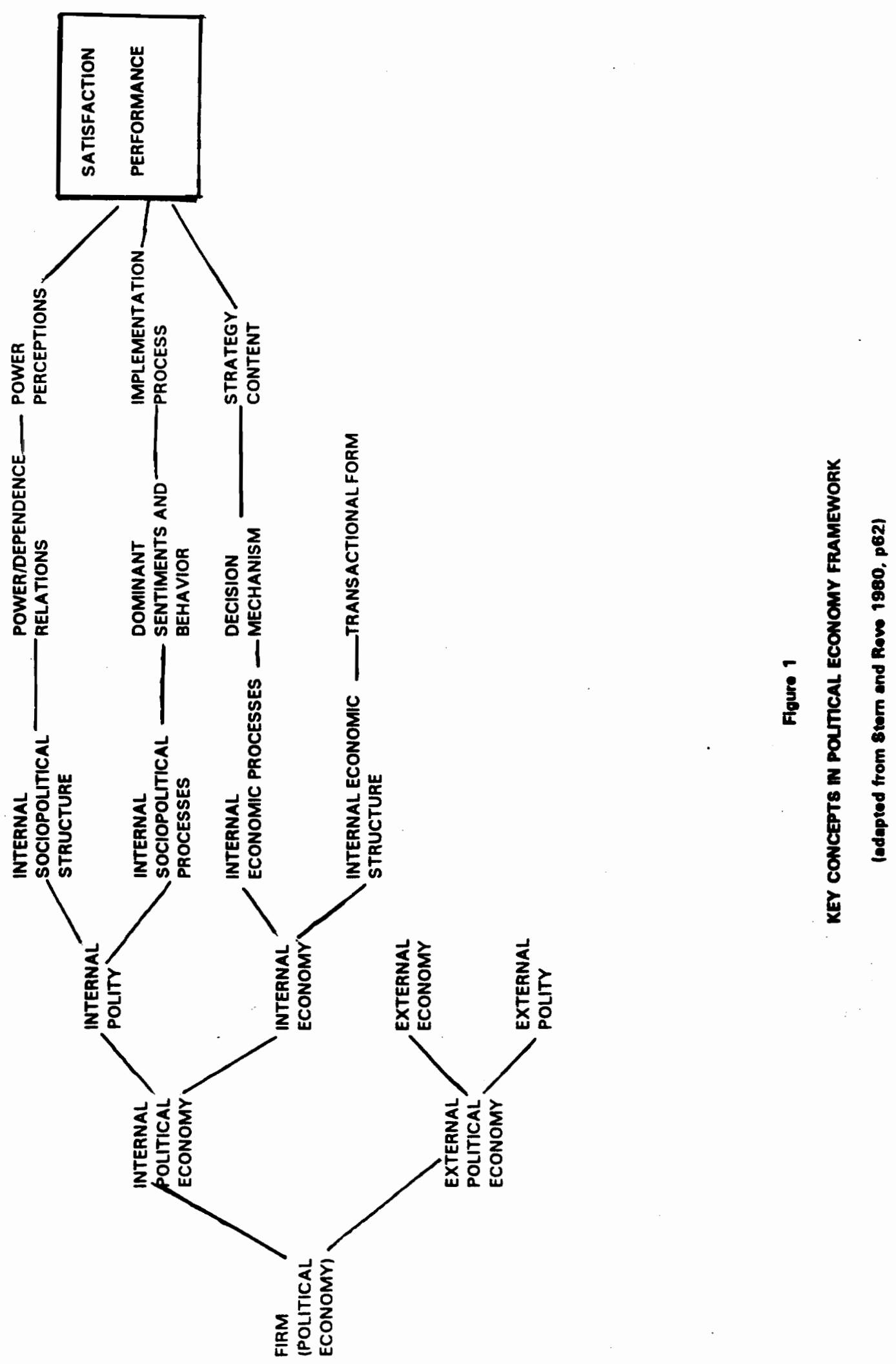


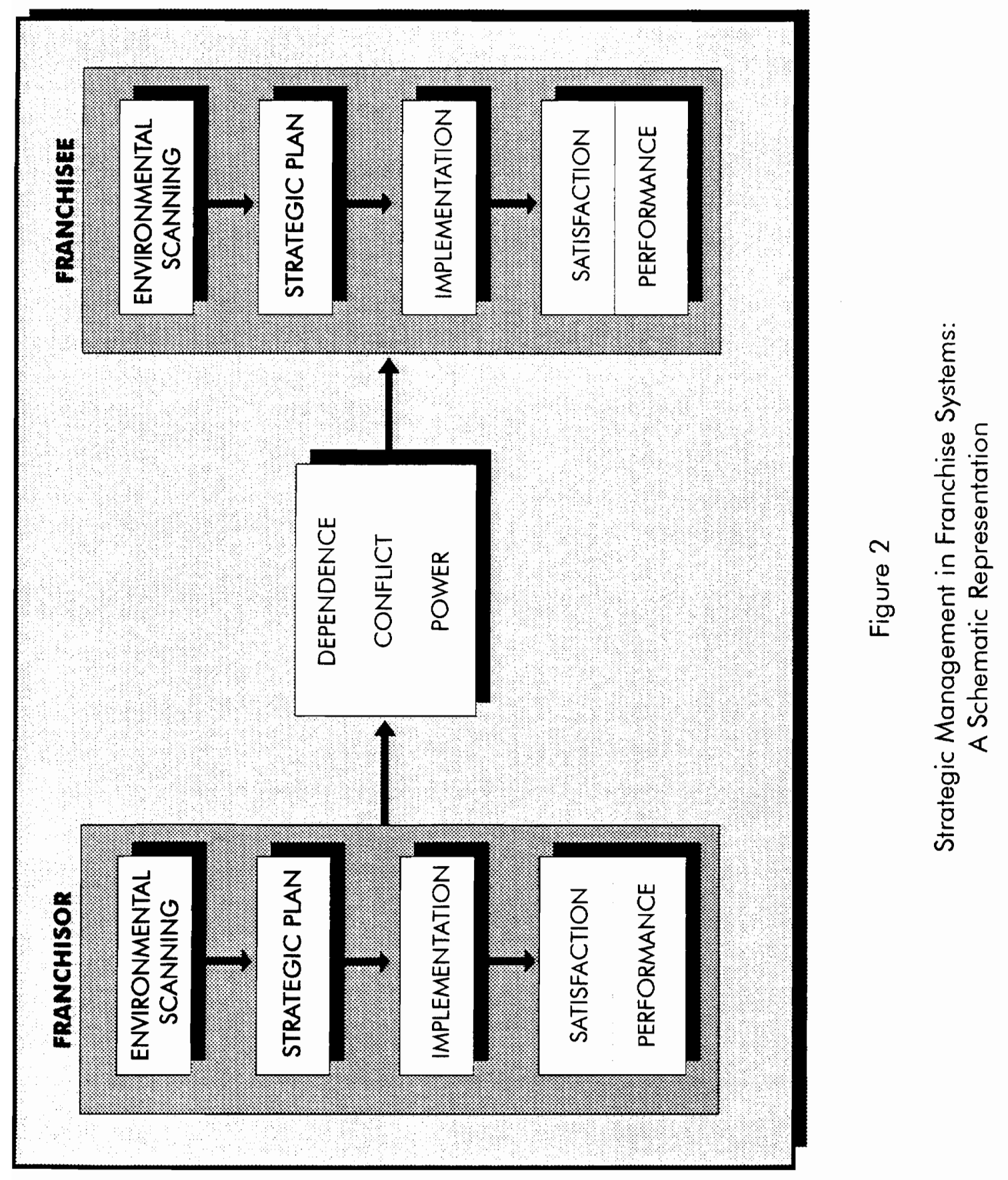




\section{THE CONCEPT OF POWER}

Organizations exist in relatively interdependent environment. In such arrangements organizations experience, intentional or unintentional influence by the other participants. When such an influence reaches some stability over a period of time it takes the form of power. In other words, every momentary social stimulus cannot be considered as power. As described by French and Raven (1959), power is a useful concept for describing social structure, only if it has certain stability over time.

Power and its impact on organizations has intrigued many social scientists from various disciplines. In 1938, Bertrand Russell predicted that the concept of 'power' would emerge as a fundamental issue in social sciences. Benson $(1975, \mathrm{p} 128)$ stated that power appears to be a 'basic explanatory variable' of all social relationships. Power in organizations, as stated earlier, has been studied from different perspectives, such as, sociology, marketing, management, political science, organization theory, organization behavior, and human resource. Commonly accepted conceptual definition of power varies from discipline to discipline. To overcome this limitation, in the present study, emphasis is placed on the concept of power as developed in marketing channels literature (Appendix - III).

Cavanaugh (1984), in her review of literature on power, classified the studies into five

types based on conceptual treatment of the construct. According to her, power may be considered as 1) a characteristic of the individual; 2) an interpersonal construct; 3) a cornmodity; 4) a causal construct; and 5) a philosophical construct. In the present study power is considered as a causal construct, as is often done in the marketing channels literature. 
The concept of power is extended to intrafirm arrangements by Lawrence and Lorsch (1967), Tannenbaum (1968), and Hickson et al. (1971). In an organization, tasks are divided and allotted to subsystems, creating division of labor and interdependence among subsystems. Emergence and maintenance of inter-subsystem interdependence leads to a dynamic process of power trade among the constituent members. The groups may prefer to use differential power to maximize their current and potential benefits. Crozier (1964) stated that since each group's privileges in a system depend to a large extent on the existence of other group's privileges, attempts to live together become imperative. The power groups learn to perform and function within the system rather than to destroy it.

Studies in marketing channels consider power as an interpersonal construct (Dahl 1957; Emerson 1962; Cartwright 1965) and/or a causal construct (French and Raven 1959; Crozier 1964; El-Ansary and Stern 1972; Pettigrew 1973; Hunt and Nevin 1974; Lusch 1976a,b, 1977, 1989; Brown and Frazier 1978; Dwyer 1980; Brown, Lusch and Muehling 1983 etc.).

The nature and type of power observed in relationships depend on the sources of power, and the degree of dependence between the organizations. French and Raven (1959) described five different types of power sources: coercive, reward, legitimate, expert, and referent. Later, marketing channel researchers attempted to classify French and Raven's (1959) description of sources of power into distinct groups: Coercive and Noncoercive (Hunt and Nevin 1974); Economic and Noneconomic (Etgar 1978); Direct and Indirect (Kasulis, Speckman and Bagozzi 1979); Qualitative Sources of Power (Gaski 1986); Mediated and Nonmediated (Johnson, Koening and Brown 1985). Brown Lusch, and Muehling (1983) described another source of power, information power, and classified bases of power into two types: economic (coercive, legitimate, and reward) and noneconomic (expert, information, and referent). For the 
current study, Brown, Lusch and Muehling (1983) classification of bases of power, economic and noneconomic, is accepted because it is based on strong empirical support and it is not tested in the hospitality context.

A review of marketing channel literature indicates that majority of the channel researchers prefer to measure firm outcomes in the form of channel member satisfaction as the dependent variable (Hunt and Nevin 1974; Lusch 1977; Brown and Frazier 1978; Dwyer 1980; Michie 1978; Wilkinson 1981; and Frazier and Summers 1984). In his review article on power and conflict in marketing channels, Gaski (1984) accounted for only two articles that relate power and performance (Porter 1974, and Etgar 1976a). Predominance of satisfaction as an outcome measure in channel literature may be attributed to the greater acceptance of behavioral perspective of the firm, where goal satisfaction is the major objective of the firm. As a corollary, obvious absence of interest in firm performance as measured by economic outcomes may be explained by the absence of support to the economic perspectives of the firm in marketing channels. In light of emerging literature on the political economy framework, in the current study, impact of organization power (economic and noneconomic) on firm strategy implementation process and performance will be measured both in terms of channel member satisfaction and financial outcome.

Numerous authors (Hunt and Nevin 1974; Lusch 1977; and Brown and Frazier 1978) showed that coercive sources of power are negatively related to satisfaction and indicated that noncoercive sources of power are positively related to satisfaction (Michie 1978; Dwyer 1980; and Wilkinson 1981). These results were later confirmed by Sibley and Michie (1985). Directions of these relations between the bases of power and channel member satisfaction are well supported by empirical evidence. 
In the hospitality literature, studies on franchise systems are very limited. Review of hospitality literature (1976-1991) produced little or no information on food service franchise systems. Dev and Brown (1991) studied contractual arrangements in the lodging segment. Hunt and Nevin's (1974) study was the earliest empirical research on QSR franchise systems. When their study was conducted the QSR industry was in the growth stage of its life cycle (Parsa and Khan 1992). Etgar (1977) indicated that a channel's objectives change as the industry evolves through various stages of life cycle. His study also demonstrated that franchisors tend to gain greater control under declining demand (maturity stage) rather than growing demand (growth stage) conditions. Considering the current maturity stage of the QSR industry (Sasser, Olsen and Wykcoff 1978; Tse 1988; West 1988; and Parsa and Khan 1991, 1992) one may expect QSR franchisors to gain greater control over their franchisees. Such actions may lead to the perception of loss of control and eventual loss of satisfaction by the QSR franchisees. This leads to the proposition (Figure 3) (Appendix - IV):

P1. In QSR franchise systems, franchisees experience use of economic and noneconomic power sources by the franchisors, and consequent change in their satisfaction levels.

Porter (1974) empirically presented that retailers' countervailing power has significant influence on manufacturers' performance. This is one of the earliest pioneering empirical studies relating power, strategy, and performance in marketing channels. Etgar (1976a), in his study with the insurance agents in California, indicated that power has a positive effect on channel performance. Michie and Sibley (1987) indicated that franchisee performance is affected by the level of economic and noneconomic power sources. Hence, this leads to the next proposition: 


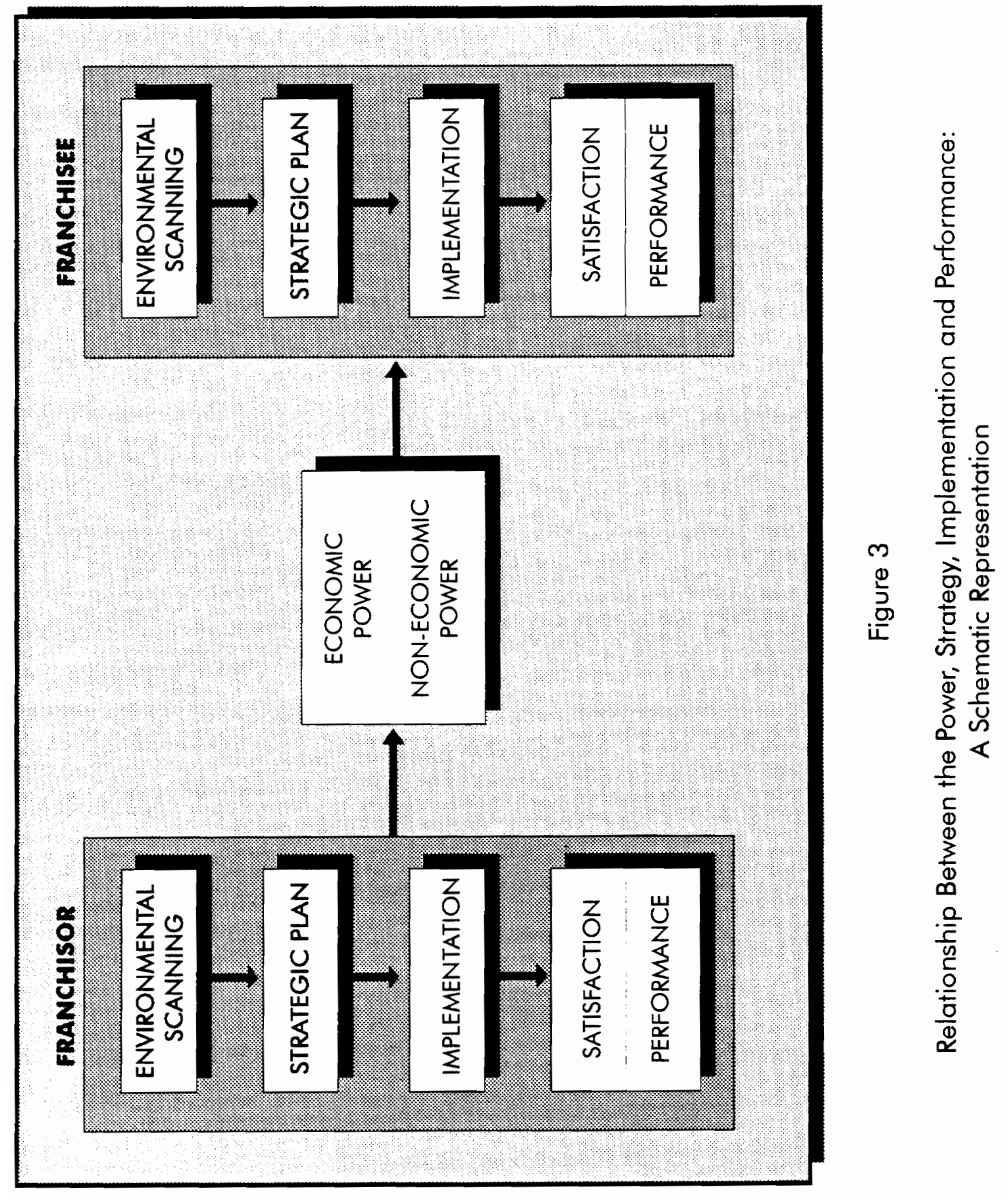


P2: In OSR franchise systems the nature of power sources held by the franchisors affects a franchisees' business performance.

\section{STRATEGY IMPLEMENTATION PROCESS}

Implementation is accomplishing or acting out certain plans or activities. Steiner and Miner (1977) stated that the process of implementation of policies and strategies is concerned with the design and management of systems to achieve the best integration of people, structures, processes, and resources in reaching organizational goals and objectives. Alexander (1985) states that implementation generally begins after a strategic decision has been made, and carries through all the intermediary steps, until performance achieves what the strategic decisions have intended.

The implementation process is generally accomplished using a wide source of administrative or managerial tools. The tools may be classified (Schendel and Hofer, 1979) into three major groups: 1) structures: organization structure, delegation of authority, specialization, departmentalization, and coordination; 2) processes: information, reinforcement (sanctions and rewards), personnel selection, evaluations, and resource allocation decisions; and 3) behavior: stress and power, individual behavior, interpersonal behavior, and leadership styles.

Stonich (1982) related strategy formulation and implementation in his two by two model describing four types of strategic management types. He emphasizes the importance of balance between strategy content and strategy implementation in light of their impact on organization performance. In brief, his model includes four types of firms: 
1) Winning Combination: Sound strategy based on objective and in-depth situation analyses, followed by intensive involvement by the high level management in strategy implementation. This strategy assures best results but it is time and resource consuming. These firms can be expected to experience higher performance. Only firms with established strategy management programs can be expected to follow this strategy successfully.

2) Ivory Tower: Ivory tower consists of in-depth analysis and sound strategy with little or no top management involvement. Often such strategy evolves when external specialists develop strategic plans and the line management either do not commit or lacks the capability to implement those novel plans. This also happens when strategy is developed top down. These firms are idealistic in their philosophy. During the early stages of formalization of strategy management, many firms fall in this trap.

3) Business as Usual: This type of strategy can be expected when operating managers get together and develop a plan without considering external facts. It may also be described as "all work no plan." Such firms are often efficiency-oriented with "seat-of-the-pants" management style. Most food service firms can be classified in this category.

4) All Form/No Substance: This type of strategy can be expected when top management delegates planning to their assistants as an annual ritual. With such strategy, the way business is conducted does not change in spite of reported change in policy. It may also be called "paper-pusher" style of management. Nonprofit organizations and government agencies often fall in this category. 
In spite of well documented case studies emphasizing the importance of strategy implementation, strategy researchers have not paid much attention to the implementation process. Alexander (1990) summarized why strategy implementation has not received enough attention in strategy research. He offers the following reasons: 1) most people believe that anybody can implement, once the strategy is developed; 2) many researchers and academicians believe that every firm is capable of implementing strategy. Hence, they focus more on formulation than implementation; 3) the research community is not very certain where and how strategy implementation stops and starts; 4) only a limited number of conceptual models of strategy implementation are available; and 5) data on strategy implementation may be more difficult to collect than strategy content. Often it requires face-to-face interviews or on sight observation which may be less practical compared to other methods.

According to Alexander (1990), one key reason why strategy implementation fails is that many practicing executives, managers, and supervisors do not have practical, yet theoretically sound, models to guide their actions during implementation. Hrebiniak and Joyce (1984) stated that "the problem is not that we know too little about strategy implementation, but what we do know is fragmented among several fields of organization and management studies." The lack of theoretically sound models, and the fragmented nature of the research, indicate a need for proper direction in research on implementation programs.

Research on strategy implementation, though limited, includes some resourceful models. One of the better known models presented by Stonich (1982), explains the interrelation between strategy formulation, firm performance, and the role of implementation in achieving organization goals. His model includes organization structure, human resource, management processes, and organization culture. His model is one of the more advanced and elaborate 
models in demonstrating the importance of strategy implementation. Four components of his model are: Organization Structure; Organization Culture; Human Resource; and Management Processes (Systems).

Different conceptual, descriptive, and empirical models of strategy implementation were presented by various authors (Le Breton 1965; Quinn 1980; Stonich 1982; Nutt 1983; Hrebiniak and Joyce 1984; Galbraith and Kazanjian 1986; Lorange, Morton and Ghoshal 1986; Nutt 1986; Thompson and Strickland 1987). Majority of the implementation models have not advanced too far beyond common-sense formulations or traditional business policy or strategic policy approaches developed at various business schools (Andrews 1971; and Bourgeois and Brodwin 1984)

For the current study, a model presented by Bourgeois and Brodwin (1984) is selected for the following reasons. Majority of the currently available models in strategy implementation tend to be practitioner-oriented. They are often developed from on-site observations, thus becoming context specific and frequently lack theoretical grounding. In contrast, Bougeois and Brodwin's model (1984) is comprehensive and based on specific assumptions. According to Bourgeois and Brodwin (1984), a Chief Executive Officer (CEO) has greater control on a firm's destiny since he (she) has the option to choose the method of strategy implementation. The CEO of a firm makes rational decisions to achieve selected objectives. As firms grow and evolve from small entrepreneurial type to multi-unit and multi-divisional organizations, the strategy implementation methods also evolve accordingly. In other words, various implementation models described by Bourgeois and Brodwin (1984) are meant to meet the changing needs of firms as they evolve through the various stages of life cycle. Lastly, this model is more 
prescriptive in nature, in contrast to the earlier descriptive models, thus deserving empirical support.

Bourgeois and Brodwin's (1984) classification consists of five models in strategy implementation: 1) Commander; 2) Change; 3) Collaborative; 4) Cultural; and 5) Crescive.

\section{COMMANDER MODEL}

In this model, the role of a CEO is of a 'Rational Actor' issuing directives from the seat of power. The CEO of this model has greater power than all the other models. In this model economic rationality dominates the nature of the firm. The CEO assumes the responsibility to possess most accurate and relevant information about the firm as well as the environment. The Commander Model splits the firm into thinkers (strategists) and doers (implementors). Revenue or profit maximization as an outcome measure is appropriate for this model.

Popularity of this model can be attributed to 1) power accumulation and decision making by a single person, the CEO, 2) ability to identify the responsibility for performance outcomes by dividing the firm into thinkers and doers, 3) objectives of a firm are predominantly economic and quantifiable, and 4) behavioral aspects of a firm are either ignored or considered constant. This model can be noted in Reactor or Defender type of strategies of Miles and Snow's Typology. 


\section{CHANGE MODEL}

In this model, the CEO applies behavioral science techniques to manage his/her organization into compliance with the strategic plan. The role of the CEO is that of an architect, designing administrative systems to orchestrate implementation and push his inertia-ridden economic unit toward goal achievement. Behavioral methods are adapted to achieve economic goals. Strategy outcomes are measured in terms of economic goals. Stockholders' wealth and/or present value maximization are appropriate goals for this model.

According to this model, there is a greater congruence between the thinkers and doers. Understanding of political nature of the firm is helpful in implementing desired strategies. The strategy content is considered as an evolving process than as a set of predetermined plans, as in the case of Commander model. Goals of a firm, though remain predominantly economic, but are adjusted to reflect specific strengths and weaknesses of the firm. This model does not redress many of the limitations noted in the Commander model. The CEO of this model chooses the desired strategy and adapts it to the organizational environment. This model can be noted in Defender or Analyzer type of strategies of Miles and Snow's Typology.

\section{COLLABORATIVE MODEL}

This model expects a semi-formalized to formalized strategic planning. In this model, reality of 'dominant coalition' and its influence on strategic decision making are accepted. The role of a CEO is that of a coordinator encouraging and promoting differing ideas, and consensus generator. Team-work is strongly encouraged. Decision making is decentralized and 
participatory. As a result, behavioral nature of the firm dominates. Hence, an organization's goals would be more behavioral than economic.

In this model, organizations have strong culture and traditions. Successful implementation requires nurturing of proper cultural values to meet changing organizational needs. The distinction between the thinkers and the doers begin to disintegrate, but doesn't disappear yet. This model also requires greater emphasis on human resource practices. The team commitment comes at the expense of economic rationality. In other words, strategy is a best possible compromise among the conflicting views of the differing groups. The outcome measures are not necessarily measured in economic terms but as the level of long term goal achievement.

\section{CULTURAL MODEL}

This model takes collaborative decision making to the lower level, thus leading to disappearance of separation of thinkers and doers. The CEO, in this model, is an initiator and a communicator forward thinking process, and visionary in nature. The strategy of an organization is stated in terms of broad guidelines and long term direction. The details of a plan and its implementation is left to the individual business units. Understanding of 'superordinate goals', style, and cultural norms become essential tools for continued success of a firm. Power equalization among differing groups is no longer a management objective. The cultural model contradicts and challenges many basic objectives from economic perspective of a firm. A 'clan' like (Ouchi 1981) organization is expected to prevail. 
Group dynamics and organizational ethos in place, the CEO's implementation task is 90 percent done. Economic price to develop and nourish such an organization is relatively high. High level of organization slack is needed to install and maintain a cultural model. This model has several limitations: it assumes well informed and intelligent participants; firms with this model tend to drift and lose focus; cost of change in culture often comes at high price; increased homogeneity leads to loss of diversity, and creativity consequently.

\section{CRESCIVE MODEL}

The term crescive came from Latin CRESCERE which means 'to grow'. The last model, Crescive Model, considers the firm as a social entity striving to achieve economic as well as social objectives. The strategy formulation is an upward process and the role of a CEO changes from a designer to that of a premise-setter and judge. The main purpose of a CEO is to define the purpose of a firm and function as a filter for screening inappropriate programs. A CEO needs to give up some power and control over the resources in order to attain successful strategy implementation. In this model, a CEO accepts 'bounded rationality' of an individual and promotes common wisdom. Success of a firm depends greatly upon the visionary abilities of a CEO than his ability to accomplish specified objectives.

From the practical point of view, the CEO acts as an outsider, with greater knowledge about the general environment, working with the top management in deciding the future direction. The CEO intervenes in the 'logical incrementalist' (Quinn 1978) manner and adjusts organization systems to meet ever changing environmental challenges. The top management 
tries to understand the 'multicultural coexistence' (Ansoff 1979) nature of a firm. In other words, firm is considered as a political entity with economic and political objectives.

As evident from the above description, different firms opt for different methods in implementing their chosen strategies. Though all models are equally important and effective, the appropriateness of an implementation model is contingent upon the nature of the firm. The performance outcomes, economic or political, of a firm are contingent upon the nature of implementation model chosen. Empirical studies relating strategy implementation and firm performance are very limited. Review of hospitality literature did not reveal any empirical studies on strategy implementation. Thus, this leads to the next proposition:

P3: In OSR franchise systems, a firm's performance is contingent upon the type of implementation model it selects.

\section{SATISFACTION AND PERFORMANCE}

Performance improvement is at the heart of strategic management IVenkatraman and Ramanujam 1986). Although organizational performance is often a dominant variable in the study of organizations, it remains one of the most used yet least understood constructs in organization theory. This has led to a fragmented, scattered and theoretically unintegrated analysis, divergent definitions and identification of many different explanatory variable sets and diverse scenes (Bedian, 1986). In strategic literature, economic performance is often measured in terms of profitability (Hambrick, 1983), growth rate, and market share (McKee, Varadarajan 
and Pride 1989). These measures are often operationalized as ratios, such as, liquidity, solvency, profitability, and asset utilization (Gale 1972; and Bourgeois 1980).

Different strategy types have different organizational goals. Financial performance, as indicated by the profitability ratios, may not necessarily be an organization's objective, as noticed in the case of prospector firms (Miles and Snow, 1978). An organization's objectives, sometimes, may be accomplished at the expense of its financial performance (Schendel and Patton, 1978). This can be better explained when one examines the nature of different strategic types and their goals.

The defender organizations, as described by Miles et al. (1977), prefer to operate in narrow segments with limited set of products. Defenders strive aggressively to prevent competitors from entering their "turf" by either using competitive pricing or by producing high quality products at low cost margins. Defenders emphasize production efficiency and limit research investments to the core line of products. Often defenders, to match their strategic philosophy, implement 'mechanistic' organization structures. By placing emphasis on profitability and operational efficiency, defender firms are susceptible to sudden changes in the environment and decreased long term survivability.

The prospector organizations are more dynamic than the defenders with a broad line of products, and constantly exploiting new product and market opportunities. To keep pace with the organizational changes, prospector firms prefer 'organic' organization structure with focus on marketing and research and development (R\&D) activities. The prospector firms can be characterized by low formalization, decentralized decision making, increased informal and lateral communication, low degree of channel control, increased vertical span of control, and 
greater emphasis on goal achievement (effectiveness) than on operational procedures (efficiency). The prospector firms, with the constant emphasis on market expansion and survival, run the risk of low profitability, under utilization of resources, and weaker controls.

The analyzer organizations are often described as viable alternatives to the two extreme strategic positions, defenders and prospectors. A true analyzer (Miles et al. 1977) attempts to minimize the risk and maximize the profit, with a unique organization structure that strives to compensate for the weaknesses of both mechanistic and organic structures. Analyzers emphasize marketing over R\&D, and increased production efficiency and adaptability. In their organization structure, analyzers maintain greater flexibility, moderately decentralized decision making, less formalization and standardization, and moderate vertical span of control. Analyzers emphasize production efficiency (like defenders), and administration effectiveness llike prospectors), at the same time. Such a policy may lead, contrary to the expectations, to either operational inefficiency and/or administrative ineffectiveness, due to the philosophical incompatibility between the two strategies.

All three strategic types can be proactive with respect to their environments, though each is different in the direction, nature, and the degree of alignment with the environment. The goals and needs of a firm depend on its chosen strategy, and structure, and its ability to align with the environment. In other words, high financial performance (profitability) may not necessarily be the common goal among different strategic types.

Since, Miles and Snow's strategic types are distinctly different with differing long term organization goals, needs, and organization structures, it will be less than prudent to compare their performance on any single, either financial or nonfinancial measure. Therefore, to achieve 
comparability in performance among different strategic types, both financial and nonfinancial measures are recommended in the current study.

Chakravarty (1986) attempted to assess stakeholders satisfaction as a measure of firm performance. McDaniel and Kolari (1987) used various marketing elements (price, place, product, market research, integration/diversification) to discriminate different strategic types in the banking industry. Buzzell et al. (1974) used market share as a measure of organizational success. Other nonfinancial measures may include channel member satisfaction, employee turnover, top management turn over, firm growth rate, ratio of distressed units to the total units and change in market share.

Organizational performance is contingent upon the fit between selected strategy and implementation process. Therefore, for better performance, firms should consider the constituents of the implementation process and the impact of selected strategy on these factors, rather than relying solely on a good strategic plan. With increased reliance on correlational studies between strategy content and performance, unintentionally, many researchers have ignored the importance of the implementation process (Figure 4).

Since an important theoretical intermediate step, the implementation process, is excluded from the equation, any statistical correlation obtained between a strategic objectives and organization performance may be subject to high levels of 'noise.' Because of the importance of intermediary role played by the implementation process between strategic planning and performance, the reliability and generalizability of such correlational results are questionable. Lastly, any empirical support or lack of it for a strategic typology deserves further replication with due consideration to the effects of the implementation process on the outcome. 
This argument is not limited to organizational performance only, it can also be extended to the level of satisfaction desired. In other words, the level of performance and satisfaction pursued by an organization are affected by the method of implementation selected.

Political economy framework (Arndt 1983; Stern and Reve 1980) offers a viable alternative by integrating economic structures with socio-political phenomena in analyzing organizations for difference in performance. This framework connects the changes in economic processes to organization structure, goals of social units, external power wielders, and dominant internal interest groups. While the political economy framework does not provide all the answers, it offers a framework for defining proper research questions to be asked. With its ability to relate internal socio-political structure to the dynamic nature of the external environment, the political economy framework is extremely useful in developing a research program in strategic management.

Since, success of strategy content is more dependent upon the implementation process, study of internal polity with behavioral constructs seems to be more effective in understanding differences in organization performance. Differences in organizational performance can be better explained within this framework, when the help of behavioral constructs such as interdependence, power, and conflict. In strategy implementation organization culture, management rewards and controls, and human resource play a significant role. Therefore, behavioral constructs, such as power and conflict, are more appropriate to capture the impact of internal polity and social structure on organization performance. Because of various limitations such as resources, time, and parsimony the present study is limited to a single 


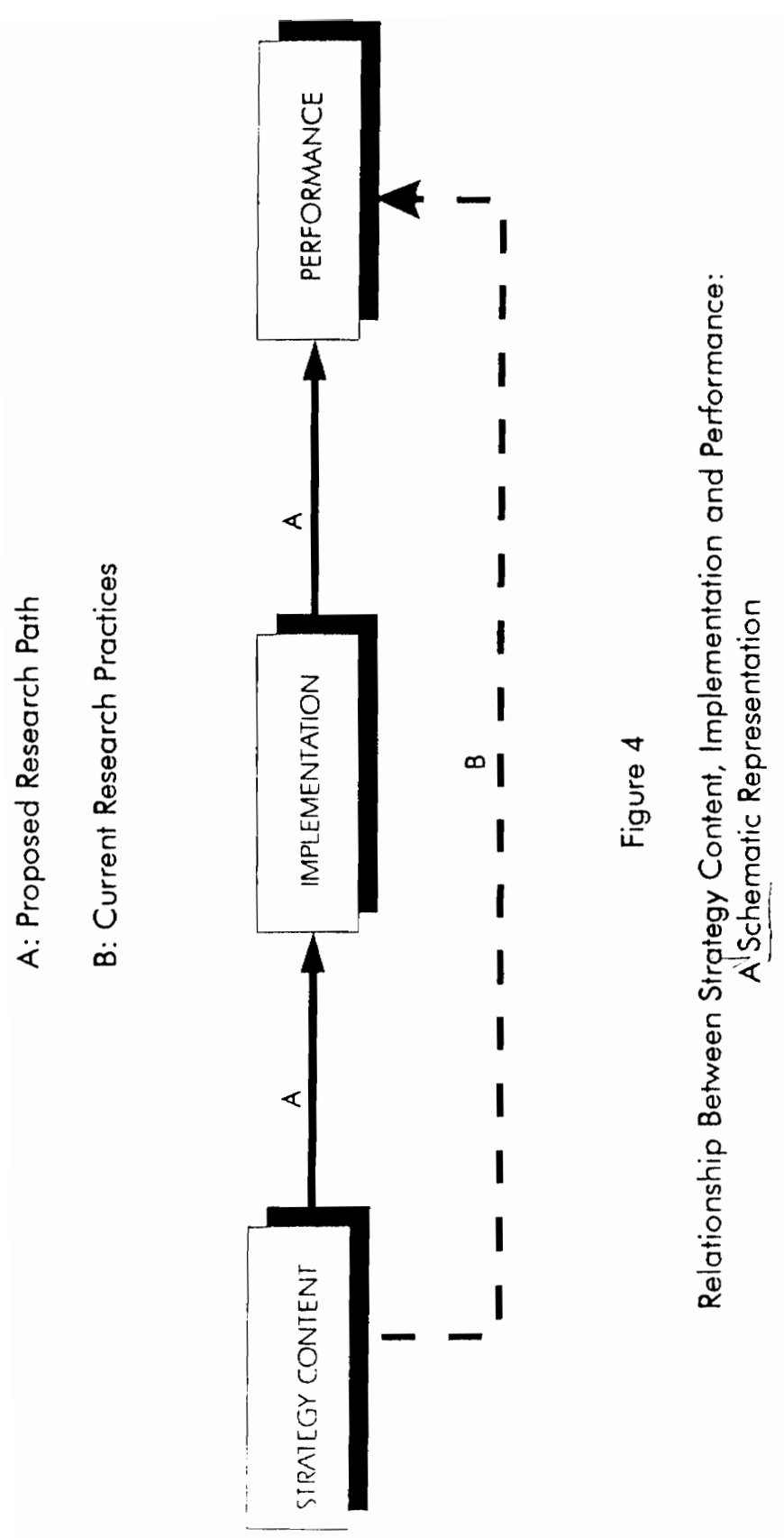


behavioral construct, organization power, and its impact on the implementation process and consequent organization performance.

\section{DISCUSSION}

Researchers that are interested in the issue of organization performance normally follow either an economic or behavioral perspective. Organization theorists, with their predominantly economic perspective, express more interest in determining long term financial performance. Hence, they naturally studied long range planning as a possible source of performance differential. Studies in long range planning gradually expanded their scope by including resource dependence, environment, and organization structure which led to its eventual evolution into strategic management. Therefore, it is only logical to find predominance of economic perspective in strategy management literature.

Strategy content researchers attributed performance variances to organization structure (Chandler 1962; Khandwalla 1976); choice of strategy type (Miles and Snow 1978; Porter 1985; Schendel and Hofer 1979); and strategy formulation process (Ansoff 1965, 1979, 1980; Shrader, et al. 1984; Chakravarty 1984). Strategy content researchers, while explaining difference in performance among organizations, might have assumed that the implementation process is either constant across contexts or immaterial for achieving organizational outcomes. Such assumptions severely limit the explanatory power of a theory, as clearly indicated by various implementation models. Many studies have demonstrated that effectiveness of strategy implementation process is equally important to achieve long range success of a firm. Literature in marketing channels, organization behavior, decision science and human resource have 
plethora of examples to indicate impact of communication, conflict resolution, dissent, interest group formation and politics and power distribution on organization performance.

The strategy implementation process is predominantly behavioristic in nature. Understanding of the implementation process and its impact on organization performance involves comprehension of organization behavior, group dynamics, human resource factors, performance evaluation, reward systems and structural limitations. Hence, another plausible explanation for lack of emphasis on strategy implementation process may be that strategy content research, limited by its strong economic roots, was unable to consider implementation process for its predominantly behavioristic nature. But the 'theory of the firm' literature ICoase 1937; Demsetz 1972; Jensen and Meckling 1976; Williamson 1978; Rubin 1978; Anderson 1982) suggests that objectives of an organization comprise both economic and behavioristic elements. Therefore, study of economic-centered strategy content and behavioristic-centered strategy implementation is essential to enhance the understanding of organization performance, defined as an ability to achieve set objectives.

In the current study an attempt has been made to explain the socio-political and economic nature of organizations within the political economy framework (Stern and Reve 1980; and Arndt 1983). This framework supports and complements the presently prevailing micro/macro economic management concepts, while integrating behavioral theories of the firm (Anderson 1982), and builds on Pfeffer and Salancik's (1978) resource dependency model in recognizing the complementary nature of economic and behavioral theories.

Organizations are not static and neither are their environments. As organizations experience increasingly dynamic environments, they prefer to have more organic structures to 
allow flexibility. Organic structures are characterized by increased organization slack to accommodate needed adaptability. In turn, maintenance of quality and quantity of organization slack is dependent upon intraorganizational level of conflict, power structure, and its dependence on other organizations. Therefore, to enhance our understanding of performance differential, consideration of both economic and behavioral factors, and their independent and interaction effect on organization performance is essential.

With this understanding, political economy framework, with its integrated (economic and behavioral) approach, is presented as an alternate approach to investigate difference in performance among organizations. The political-economy framework functions as an underlying structure that accommodates and unifies various assumption on the nature of the firm and facilitates further research to enhance understanding of organization performance. The basic assumptions behind the constructs such as power, conflict and dependence can be found embedded in the political economy framework. Because of various limitations, the present study is limited to only one construct, the power and its impact on performance. This leads to the next proposition:

P4: In QSR franchise systems, the performance of a firm can be understood better by determining the impact of organization power on the strategy implementation process.

The political economy framework relates internal socio-political and economic structure and process with the external economic and political environment. This framework is not a theory by itself, but suggests major constructs to build a theory. Political economy framework, with its ability to logically relate internal and external environments, offers a base to raise many 
research questions. Research hypotheses can be presented relating marketing strategy content, implementation process and content, environment (internal and external), and organization internal structure and process, and interaction to the external polity and economy. Understanding and acceptance of political economy framework opens many frontiers for further research in strategy content, implementation, organization performance. From marketing perspective it enhances communication between marketing and strategy researchers and widens the scope of research.

Thus far, marketing strategy research has been predominantly concerned with strategy content and empirical extension of strategic typologies (Buzzell et al. 1975; Abell 1978; Day 1981, Wind and Robertson 1983; Ruekert, Walker and Roering 1985; McDaniel and Kolari 1987; Day and Fahey 1988; McKee et al. 1989). Literature on implementation process and content of marketing strategy is very limited. Plausible explanations for lack of interest in the marketing strategy implementation include either lack of understanding of the implementation process or absence of theoretical rationale relating marketing strategy implementation process and organization performance.

The current study attempts to overcome some of these limitations by developing a theoretical rationale for appropriateness of behavioral constructs to study organization performance; and an argument for strategy implementation process and content. 


\section{SUMMARY}

The primary objective of this chapter is to present the theoretical rationale for conducting this study. Various theories of the firm and their implications in research on franchise systems are discussed. The concept of political-economy was discussed and definitions are included.

This chapter has included a discussion of strategy implementation and its relevance to the franchise systems. Rationale for selecting financial and nonfinancial objectives is discussed. Finally, four theoretical propositions are posited for further investigation.

From the presented propositions, testable research hypotheses will be presented in the next chapter. The next chapter also includes operational definitions of the research constructs and development of relationships between the variables. 
Chapter 3

\section{METHODOLOGY}

\section{INTRODUCTION}

Palamountain (1955, p54-55) stated that a franchisor is naturally inclined to develop and express power in order to gain more control over his system of distribution and thereby reduce the uncertainties and limitations of a purely market environment. At the same time there is a reasonable argument in favor of individual franchisee exerting independence (Little 1970). Stern and Reve (1980 p60)) postulated that the channel member that possess greater proportion of relative power will have higher level of business performance. They also stated that socio-political processes associated with internal economy vary with that of the total channel performance. Etgar (1977) indicated that certain aspects of internal political economy of channels may explain more of variance in channel performance than environmental factors. Tushman (1977) argued that understanding of organizations as political entities enhances researchers' ability to explain performance differential. Lusch and Laczniak (1989) emphasized the need for further research in understanding the importance of strategy content channel 
performance. To further the knowledge of channel performance, a research methodology to test the theoretical relationships is presented in this chapter.

The preceding chapter defined the research domain and presented theoretical relationships among power, strategy content, implementation process and firm performance. This chapter includes operationalization of the presented theoretical constructs and assessment of franchisee performance in light of relative power, strategy content, and implementation process.

Basing on the theoretical considerations discussed earlier, this chapter presents operational definitions of the constructs and development of hypotheses; nature and pretesting of the instrument; assessment of reliability and validity concerns; sample selection; methods of data collection and response rate; and rationale for the analytical methods.

\section{OPERATIONAL DEFINITIONS}

The operational definitions of the research constructs and the theoretical interrelationships among them will be presented in this section. This section also includes development of research hypotheses.

\section{POWER IN MARKETING CHANNELS}

Since Aristotle (357 BC), power has been the topic of countless essays and discussions about what it is, how to get it, how to use it, and how to cope with it (Dwyer 1984). According 
to Gaski (1984), in spite of plethora of definitions of power (Simon 1955; Dahl 1957; French and Raven 1959; Emerson 1962; Cartwright 1965; Wilemon 1972; El-Ansary and Stern 1972) understanding of the concept of power is fairly consistent throughout the channel literature. According to Beier and Stern (1959), "... power of $O$ depends on the perceptions of $P$ in terms of O's ability to satisfy $P^{\prime} s$ desires...." Similarly, Thibaut and Kelley (1959) also defined power in terms of perceptions of one that is subjected to influence. Review of marketing channel literature indicates common acceptance of power, as explained by French and Raven (1959), as sources of power. Hunt and Nevin (1974 p188), one of the earliest empirical works on hospitality franchise systems, stated that "Power does not refer to the objective ability of one individual or group to control or influence the behavior of the other, but rather to the potential ability of the controlling or influencing agent as perceived by the controllee or influencee."

Later, many empirical studies (Frazier and Summers 1984; Brown, Lusch and Muehling 1983; Etgar 1976; Lusch 1977; Dwyer 1980; Philipps 1981; Porter 1974; Lusch and Brown 1982 ) in marketing channels adapted Hunt and Nevin's (1974) operationalization of power. Supported by this rich empirical research tradition, in the current study, organization power is operationalized as perceptions of OSR franchisees about franchisor's ability to influence franchisee's decisions. Brown et al. (1983) considered information as an independent power source, and classified the sources of power into economic and noneconomic sources. The classification of power sources, economic and noneconomic, presented by Brown et al. (1983) is adopted for the current study.

Hunt and Nevin (1974) demonstrated that franchisees experienced low satisfaction when franchisors used coercive sources of powers, and high satisfaction when noncoercive power sources were used. Results from Hunt and Nevin's (1974) study were later confirmed, 
in different contexts, by Lusch (1977) and Michie and Sibley (1985). When Hunt and Nevin's (1974) study was conducted, the QSR industry was in the growth stage of its life cycle (Parsa and Khan 1989). Currently, the QSR industry is in the maturity stage of life cycle (Sasser et al., 1978; Tse 1988; West 1988; Parsa and Khan 1992). Etgar (1977) indicated that, during the maturity stage of life cycle and under uncertain environmental conditions, franchisors exercise greater controls over their franchisees. Thus, considering the current maturity stage of the hospitality industry, one may expect greater controls by the hospitality franchisors over the franchisees which in turn may affect franchisee satisfaction. As presented by Brown et al. (1983), franchisor control could be expressed either as economic or noneconomic sources of power. In other words, the level of satisfaction of QSR franchisees is related to their perception of power sources (economic and noneconomic) held by their franchisors. This leads to the following hypotheses (Figure 5) (Appendix - V):

H1: In QSR franchise systems, franchisees experience low level of satisfaction when they perceive their franchisors to possess economic sources power.

H2: In QSR franchise systems, franchisees experience high level of satisfaction when they perceive their franchisors to possess noneconomic source of power.

Etgar (1976a) indicated that channel member performance is negatively affected by the level of power perceived. In his study, insurance agents performance has decreased significantly when they perceived their company to possess greater power. Later, Sibley and Michie (1981) observed improvement in the performance of farm equipment dealers when they 


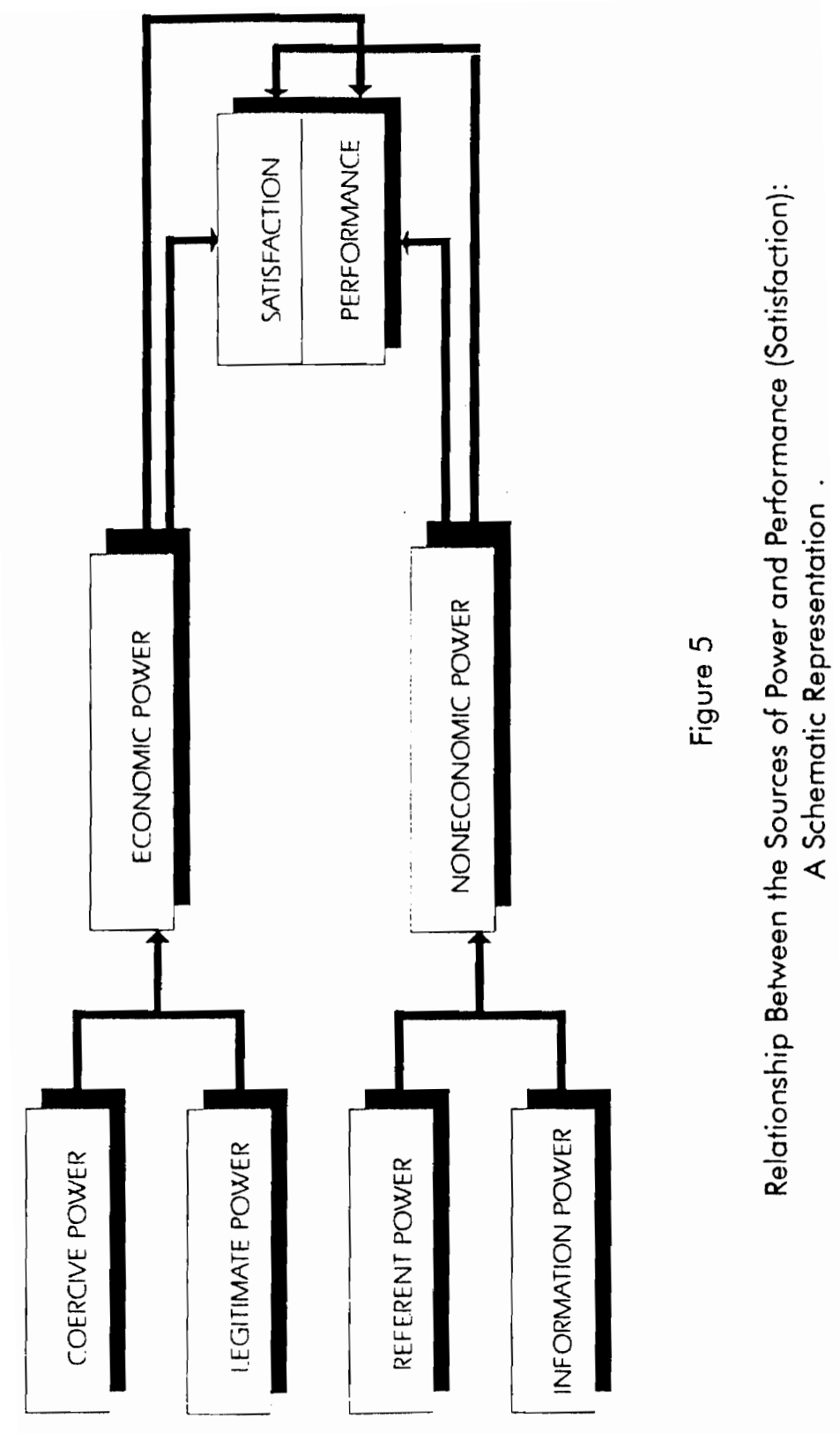


perceived their manufacturers to have high level of noneconomic (noncoercive) sources of power. These studies indicate that performance of franchisees is affected by the nature and level of power sources held by the franchisors. Hence, one may expect positive change in the performance of QSR franchisees when the franchisors possess high level of noneconomic power sources, and negative change with high level of economic power. This leads to the following hypotheses (Figure 5):

H3: In OSR franchise systems, franchisees' performance is positively related to their perception of noneconomic sources of power possessed by their franchisors.

H4: In QSR franchise systems, franchisees' performance is negatively related to their perception of economic sources of power possessed by the franchisors.

\section{STRATEGY IMPLEMENTATION PROCESS}

The concept of strategy has been around since the time of Greek and Roman empires. The word strategy is derived from the Greek word, Stratego (a general), which in turn comes from the roots meaning "army" and "lead". The Greek verb stratego means to "plan the destruction of one's enemies through effective use of resources" (Bracker 1980). Numerous definitions of the word "strategy" are available in the current strategy literature (Bracker 1980). Of all the available definitions most commonly accepted definition of strategy is provided by Mintzberg (1978, p935), "a pattern in a stream of decisions". In spite of increasing acceptance of the above definition, there is no consensus in operationalization of the concept of strategy. 
This is attributed to the differences in research vocabulary, and diversity in underlying disciplines from which the field of strategic management has evolved (Ginsberg 1984).

Many researchers in strategic management, as stated earlier, place greater emphasis on strategic planning process, and consider strategy implementation as constant or inconsequential in achieving organizational objectives. Lack of emphasis on implementation process may be attributed to the commonly held assumption that firms that achieve level of sophistication high enough to possess formalized strategic planning process tend to be better prepared as strategy implementors. This assumption, though very common, lacks both theoretical and empirical support. In spite of absence of empirical support, bias towards planning process over implementation methods still dominates in the strategic management literature. Hence, very limited empirical research work is reported in the strategy literature that pertains to the implementation process. However, importance of implementation process is well documented in the form of numerous case studies and observational research findings (Pressman and Wildavsky 1973; Steiner and Miner 1977; Galbraith and Nathanson 1978; Quinn 1980; Thompson and Strickland 1987, 1991) in the general management literature.

Alexander (1981) reported that method of implementation can be a significant factor in determining the performance of a firm. According to him, successful firms are different from unsuccessful firms in their ability to implement chosen strategies. In his study, the successful firms experienced significantly fewer problems than the unsuccessful firms while implementing their chosen strategies. The unsuccessful firms have experienced three times more major problems than the successful firms. Therefore, in QSR franchise systems, one may expect method of implementation to have a significant effect on firm performance. 
Majority of the earlier studies in strategy implementation followed either case study approach or observational analysis. These methods are descriptive in nature. Descriptive studies tend to be context specific. Typically, in descriptive studies, data are collected by the researcher either by observing the implementation process or participating in it. Upon analyzing the collected data and the noted facts, researchers prefer to draw prescriptive deductions which are specific to the context. Based on the conclusions and the nature of the research context plausible generalizations are presented. Some of the drawbacks of these methods include high demand for monetary, nonmonetary, and time resources. Another limitation is the difficulty in finding willing participants (firms) for research observations. Hence, alternative methods were chosen for the current study.

The selected research method may be described as a single respondent, random survey method. The survey research method is well grounded in theory (Kalton 1983) and highly acceptable both in the hospitality and the marketing channels literature. In this method, normative models that are theoretically validated are be tested in a well defined and carefully selected research context. The chosen random survey method is consistent with the earlier studies in the marketing channels and the hospitality literature. Bourgeois and Brodwin (1984) presented a normative model to describe the strategy implementation process. Their model is conceptually well defined and consistent with the earlier research in strategy implementation. This model is based on leadership theories of strategy implementation. It makes two basic assumptions: CEO of a firm is capable of determining the appropriate implementation method for a firm; and the role of a CEO changes according to the method of implementation selected.

The Bourgeois and Brodwin's (1984) model prescribes implementation methods appropriate for a spectrum of firms ranging from entrepreneurial to diversified multinational 
corporations. Because of its comprehensiveness, Bourgeois and Brodwin's (1984) model is selected for the present empirical study with QSR franchise systems to explore the nature of strategy implementation process. As mentioned in the previous chapter, the Bourgeois and Brodwin's (1984) model consists of five types of strategy implementation models: the Commander model; the Change model; the Collaborative model; the Cultural model; and the Crescive model. All of the presented models are equally effective. These models tend to be mutually exclusive. Therefore, appropriateness of a model to a firm depends on various factors, such as, nature of the firm; type of industry; life cycle stage of the firm and the industry; level of complexity; degree of diversification; size of the firm; etc.. Bourgeois and Brodwin (1984 p260) also indicated that "the Cultural and Crescive models would be too elaborate for some, perhaps less diversified and less complex firms." Hence, considering the predominantly single concept dependent and less diversified nature of QSR franchise systems, one may expect successful franchisees to follow one of the earlier models (the Commander; the Change; or the Collaborative) while implementing strategic plans.

Reported empirical studies in support of implementation process are very limited both in the marketing channel and the hospitality literature. For lack of empirical and theoretical precedence in strategy implementation process, one cannot state, with a degree of certainty, which one of the three models will be more successful than the others. This leads to next hypotheses stated in null form (Figure 6):

H5: In QSR franchise systems, there is no difference in the performance level of franchisees classified according to the type of implementation model. 
Majority of the studies in the marketing channels, the strategic management and the hospitality literature measured organization performance in terms of financial outcomes. This bias towards financial measures can be attributed to the assumption that firms are primarily economic in nature. Chakravarty (1986) addressed the controversy of financial performance. He stated that financial ratios are limited in their ability to capture the total effectiveness of strategic planning. According to him, "Strategic management is the process through which managers ensure the long-term adaptation of their firm to its environment. Useful measures of strategic performance are therefore those that help assess the quality of a firm's adaptation."

From the performance analysis of fourteen major computer firms, Chakravarty (1986) concluded that excellent firms are not necessarily high financial performers. In fact, efforts to maximize financial performance may detract firms from achieving excellence and may even compromise a firm's ability to adapt to future environments. Hence, measurement of only financial performance as a measure of performance outcome limits one's ability to capture effectiveness of strategy content. Therefore, consideration of organizational objectives other than financial measures becomes imperative. Researchers such as Tushman (1977), Stern and Reve (1980), Achrol et al. (1983) proposed that the firms should be considered as political economies. As demonstrated by Smith et al. (1985) firms tend to become more political in the maturity stage of life cycle. When firms are considered as behavioral in nature, the primary objective of a firm becomes goal satisfaction. Considering the maturity stage of current hospitality industry goal satisfaction has been chosen as one of the outcome measures. Validity of measuring of channel member satisfaction as an outcome measure is well established in the marketing channel literature. This leads to the next hypothesis, stated in null form (Figure 6): 


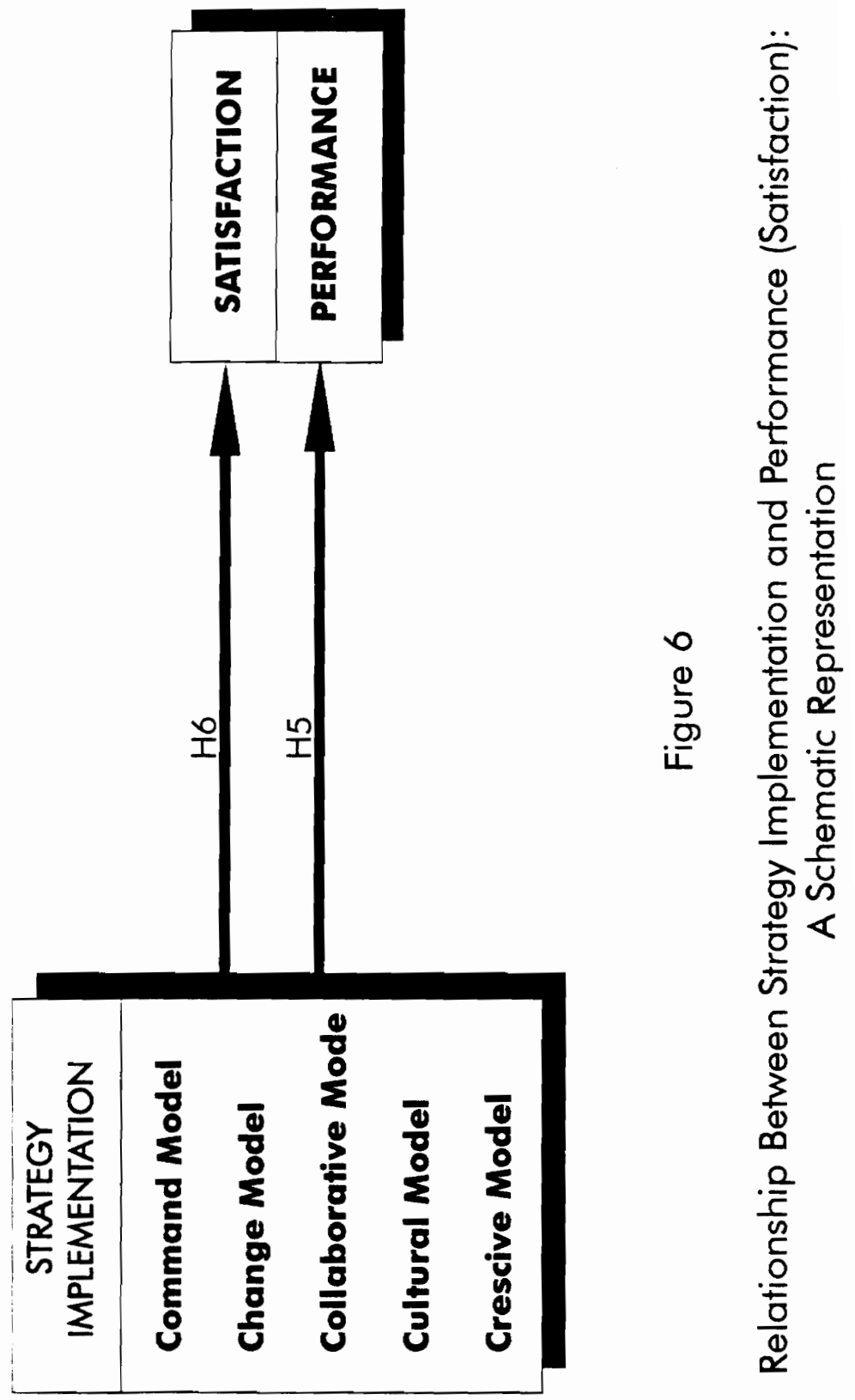


H6: In QSR franchise systems, there is no difference in the satisfaction level of franchisees classified according to the type of implementation selected.

\section{POWER AND STRATEGY IMPLEMENTATION}

Organizational performance is a multidimensional and complex construct. Andrews (1971) stated that distinctiveness of strategy concept lies in its uniqueness to a particular setting. Underlying implication of his statement is that strategy can be best described verbally and best captured in case studies, and measurement instruments are often incapable of capturing total concept of strategy. Such an approach may be essential during conceptual development of a theory, but it may be inefficient or inappropriate in theory testing (Venkatraman 1989). To overcome this limitation, many strategic management researchers have followed different methodologies with strategy content as an independent variable and business performance as a dependent variable.

In the hospitality literature, Dev (1988) demonstrated that in U.S. lodging industry, high performance firms are significantly different from the low performers when classified according to the type of strategy content. Schaffer (1986), Tse (1988), and West (1988) also used strategy content to explain performance differential among the hospitality firms. Unfortunately, at the present time, no empirical research has been reported to explain performance differential among the firms classified according to their strategy implementation process, either in the hospitality or in the marketing channel literature. 
In foodservice franchise systems, negative relation between the perception of coercive (economic) power and franchisee satisfaction, and positive relation between the noncoercive (noneconomic) power and franchisee satisfaction was first reported by Hunt and Nevin (1974). This is further confirmed by many researchers in marketing channels, as discussed in the preceding chapter. In hospitality literature, Parsa and Khan (1989) reported that QSR franchisee satisfaction is affected by the level of conflict in franchise system. Impact of power on firm performance or franchisee satisfaction received little or no attention in hospitality literature.

Badovick and Beatty (1987) reported that strategy implementation process is positively affected by the differences in the organizations shared values. According to their study, greater the level of shared values higher the degree of success in implementing chosen strategies. The described phenomena of organization shared values is akin to the socialization process observed in relational governance structures of marketing channels as described by Ruekert, Walker and Roering (1985). The variations in shared values noted by Badovick and Beatty (1987) may be attributed to the differences in the level of behavioral perceptions such as, relative power, dependence, or conflict, which are specific to the research context.

In QSR franchise systems, in spite of predominance of shared values, the OSR franchisors and franchisees are separated by certain fundamental differences. One of the important differences, may be stated as: franchisors' want to maximize (satisfice) sales while franchisees prefer to maximize (satisfice) profits (Carman and Klein 1986). Therefore, even though the shared values (agreed upon strategy) are predominant in QSR franchise systems, the franchisors resort to behavioral measures (economic and noneconomic power sources) when their ultimate objectives (sales maximization) are in jeopardy which is reflected in strategy implementation chosen by a franchisee. 
Badovick and Beatty (1987) demonstrated that when the shared values differ significantly from the participants' individual values, individual's commitment and participation declines significantly. Such a decline will be reflected more in implementation process rather than in goal formulation (strategy content). That means, when the shared values of a franchise system differ significantly from the objectives of an individual franchisee, his/her commitment and participation in achieving overall objectives of the franchise system declines significantly.

As presented by Badovick and Beatty (1987), the loss of commitment of a franchisee will be reflected more in strategy implementation process rather than strategy content. In other words, when a franchisee differs with the franchisor in shared values, the deviation will be reflected significantly in implementation process rather than the strategy content. Hence, one may state that in QSR franchise systems, franchisees if necessary would deviate from their franchisors in implementation process rather than the strategy content. Therefore, measurement of implementation process may be more effective in understanding performance differential among the QSR franchisees.

In order to reduce the number of deviations from the chosen strategy content by the franchisees, the OSR franchisors may resort to behavioral measures such as economic and noneconomic power sources. This can be substantiated from the following OSR industry example. In the early 1980 s, Wendy's International Inc. has decided to enter breakfast segment by offering omelettes, scrambled eggs, pancakes and meats. Wendy's franchisees quickly learned that the new breakfast program produces increased revenues at the expense of profits. That means, Wendy's breakfast program was meeting franchisor's objective of sales maximization at the expense of franchisees' objective of profit maximization. Consequently, 
Wendy's franchisees chose to refuse breakfast implementation rather than challenging rationale for the program itself. At that point, according to Emerson (1991), Wendy's International Inc. opted to use economic sources of power to force its franchisees to implement the breakfast programs. The Chairman of Wendy's, Robert L. Barney stated that "Tell them to put the (expletive deleted) breakfast in or take the sign down" Emerson (1991, p57). That particular franchisee eventually filed for bankruptcy because of the breakfast program. Therefore, franchisors' power sources have significant effect on franchisees ability to implement chosen strategic objectives and eventual performance.

Difference in the level of performance among the hospitality franchisees can be better explained by understanding the impact of congruence between power perceptions and strategy implementation process on firm performance. This leads to the next hypotheses (Figure 7):

H7: In QSR franchise systems, high performance franchisees are different from low performers when grouped according to the nature of congruence between economic sources of power and the type of implementation process.

H8: In QSR franchise systems, franchisees with high level of satisfaction are different from those with low level of satisfaction when grouped according to the nature of congruence between economic sources of power and the type of implementation process.

When franchisees do not comply with the dernands or decline to participate in implementing the franchisors' strategy, the franchisors may prefer to use noneconomic sources instead of economic sources of power. In the earlier industry example, Wendy's International 
Inc., the franchisor preferred to use economic sources of power to achieve the desired objectives. During the mid-1980s, the same franchisor, Wendy's International Inc., decided to introduce the Super Bar concept across the franchise system. As happened earlier, the Super Bar concept was not profitable to the franchisees since it required significant capital investment and reduction of dinning space. Many franchisees were reluctant to implement the Super Bars. At that point, Mr. Jim Near, president of Wendy's and an ex-franchisee himself one time, preferred to apply noneconomic sources of power rather than economic sources of power.

The chosen noneconomic sources of power were reflected in the form of expert and financial assistance, time delay, redesign of restaurant dinning area to prevent loss of customer seating, total reevaluation of unit construction costs to reduce capital investments, and finally, franchisees were given the option to participate according to their abilities. Selection of noneconomic over economic sources of power has resulted in significant improvement in Wendy's franchisee satisfaction (performance). For his efforts, Mr. Near was recognized as the "Operator of The Year" by the association of multiunit food service operators in 1992. Therefore, one may state that satisfaction of QSR franchisees can be best explained by understanding the level congruence between the noneconomic sources of power and implementation process. This leads to the next hypotheses (Figure 7 ):

H9: In QSR franchise systems, franchisees with high level of satisfaction are different from those with low level of satisfaction when grouped according to the nature of congruence between noneconomic sources of power and the type of implementation process. 


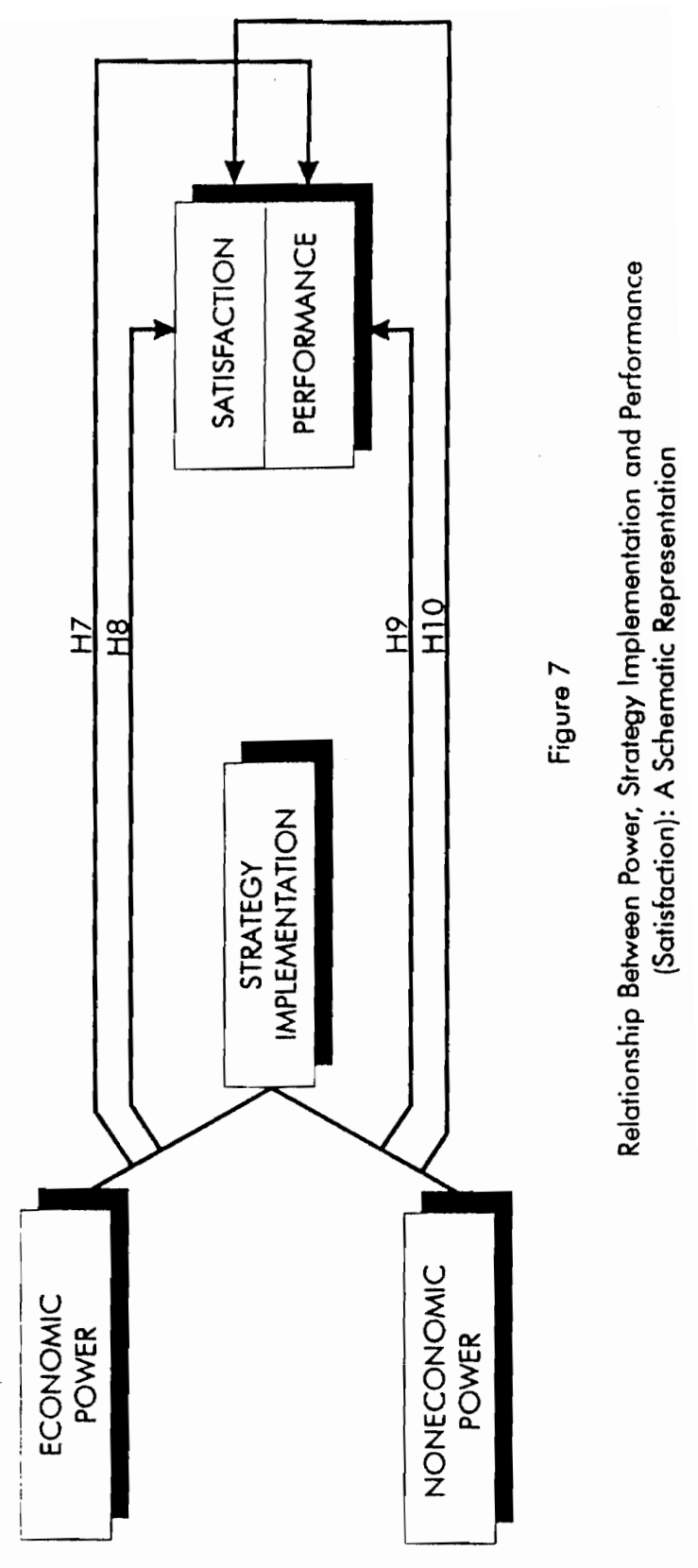


H10: In QSR franchise systems, high performance franchisees are different from those with low level of performance when grouped according to the nature of congruence between noneconomic sources of power and the type of implementation process.

\section{SUMMARY}

In this chapter, theoretical relationships between the variables, testable research hypotheses, and discussion of interrelationships between the variables are presented. In total, ten research hypotheses are presented.

This chapter also consists of operational definitions of the selected variables. The first four posited hypotheses relate to power sources (economic and noneconomic) and performance (satisfaction). The hypotheses five and six relate to strategy implementation and performance (satisfaction). The final four hypotheses, seven through ten, measure the impact of congruence of two independent variables (power sources and implementation) on performance (satisfaction).

Research methodology chosen to test the presented hypotheses will be discussed in the next chapter. The next chapter also includes research design, limitations of the methodology, sample frame, validity and reliability, and statistical analyses preferred. 


\section{Chapter 4}

\section{RESEARCH DESIGN}

\section{INTRODUCTION}

Research design deals with the broader question of establishing the framework within which construct measurement and data collection are considered. In selecting appropriate research design, according to Runkel and McGrath (1972) consideration should be given to three important factors: precision, generalizability, and realism. Since it is not possible to maximize any one of the factors without compromising others, it is suggested that optimization of all three factors should be attempted (McGrath 1982). Case study and participation approaches might maximize realism, but they induce subjectivity of the 'manager' or the observer. Conceptual generalization can be maximized by applying literature review method. But it is insufficient for the current study because of its obvious inability to provide empirical results. Finally, precision can be enhanced by using simulation or laboratory experiments, but they compromise on generalizability and realism. 
After considering various alternatives and reviewing earlier research studies, the selfadministered, structured questionnaire, sample survey method was selected. Similar methods were followed successfully by numerous researchers in the field of hospitality and marketing channels (Hunt and Nevin 1974; Etgar 1976a, 1976b, 1977; Lusch 1977; Dwyer 1980; Brown, Lusch and Muehling 1983; Schaffer 1984; Dev 1988; Tse 1988).

Some of the limitations of the survey method include loss of precision and realism. To compensate for the loss of realism a larger, and a representative sample was recommended with the underlying assumption that a larger representative sample is sufficiently effective in capturing essence of the required constructs from a chosen context. Precision of a research design can be enhanced by selecting a research context with least heterogeneity among its constituent members. Finally, precision of the survey instruments can be enhanced by adapting rigorous pretesting procedures as described in the following section. In the present study, context is defined as U.S. QSR franchisees that were believed to be a demographically homogeneous group in reference to the behavioral constructs.

Phillips (1981) indicated that perceptions of channel members are influenced by the position of the respondent in the organization. However, in QSR franchise systems, unit general manager/owner-operator is the primary link between the franchisor and the franchisee, especially in reference to strategy content and the implementation process. A unit general manager is often the best source to assess unit performance and satisfaction. Selection of single informant to reflect channel relations is supported by Rosenberg and Stern (1970), Brown et al.(1983), and Brown, Johnson and Kim (1986). Hence, the single informant method was not considered as a severe limitation. 
Selection of one member from a dyadic relationship, such as QSR franchise systems which consist of franchisees and franchisors, as an informant could be a potential limitation. Perceptions of power held by QSR franchisees might differ from that of franchisors. Earlier studies in marketing channels by Lowe and McCrohan (1979), Ross, Lusch and Brown (1982), John and Reve (1982), and Lusch and Ross (1985) indicated that power perceptions of channel members representing different sides of a dyad are similar. Therefore, selection of only franchisees from QSR franchise systems was not considered as a major limitation.

The current study was based on the premise that the OSR franchisees' performance and the level of satisfaction were affected by the level of perception of power, strategy content, and the type of implementation process. It was also contended that the level of power perception has direct as well as indirect effect on firm performance and franchisee satisfaction. To test these contentions working hypotheses were presented. Majority of studies in the hospitality literature did not consider the importance of franchising and franchisee satisfaction in exploring performance differential among the food service or lodging firms. Therefore, the present study on QSR franchise systems can be best described as exploratory in nature.

An exploratory study can be conducted in many ways, such as, case analysis, literature review, interview technique, self-administered questionnaire survey, or some combination of above mentioned methods. To test the presented research hypotheses, a cross sectional study of food service franchise owners/general managers using a survey instrument was proposed. 


\section{POPULATION \& SAMPLE SELECTION}

As stated earlier, precision of a research design can be enhanced by selecting a population with minimum heterogeneity. Such a selection also increases reliability of the obtained results. Reliability will be discussed in the following section.

Research questions relating to power perceptions, strategy content, implementation process, and performance can be tested across many contexts. Choice of relevant contexts that can be studied become 'problem universe' (Brown 1980). The research hypotheses presented in the current study were specific to the QSR franchise systems. Therefore, they can be tested, in the current form, within the context of QSR franchise systems only. Hence, the QSR franchise systems may be referred to as 'research universe' (Brown 1980).

The area of overlap between the problem universe and research universe defines the boundaries of a target population. Therefore, population selected for the current study can be defined as "hospitality franchisees (owner-operators or unit managers) that are actively involved in OSR franchise unit operations and are well informed on unit strategy implementation process, and performance." This definition eliminates inactive franchisees, absentee owners, and also franchise executives who do not possess knowledge of strategy implementation process.

\section{SAMPLING METHOD}

Since complete enumeration of all the elements in population is neither appropriate nor economical (Kalton 1990, p7) sample selection became necessary. Of all the available sampling 
methods, simple random sampling (SRS) method is mostly commonly used. Kalton (1990) attributes greater acceptance of SRS method to its simplicity and parsimony. SRS may be defined as a 'procedure that gives each of the $\mathrm{N}$ sampling units of the population an equal and nonzero probability of being selected' (Nachmias and Nachmias 1981 p432). SRS can be conducted with replacement or without replacement. For the current study, SRS without replacement was selected over SRS with replacement since it offers more precise estimators than the latter.

\section{SAMPLE SIZE SELECTION}

Sample size can be determined by numerous means such as fraction method, cluster method, or prior research practices. Fowler (1988 p42) recommends estimation of minimally adequate sample of subgroups for which analysis is needed. Hair et al. (1987 p237) recommend at least four to five times as many observations as there are variables to be analyzed and preferably a sample size of 100 or larger. In the current study, the seven research variables (coercive power; referent power; legitimate power; information power; strategy implementation; satisfaction; and business performance) were measured with a forty three item instrument.

A review of earlier studies indicated significant variance in response rates across different contexts. In marketing channels, a response rate between twenty and thirty percent is considered acceptable when the sample size is larger than one hundred. In the hospitality literature reported response rates vary from ten percent (Evans and Dev 1987) to 58.9 percent (Chon 1990). Parsa et al. (1989) reported 22.8 percent response rate in their study with U.S. 
QSR franchisees. A response rate of 22 to 25 percent is considered realistic for the current study. With this background, a sample frame was determined to be as four to five times (22 to 25 percent response rate) larger than the recommended sample size of one hundred.

\section{SOURCES OF DATA}

The sample selection, by necessity, was not random. There is no single umbrella organization for the foodservice franchise systems. Unlike other industries such as automobile and gasoline distribution, there is no comprehensive official listing of QSR franchisees. Absence of such a listing leads one to seek varied sources of information on OSR franchisees. Names and addresses of potential respondents were obtained from the following sources:

1) International Franchise Association membership list.

2) Nation's Restaurant News, the 1990 annual edition.

3) Restaurants and Institutions, "Top 400" list.

4) Who is Who in the Food Service Industry 1989-1990.

5) National Restaurant Association membership list.

6) Handbook of Franchising.

7) List of Multiunit Restaurant Operators.

In spite of multiple sources of information one cannot claim to have a comprehensive listing of QSR franchisees. Therefore, there is a possibility of unintentional selection bias in choosing potential respondents. Since the selected sample frame was large enough to provide representative sample, the sample selection bias was not considered significant enough to affect the research outcomes. From the available lists six OSR companies (Dominos; Hardees; 
Little Caesars; Show Biz; Subway; and Sizzler) agreed to participate in the study (Appendix VI). A comprehensive list of franchisees was received from the selected companies. Single unit franchisees from the available lists were selected for the current study. Single unit franchisees are often directly responsible for strategy implementation and have 'first hand' knowledge on franchise relations. Hence, it was most appropriate to include single unit franchisees in this study on franchise relations and strategy implementation.

\section{RESPONSE RATE}

Efficiency of the data collection methods is measured by the level of response rate. Nonresponse bias is one of the major contributors of systematic error. Failure to collect the survey data from some sampled elements, or nonresponse, is a major problem in survey research (Kalton 1990). "The cause of concern about nonresponse is the risk that nonrespondents will differ from the respondents with regard to the survey variables..." (Kalton 1990 p63). Concern for nonresponse bias is well founded. Donald (1960) noted that, in mail surveys, people who have direct interest in the subject of research are more likely to respond. That means, low response rates are invariably biased towards the respondents opinions. Even though low response rate is a major concern, there is no agreed-upon standard for minimum acceptable response rate (Fowler Jr. 1988).

In social sciences, response rates vary from twenty percent to eighty percent. The reason for obvious variance may be attributed to the nature of sample frame, available resources, efficiency of the technique, simplicity of the survey instrument, persistence of the 
researcher, and method of mailing. In marketing channels response rates varied from 6.3 percent (Dwyer and Welsh 1983) to 37.5 percent (Gaski 1986).

In the hospitality literature, response rates varied significantly from 13.5 percent (Weaver et al. 1991 ) to 58.9 percent (Chon 1990). Majority of the reported response rates fell between 20 percent and 30 percent. Hunt and Nevin (1974), in their study with OSR franchisees, reported a response rate of 26 percent. As stated earlier, Parsa et al. (1989) reported 22.8 percent response rate with OSR franchisees. Based on all above mentioned studies, in the current study, a response rate of approximately 20 percent was considered acceptable.

\section{DATA COLLECTION}

One of the most important decisions a researcher must make is the way in which data are collected (Fowler Jr. 1988). As mentioned earlier, self-administered, simple random survey method was found to be more appropriate for the current study.

The process of data collection can be considered in two steps: instrumentation and field work (Brown F.E. 1980). Instrumentation refers to the process of developing survey instruments, pretesting, validation, reliability and validity issues, and refinement of the instruments. Field work consists of actual method of delivering and receiving the instruments, such as interviews and mail surveys, response rate, and data coding methods. 
A survey instrument can be delivered to potential respondents in numerous ways: bulk mail, first class mail, hand delivered, drop off, and volunteer response. Parsa et al. (1989) experienced that a simple but well designed instrument with a strong help-the-sponsor appeal on a university stationery produced significant increase in the response rate. Therefore, in the current study, a well refined, rigorously pretested instrument was mailed to the potential respondents on a university stationery using bulk mail and first class mail. Weaver et al. (1991) mentioned that first class U.S. mail has produced a higher response rate (15.6 percent) than bulk mail $(0.89$ percent). Advantages of this include low administrative costs, ability to reach widely spread out respondents, and sufficient time for respondents to think and respond. Limitations, though not major, of this method include cost of first class mail, low response rate, and difficulty in compiling comprehensive mailing lists.

To increase response rate, many researchers have recommended a three step method using invitation, actual delivery, and follow up. Because of resource limitations two-step method where survey instruments is mailed in two waves was preferred for the current study (Appendix - VII, VIII). It was believed that this will ensure needed response rate. To verify nonresponse bias or lack of it, follow up telephone interview method was used to contact nonrespondents. A minimal sample of ten nonrespondents were randomly selected for an interview to verify nonresponse bias. They were interviewed for satisfaction with the same five questions presented to the respondents. The obtained mean value for satisfaction was not significantly different from the mean value for respondents' score on satisfaction indicating absence of nonresponse bias. 


\section{INSTRUMENTATION}

Research constructs that were being tested in this study include power perceptions, implementation process, and performance (business performance \& satisfaction). Perceptions of QSR franchisees on channel partner (franchisor) power will be measured by adapting Hunt and Nevin's (1974) and Gaski (1986) instrument of channel power. Implementation process was measured by developing a new instrument based on Bourgeois and Brodwin's (1984) description of five types of implementation. Structure of this instrument will be similar to that of Miles and Snow's (1978) self-typing instrument on strategy content. Finally, business performance was measured in terms of return on sale (ROS), earning before fixed costs (EBFC), and growth rate. Satisfaction was measured, as often done in marketing channels, by the level of satisfaction experienced by QSR franchisees with channel arrangements, relations, and channel performance (Appendix - VIII).

\section{VALIDITY AND RELIABILITY}

Validity essentially means the degree to which we observe what we purport to observe, and reliability is the degree to which our observations are consistent or stable (Rosenthal and Rosnow, 1984). This process of establishing construct validity involves three distinct steps: 11 specification of theoretical relation between the constructs (Nomological Validity); 2) empirical relation between the measures of the construct (Convergent and Discriminant Validity); and 3) empirical evidence supporting the theoretical relations among the constructs (Predictive Validity). 
Nomological validity was established in the form of theoretical relations among the research constructs under consideration. The proposed theoretical relations were explained earlier in hypotheses development section.

Convergent and discriminant validity were established by the following method: The empirical relations between the measures are formalized on a statistical basis, in two ways; 1 ) testing for "convergence" across different measures of the same construct, and 2) testing for "divergence" (also referred as "discriminant") between measures of related but conceptually distinct behaviors (Rosenthal and Rosnow 1984, p78). The discriminant validity is an absolute necessity to really pin down the meaning of the measures, since measures may converge with measures of other variables in addition to the one of interest. For example, in the current study, "convergence" among the measures of sources of power, and "divergence" of measures of power from each other and the measures related to the strategy implementation and satisfaction were expected.

To ascertain convergent validity (all items that measure a variable should form a single cluster) and discriminant validity (all items that measure a variable should not contribute to another cluster of a different variable) a factor analysis was performed on all sources of power, the independent variables. Factor analysis was preceded by Cronbach Alpha test for reliability. Selected items with acceptable level of alpha values was included in factor analysis. Such a procedure eliminates some of the items with low reliability from contributing to the noise level in the data.

Predictive validity, the third requirement, was considered after data analysis. Predictive validity is attained when the obtained data leads to verification of theoretical relationships. In 
other words, if the hypothesized relationships were empirically supported by the collected data the predictive validity was achieved. It was possible only after analysing the relevant data.

Perfect validity of a construct is a theoretical reality, because reliability of the measuring instruments in social sciences are subject to both random and systematic errors. Construct validity is a matter of degree of instrument reliability. Therefore, to increase construct validity, in the current study, greater emphasis was placed on refining and calibrating the instrument.

The tendency toward consistency in repeated measurements of the same phenomenon is referred to as reliability. Achievement of reliability, as mentioned earlier, is affected by both random errors and systematic errors. The random errors are unidentifiable, unsystematic, and "self-cancelling" in nature, but cannot be totally ruled out (Carmines and Zeller, 1989). In contrast, the systematic errors are specifically identifiable, and not "self-cancelling". The systematic errors prevent the indicators from representing the theoretical concepts as intended. Therefore, the systematic errors must be reduced to a minimum acceptable level to increase instrument reliability, in turn, the construct validity. One of the recommended measures to reduce systematic errors, and thereby achieving greater reliability, is rigorous pretesting of the instruments (Carmines and Zeller, 1989). Pretesting methods are discussed in the following section.

\section{PRE-TESTING METHODS}

In the current study, pre-testing procedures include a three step process as recommended by Fortune (1990). First step involves 2 to 3 context experts, such as faculty 
or industry professionals, to verify the relevancy of the questionnaires to the context under consideration. The second step includes a group of eight to twelve respondents to provide feedback on the instruments. The major objectives of the second step was to determine the duration of the test, identify and correct for "double barrel" statements and complex words, and isolate and correct context affects, if any. The third step consists of testing a subsample of QSR general managers/franchisees, to refine the instruments, estimate response rate, and evaluate the appropriateness of analytical procedures, and any other unexpected problems. This step may involve both personal interviews and mail survey process. Application of such a rigorous pretesting procedure, ensure sufficient refinement of the survey instruments to produce desired response rate and effective outcomes.

\section{SURVEY INSTRUMENT}

Since, most of the studies are single test ${ }_{t}$ cross sectional, nationwide surveys, Cronbach alpha is found to be most appropriate to establish instrument reliability (Carmines and Zeller 1989, p51). The pretesting step one was conducted with the help of two faculty members and an industry expert. Pretesting steps two and three were conducted upon approval of the research proposal in a large northeastern city in USA.

The survey instrument has five parts (Appendix - VIII). First part relates to the demographic information of franchisees, specifically nature of franchise contract. This section attempts to measure the impact of demographics on unit performance and other research constructs. 
Second part was concerned with behavioral measures, power perceptions, in QSR franchise systems. This part was adapted from Hunt and Nevin's (1974) in their study of QSR franchisees, and Gaski's (1986) instruments. Power in this study refers to the ability of the franchisor, as perceived by the franchisee, to influence or control decision variables of the franchisee (Hunt and Nevin 1974, p188). Economic power bases were operationalized (five questions) by measuring franchisor's legal control over restaurant building, ability to terminate franchise contract, franchisee's perception on the need for government regulation to limit franchisor's right to terminate franchise contracts, and franchisee's right to resell franchise units (Questions \#3,4,5,20, \& 21).

Gaski (1986) measured noneconomic power sources by measuring referent, legitimate, and expert power sources. In the current study, referent power was measured by the questions $\# 6,7,8, \&$ 9; expert power was measured by a single item \#10; and legitimate power was measured by the items \#11,12,13, \& 14. Hunt and Nevin (1974) indicated that noneconomic bases of power can be best understood by measuring various assistance provided by the franchisor. In the current study, noneconomic bases of power were operationalized by measuring franchisee's perception of the quality of assistance received in the following areas: local marketing; training; menu selection; field supervision; and total marketing (Questions: \#15, $16,17,18, \& 19)$.

The third part was related to implementation process. As stated earlier, research in strategy implementation process is still in embryonic stage of development. Supporting empirical studies are very limited. There are no emperical studies reported on implementation process in the hospitality or marketing channel literature. Therefore, it became necessary to design a new instrument that was specific to the QSR franchise systems. Based on the success 
achieved by Miles and Snow (1978) with their self-reported instrument type, a new instrument to measure implementation process was developed. Theoretical underpinnings for the research instrument on implementation process were provided by Bourgeois and Brodwin (1984). Personal interviews with QSR franchisees have contributed significantly to the development of this part.

The section on implementation process consists of five choices and respondents were asked to choose one category that best describes their method of strategy implementation. Instruments of this nature were found to be very effective in measuring research constructs in hospitality and marketing literature (McDaniel and Kolari 1987; Dev 1988; and McKee et al. 1989).

The fourth part consists of two sub-sections: financial performance and satisfaction. Majority of the studies in strategy and hospitality literature preferred to measure organization performance by considering financial performance in terms of profitability, liquidity, revenue growth, and market share (Chakravarty 1986). In hospitality literature, Schaffer (1986), Dev (1988), West (1988) and Tse (1988) measured the business performance in terms of return on sales, return on assets, revenue growth, and profit margins. In the current study, business performance was measured in terms of revenues (net annual sales per restaurant), profitability (gross margin percentage and income before fixed costs), and growth rate (sales over last year) (Questions Part IV, \#1, 2, 3, \& 4).

The second sub-section, franchisee satisfaction, was measured to capture behavioral aspects of the firms. Study of satisfaction of the participating channel members has been the major thrust of marketing channel literature. Hunt and Nevin (1974 p189) measured satisfaction 
of OSR franchisees by asking a question "what he would do if he had to do over again." Answers were coded as " 1 " if franchisee would still choose same franchise, and " 0 " if not. Ruekert and Churchill (1984) measured satisfaction by direct and indirect means. They found that both methods were equally effective in measuring franchisee satisfaction. In the current study, measures of satisfaction were developed by adapting direct measures of Ruekert and Churchill (1984), and Hunt and Nevin's (1974) question on satisfaction. There were six questions on franchisee satisfaction (Questions: Part IV, \#5, 6, 7, 8, 9, \& 10)

The final part was intended to capture the remaining demographic information such as age, gender, education, experience, and income. The question number eleven was meant to measure experience with the current franchisee. The questions $\# 12$ and 13 were concerned with the amount of prior business experience and the nature of experience. The nature of experience was divided into four types: hospitality; general business; unrelated such as school teacher, nurse, mechanic; and no experience.

The question number 14 was expected to collect demographic information on age, gender, and education. Annual income (salary as General Manager, and income from nonfranchise sources) was measured by the question number fifteen.

\section{INSTRUMENT SCALE}

In any survey instrument, questions are developed based on the presumption that there exists a set of alternative answers for each question. The possible alternative answers are arranged in some kind of order and are measured with a suitable scaling system. Therefore, it 
was essential to select appropriate scale so that theoretical relations are properly reflected in the data system. A scaling system establishes a link or rule of correspondence in a data system and the elements in the targeted context (Crocker and Algina $1990 \mathrm{p} 46$ ).

The overall survey instrument had four parts, with each part approximating about one page. The first part was meant to collect demographic information. The second part of the survey instrument measures perceptions of power and it uses six point Likert-type ordinal (Stevens 1946) scale. The third part reflects strategy implementation process. It will be measured by using a self-typing questionnaire with nominal scale. Finally, the fourth part that measures financial performance has varied scales depending on the nature of questions, and satisfaction was measured with a six-point Likert-type ordinal scale.

The primary reason to select six-point scale was to avoid neutral answers, thus gently directing respondents to take a definitive position. Second reason was ease of data reduction from six points to three levels (high, medium, and low), if necessary. This also increases heterogeneity between high and low sectors thus increasing the possibility of identifying significant groups. Nonresponse bias was analyzed using telephone interviews with at least ten nonrespondents.

\section{UNIT OF ANALYSIS}

As indicated in the literature, strategy formulation and implementation takes place not only at the corporate level, but also at the business units comprising the firm (Hambrick 1980). In the food service franchise systems, often a restaurant was the unit of business. Hence, a 
franchisee or a general manager of a restaurant was assumed to be aware of the channel power, strategy implementation, and performance. Therefore, a restaurant was taken as a unit of analysis. To reduce noise level in the data multiunit franchisees were not included in the current study.

\section{STATISTICAL ANALYSIS}

Frequency distributions were conducted to identify the relations and general patterns. The first four hypotheses (one through four) were tested by measuring the direct correlation between the research variables economic power; noneconomic power; and satisfaction and performance.

The hypotheses five and six were concerned with strategy implementation, performance, and satisfaction. Relations between the presented research constructs were tested with the help of One-way Analysis of Variance (Performance = Strategy Implementation + Error; Satisfaction $=$ Strategy Implementation + Error). This procedure was earlier followed by Dev (1988) in measuring the relationship between strategy and performance.

The last four hypotheses discriminate high and low groups based on selected independent variables. The hypotheses seven and eight include economic power and stately implementation as the independent variables, and performance and satisfaction as the dependent variables. The hospitality franchisees were classified as high and low based on their level of performance (satisfaction). Multiple Discriminant Analysis (MDA) was selected to test the independent variables' ability to discriminate between the high and low performance 
(satisfaction) franchisees. According to Hair et al. (1987, p75), "Discriminate analysis involves deriving the linear combination of the two (or more) independent variables that will discriminate best between the priori defined groups." Assumptions for MDA include equal priori group probabilities as was the case in the current research setting. A QSR franchisee has equal probability of being classified high or low on performance (satisfaction). Therefore, the selection of MDA was justified for the current research problem.

The hypotheses nine and ten involve noneconomic power and strategy implementation as independent variables and performance (satisfaction) as dependent variable. Again, Multiple Discriminant Analysis (MDA) was preferred to test the independent variables' ability to discriminate between the high and low performance (satisfaction) franchisees.

After conducting multiple discriminant analysis for hypotheses $7,8,9$, and 10 , the data were reanalyzed using multiple regression procedure. The results obtained from multiple regression were compared with the results from MDA of research variables.

\section{SUMMARY}

This chapter was dedicated to the development of research methodology that was appropriate for this study. Various research design alternatives and their limitations were discussed. 
The sample selection process, data collection methods, pretesting procedure, instrument development, and scaling were discussed in this chapter. This chapter also includes selection of statistical methods that were appropriate to test the presented hypotheses.

The next chapter presents the results attained from the current study and their implications. The next chapter also includes limitations of the statistical procedures and interpretation of the data. 


\section{Chapter 5}

\section{RESULTS AND ANALYSIS}

\section{INTRODUCTION}

The preceding chapters included methodology, research design, development of the instrument and statistical procedures selected to understand the relationship between the research constructs selected: economic power, noneconomic power, strategy implementation, and performance (satisfaction). The preceding chapter also described the research hypotheses that were derived from the theoretical propositions.

This chapter consists of discussion of the data collected, a profile of the respondents, rationale for selection of statistical tests, results of the statistical procedures, and empirical evidence for the posited research hypotheses. The outcomes of the hypothesis testing were summarized at the end of the chapter. 


\section{DATA COLLECTED}

As discussed earlier, single unit QSR franchisees were randomly selected from the data base consisting of six QSR chains: Chuck-E-Cheese (Show Biz); Dominos; Hardees; Little Caesars; Sizzler Restaurants; and Subway. The pretested instrument was mailed to randomly selected franchisees during later part of August 1992. A total of seven hundred and fifty two letters with a copy of the instrument were mailed to the single unit QSR franchisees.

Responses were collected through the months of September and October 1992, over a period of eight weeks. During that period one hundred and forty one usable responses were recorded. Ninety three percent of the responses $(131)$ were received during the first six weeks. Only ten responses were received during the last two weeks. The collection of responses was stopped after eight weeks. Since the time frame for response acknowledgement was limited to eight weeks I do not expect any significant differences between the early arrivals and late arrivals. The total usable responses were one hundred and forty one with a response rate of 18.8 percent. The obtained response rate was slightly lower than the expected rate of twenty percent. As mentioned in the earlier chapter, low response rate was not uncommon in hospitality research, especially with single unit franchisees.

In contrast to managers of franchisor-owned QSR units, the single-unit QSR franchisees have additional financial, marketing, operational and administrative responsibilities as owneroperators. Therefore, participation in industry related academic activities such as responding to survey instruments may take lower priority to their daily business demands. Concern for confidentiality could be another reason for low response rate. 
To test for nonresponse bias some of the QSR franchisees were interviewed over the telephone on satisfaction. The data collected from the interviews were analyzed and compared to the experimental data. The mean values for the respondents and nonrespondents on satisfaction did not differ significantly reflecting absence of nonresponse bias.

The returned survey instruments were reviewed for completeness and accuracies. Only the usable responses (one hundred and forty one) were coded on OPSCAN sheets to be uploaded as SPSS-X data base on the Vax system.

\section{STATISTICAL ANALYSES}

The coded data were analyzed for frequency distributions of various questions using SPSS-X statistical software. Based on the information obtained from the frequency distributions some of the responses were re-coded into broader categories. Rationale for data recoding will be explained as appropriate. The frequency studies were followed by descriptive statistics, reliability tests (Cronbach Alpha), Factor analysis, correlational studies, Oneway Analysis of Variance, Multiple Discriminant Analysis, and Multiple Regression.

\section{PROFILE OF PARTICIPATING QSR FRANCHISEES}

The profile of the QSR franchisees that responded to the study was very diverse and complex. Information provided by the respondents has included location, franchise contract (number of units), number of years with the franchisor, years of prior business experience, 
nature of prior experience, demographic data lage, gender, income, education, and annual salary) and franchise concept.

Summary of respondents' franchise affiliation was presented in the Table 1 . All the selected franchise systems (six) were represented in the final data base. Dominos' franchisees comprised slightly over fifty percent $(50.4 \%)$ of the usable responses $(n=71)$. It was followed by Little Caesars $(n=18,12.8 \%)$, Subway $(n=17,12.0 \%)$, Chuck-E-Cheese and Hardees ( $n=13,9.2 \%)$, and Sizzler $(n=9,6.4 \%)$.

\section{LOCATION}

The responded OSR franchisees are distributed among all the available choices in the location category. The majority of the respondents were located in suburban $(n=53,37.6 \%)$ areas followed by shopping centers $(n=39,27.6 \%$ ), downtowns $(n=20,14.2 \%$ ), highways $(n=13,9.2 \%)$, rural areas $(n=10,7.1 \%)$ and tourist resorts $(n=6,4.3 \%)$ (Table 2$)$.

\section{FRANCHISE CONTRACT}

The selected data base does not differentiate the single unit operators with one-unit contract from those with multiunit contracts. Hence, information was collected on nature of franchise contracts. The nature of franchise contracts were measured in terms of single unit, multiunit, and territorial contracts. The distribution of respondents was dominated by single unit contracts $(n=94,66.7 \%)$. The QSR franchisees with multiunit contracts $(n=46)$ have accounted for $32.6 \%$ of respondents followed by territorial contracts $(n=1,0.7 \%)$ (Table 3 ). 
Table - 1

Profile of the Participating QSR Franchisees:

Classification by Franchisor

\begin{tabular}{||l|c|c|}
\hline Name of the Franchisor & Number $(n)$ & Percentage \\
\hline Domino's & 71 & 50.35 \\
\hline Little Caesars & 18 & 12.77 \\
\hline Subway & 17 & 12.06 \\
\hline $\begin{array}{l}\text { Chuck-E-Cheese } \\
\text { (Show- Biz Pizza) }\end{array}$ & 13 & 9.22 \\
\hline Hardees & 13 & 9.22 \\
\hline Sizzlers & 9 & 6.38 \\
\hline \multicolumn{1}{|c|}{ Total } & 141 & 100 \\
\hline
\end{tabular}




$$
\text { Table - } 2
$$

Profile of the Participating QSR Franchisees:

Classification by Location

\begin{tabular}{||l|l|l||}
\hline \hline Type of Location & Number (n) & Percentage \\
\hline Suburban Locations & 53 & 37.58 \\
\hline Shopping Centers & 39 & 27.65 \\
\hline Downtowns & 20 & 14.18 \\
\hline Highway Locations & 13 & 9.22 \\
\hline Rural Areas & 10 & 7.09 \\
\hline Tourist Resorts & 6 & 4.28 \\
\hline \multicolumn{1}{|r|}{ Total } & 141 & 100.00 \\
\hline
\end{tabular}


Table - 3

Profile of the Participating OSR Franchisees:

Classification by Franchise Contract

\begin{tabular}{||l|c|c||}
\hline Type of Franchise Contract & Number $(\mathrm{n})$ & Percentage \\
\hline Single-Unit Contracts & 94 & 66.66 \\
\hline Multi-Uint Contracts & 46 & 32.62 \\
\hline Territorial Contracts & 1 & 0.72 \\
\hline \multicolumn{1}{|c|}{ Total } & 141 & 100.00 \\
\hline
\end{tabular}


Since majority of the respondents $(66.4 \%)$ were single-unit contract operators no further data analysis was considered.

\section{DEMOGRAPHIC DATA}

Summary of demographic data was presented in the Table 4. Gender classification of the responded franchisees was strongly in favor of males $(n=126,89.4 \%$ ) compared to females $(n=12,8.5 \%$ ). Similar results were obtained during the pretesting of the instrument. Hence, predominance of male, single-unit franchisees was a reflection of the population under consideration. Three of the respondents did not specify their gender $(n=3,2.1 \%)$ (Table 4 ).

The next demographic variable considered was the age of the respondents. The respondents were given an opportunity to select one of the five categories: under 24 yrs; 25 to 34 years; 35 to 44 years; 45 to 54 years; and over 55 years. A majority $(n=64,45.4 \%$ ) of the respondents were in the range of 25 to 34 years age indicating young, adult group. It was followed by 35 to 44 years group $(n=38,26.9 \%), 45$ to 54 age group $(n=22,15.6 \%$ ), over 55 years group $(n=12,8.5 \%)$, and under 24 years group $(n=5,3.65 \%)$. The total combined contribution of the categories and second and third was equal to $72.3 \%$ of the respondents (Table 5).

The level of education of the respondents was measured under fours categories: High school; Some college; College degree; and Graduate school or higher. Majority of the respondents ( $n=54,38.3 \%$ ) have some college education. This group was followed by college graduates $(n=48,34.0 \%)$, high school $(n=22,15.6 \%)$, and graduate school or higher $(n=17$, 
$12.1 \%)$ groups. The second and third categories collectively accounted for $72.9 \%$ of single-unit franchisees (Table 6).

Annual salary of the franchisees as an operator of a single unit QSR restaurant was measured in eight categories: Less than $\$ 14.9 \mathrm{~K} ; \$ 15$ to $\$ 24.9 \mathrm{~K} ; \$ 25$ to $34.9 \mathrm{~K} ; \$ 35$ to $44.9 \mathrm{~K}$; $\$ 45$ to $54.9 \mathrm{~K} ; \$ 55$ to $64.9 \mathrm{~K} ; \$ 65$ to $74.9 \mathrm{~K}$; and greater than $\$ 75 \mathrm{~K}$. The largest group was represented by under $\$ 25$ to $\$ 34.9$ thousand annual salary category $(n=44,31.2 \%)$. It was followed by $\$ 15$ to $\$ 24.9$ category $(n=17,12.1 \%)$; less than $\$ 14.9$ thousand $(n=17,12.2 \%)$; from $\$ 45$ to $\$ 54.9$ thousand group $(n=15,10.6 \%)$; from $\$ 35$ to $\$ 44.9$ thousand $(n=13$, $9.21 \%)$; from $\$ 55$ to $\$ 64.9$ thousand group $(n=10,7.1 \%)$; greater than $\$ 75$ thousand category $(n=9,6.4 \%)$; and from $\$ 65$ to $\$ 74.9$ thousand category $(n=2,1.4 \%)$. Some of the respondents did not specify their annual salaries $(n=14,9.9 \%)$ (Table 7$)$.

Reported income from sources other than the current franchised unit was recorded in eight categories: less than $\$ 24.9 \mathrm{~K} ; \$ 25$ to $\$ 49.9 \mathrm{~K} ; \$ 50$ to $\$ 74.9 \mathrm{~K} ; \$ 75$ to $\$ 99.9 \mathrm{~K} ; \$ 100$ to $\$ 124.9 \mathrm{~K}$; $\$ 125$ to $\$ 149.9 \mathrm{~K} ; \$ 150$ to $\$ 174.9 \mathrm{~K}$; and greater than $\$ 175 \mathrm{~K}$. Majority of the respondents $(n=77,54.6 \%$ ) belonged to the first group with incomes from sources other than the current franchise under $\$ 24.9$ thousand. It was followed by $\$ 50$ to $\$ 74.9$ thousand group $(n=10,7.0 \%), \$ 25$ to $\$ 49.9$ thousand group $(n=8,5.6 \%), \$ 75$ to $\$ 99.9$ thousand group $(n=6,4.3 \%), \$ 125$ to $\$ 149.9$ thousand and greater than $\$ 175$ thousand groups were tied $(n=2)$ with 1.4 percent each. The group with $\$ 150$ to $\$ 174.9$ thousand income did not have any respondents. Some of the respondents declined to report their incomes from other sources (n=35, 24.8\%) (Table 8$)$. 
Table - 4

Demographic Profile of the Participating QSR Franchisees:

Classification by Gender

\begin{tabular}{||l|c|l||}
\hline Nature of Gender & Number $(\mathbf{n})$ & Percentage \\
\hline Males & 126 & 89.36 \\
\hline Females & 12 & 8.51 \\
\hline Not Specified & 3 & 2.13 \\
\hline Total & 141 & 100.00 \\
\hline
\end{tabular}


Table - 5

Demographic Profile of the Participating OSR Franchisees:

Classification by Age

\begin{tabular}{||l|l|l|}
\hline Age Group & Number $(n)$ & Percentage \\
\hline Under 24 years & 5 & 3.55 \\
\hline 25 to 34 years & 64 & 45.39 \\
\hline 35 to 44 years & 38 & 26.95 \\
\hline 45 to 54 years & 22 & 15.60 \\
\hline Over 55 years & 12 & 8.51 \\
\hline & 141 & 100.00 \\
\hline
\end{tabular}


Table - 6

Demographic Profile of the Participating OSR Franchisees:

Classification by Education

\begin{tabular}{||l|l|l|}
\hline Level of Education & Numbers $(n)$ & Percentage \\
\hline Some College Education & 54 & 38.30 \\
\hline College Graduates & 48 & 34.04 \\
\hline High School Diploma & 22 & 15.60 \\
\hline Graduate School or Higher & 17 & 12.06 \\
\hline & 141 & 100.00 \\
\hline
\end{tabular}


Table - 7

Demographic Profile of the Participating QSR Franchisees:

Classification by Annual Salary

\begin{tabular}{||l|l|l||}
\hline Annual Salary & Numbers $(\mathrm{n})$ & Percentage \\
\hline Less than 14.90 thousand & 17 & 12.06 \\
\hline$\$ 15$ to 24.90 thousand & 17 & 12.06 \\
\hline$\$ 25$ to 34 thousand & 44 & 31.21 \\
\hline$\$ 35$ to 44.90 thousand & 13 & 9.22 \\
\hline$\$ 45$ to 54.90 thousand & 15 & 10.64 \\
\hline$\$ 55$ to 64.90 thousand & 10 & 7.09 \\
\hline \$65 to 74.90 thousand & 2 & 1.42 \\
\hline $\begin{array}{l}\text { Greater than } 75 \\
\text { thousand }\end{array}$ & 9 & 6.40 \\
\hline Unspecified & 14 & 9.90 \\
\hline & 141 & 100.00 \\
\hline
\end{tabular}


Table - 8

Demographic Profile of the Participating OSR Franchisees:

Classification by Income from Other Sources

\begin{tabular}{|l|c|l||}
\hline Income from Other Sources & Numbers $(n)$ & Percentage \\
\hline Under $\$ 24.90$ thousand & 77 & 54.6 \\
\hline$\$ 25$ to 49.90 thousand & 8 & 5.7 \\
\hline$\$ 50$ to 74.90 thousand & 10 & 7.1 \\
\hline$\$ 75$ to 99.90 thousand & 6 & 4.3 \\
\hline$\$ 100$ to 124.9 thousand & 1 & 0.7 \\
\hline$\$ 125$ to 149.90 thousand & 2 & 1.4 \\
\hline$\$ 150$ to 174.90 thousand & 0 & 0.0 \\
\hline Greater than $\$ 175$ & 2 & 1.4 \\
\hline Unspecified & 35 & 24.8 \\
\hline & 141 & 100.0 \\
\hline
\end{tabular}




\section{TENURE WITH THE CURRENT FRANCHISOR}

The respondents' tenure with the current franchisor was explored through an openended question. The collected responses ranged from less than one year to thirty years with the current franchisor. A majority of QSR franchisees $(n=51,36.2 \%)$ reported a tenure equal to or less than three years of experience with the current franchisor. It was followed by the group with under 10 years of experience $(n=39,27.6 \%)$; with under 5 years experience $(n=32,22.7 \%)$; and with under 30 years experience $(n=19,13.5 \%)$ (Table 9). Mean number of years with the current franchisor was reported as 6.13 years. About $90 \%$ of the respondents reported a tenure of under 11 years. No one reported a tenure of over 30 years with their franchisor.

\section{PRIOR BUSINESS EXPERIENCE}

Business experience prior to the current franchise was also noted using an open-ended question. The median value for prior business experience was 7.97 years. About $90.0 \%$ of the respondents have prior business experience of about 18 years, and $75.0 \%$ of them have under 10 years of prior business experience. The largest group $(n=37,26.2 \%$ ) of respondents reported prior business experience of 6 years or less. It wasfollowed two groups with equal number of respondents: no prior business experience group; and under 10 years of experience group $(n=34,24.1 \%)$ (Table 10$)$.

The respondents experience prior to the current franchise was classified into four categories: Foodservice related; General Business Management; Unrelated Professions; and Selfemployed. The largest group $(n=56,39.7 \%)$ of respondents has prior foodservice experience. 
Table -9

Demographic Profile of the Participating QSR Franchisees:

Classification by Tenure with the Current Franchisor

\begin{tabular}{||l|l|l|}
\hline $\begin{array}{l}\text { Number of Years with the Current } \\
\text { Franchisor }\end{array}$ & Numbers $(\mathrm{n})$ & Percent \\
\hline 3 Years or less & 51 & 36.17 \\
\hline 5 years or less & 32 & 22.70 \\
\hline 10 years or less & 39 & 27.66 \\
\hline 30 years or less & 19 & 13.47 \\
\hline & 141 & 100.00 \\
\hline
\end{tabular}


Table -10

Demographic Profile of the Participating QSR Franchisees:

Classification by Years of Prior Business Experience

\begin{tabular}{||l|l|l|}
\hline Years of Prior Business Experience & Number $(n)$ & Percent \\
\hline No Prior Business Experience & 34 & 24.11 \\
\hline Six years or less & 37 & 26.24 \\
\hline 10 years or less & 34 & 24.11 \\
\hline 18 years or less & 21 & 14.89 \\
\hline 40 years or less & 15 & 10.65 \\
\hline & 141 & 100.00 \\
\hline
\end{tabular}


It was followed by Unrelated Professions ( $n=44,31.2 \%)$, General Business Management ( $n=22,15.6 \%)$ and Self-employed $(n=19,13.5 \%)$ categories (Table 11$)$.

\section{VALIDITY AND RELIABILITY TESTS}

Validity is the degree to which one measures what he/she intended to measure (Kerlinger 1986). Nomological validity was established while developing theoretical rationale and research hypotheses. Content validity was evaluated during the pretesting process of the instrument. Finally, another measure of validity, convergent validity, was evaluated by either empirically testing the convergence of related items or differentiating the construct measures from others. Reliability of the research instrument was determined by calculating Cronbach's alpha values.

Reliability of an instrument indicates its stability or consistency over repeated measures. To enhance reliability of the instrument the test questions were selected from established and well tested earlier instruments followed by rigorous pretesting procedures. Internal consistency of research variables was examined by measuring Cronbach's alpha values. The obtained alpha values for the research variables were presented in the Table 12 .

\section{POWER PERCEPTIONS}

The independent variables, economic power and noneconomic power, were measured with 21 items on 6-point Likert-type scale, except for 020 and 021 which have dichotomous answers (yes or no). As mentioned in the literature review section, economic power, one of the 
Table - 11

Demographic Profile of the Participating QSR Franchisees:

Classification by The Nature of Prior Business Experience

\begin{tabular}{||l|l|l|}
\hline Nature of Prior Business Experience & Number $(n)$ & Percent \\
\hline Foodservice Experience & 56 & 39.72 \\
\hline Unrelated Professions & 44 & 31.21 \\
\hline General Business Mgmt. & 22 & 15.62 \\
\hline Self-employed & 19 & 13.45 \\
\hline & 141 & 100.00 \\
\hline
\end{tabular}


Table -12

Reliability Values for Multi-item Research Constructs.

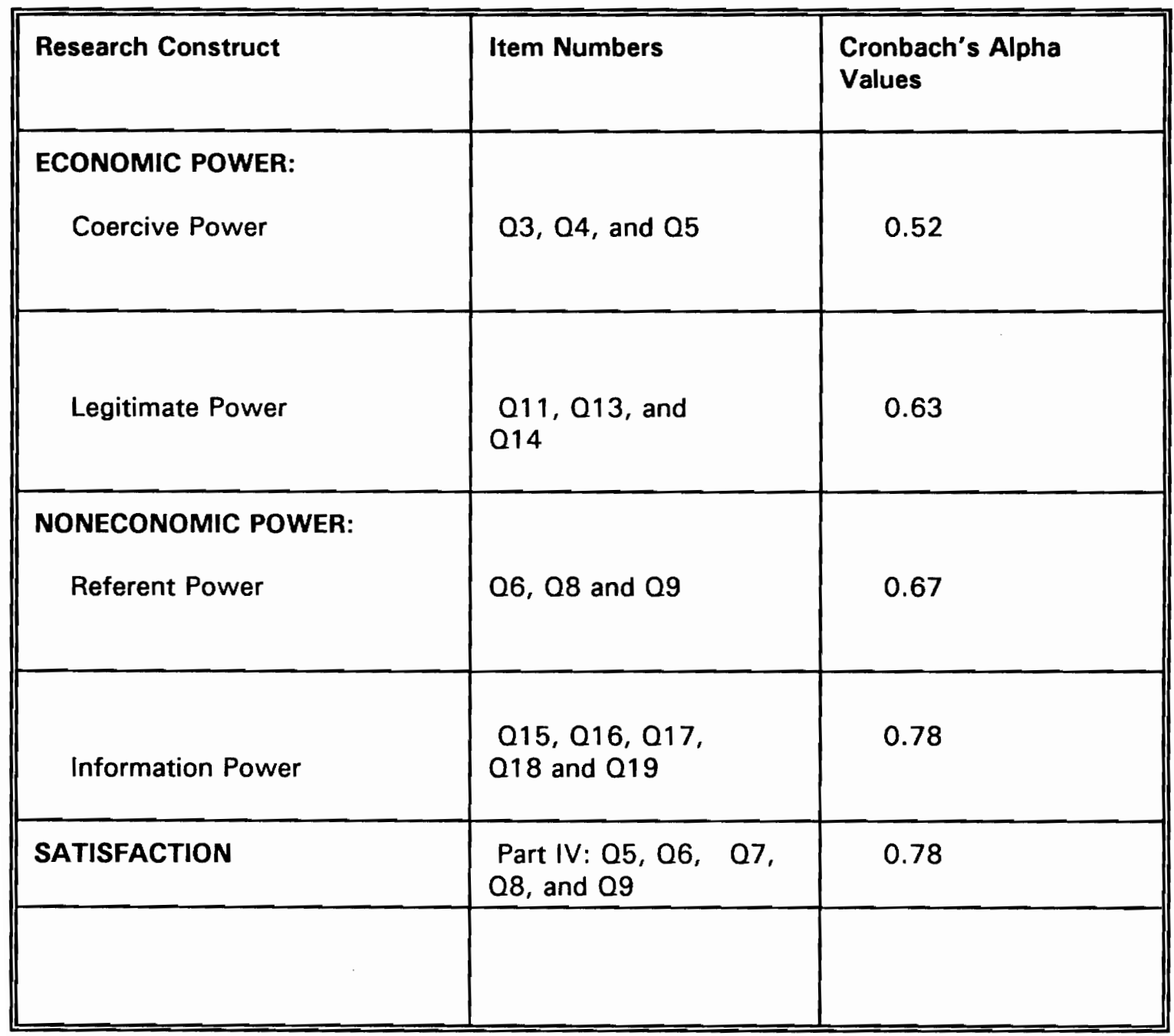


independent variables, was comprised of two sources of power: coercive power and legitimate power. The other independent variable, noneconomic power, consists of two sources of power: information and referent power.

The economic power was evaluated by measuring coercive power $103,04,05,020$, and 021$)$ and legitimate power $(011,012,013$ and Q14). The noneconomic power was represented by information $(015,016,017,018$ and 019$)$ and referent power $(06,07,08$, 09 and 0101 .

One of the measures of construct validity is convergent validity or reliability. Reliability of an instrument is enhanced by including multiple items of similar nature. Degree of convergence of related items (divergence of unrelated items) indicates the reliability of the instrument. According to Kerlinger (1986, p415), "High reliability is no guarantee of good scientific results, but there could be no good scientific results without reliability." Reliability coefficient is expressed as Cronbach's alpha.

The coercive power was measured with two sets of items: a set of three and a set of two. The first set has three items with six point Likert-type scale (03, 04, and 05). Reliability coefficient (Cronbach's alpha) for three items was 0.52 . The second set has two items 1020 and 021) with dichotomous answer (yes or nol. Cronbach's alpha for these two items was 0.15. Due to low reliability coefficient value the last two items $(020$ and 021$)$ were not included in rest of the analyses. 
The legitimate power source was measured with four items. To achieve highest reliability coefficient the item \#12 was deleted from further analyses. The final alpha value for the legitimate power with items 011,013 , and 014 was 0.63 .

The referent power was measured with five iterns. Upon analysis for reliability two of the items, 07 and 010 , were deleted from further analyses. With the inclusion of items 06,08 and 09 the reliability coefficient was 0.67 .

The information power, one of the power sources in noneconomic power, was measured with five items. The reliability coefficient for information power source with all items (Q15 through Q19) included was 0.78 .

To establish convergent and divergent validity of the items that measure sources of power, a factor analysis was performed. Items selected from the Cronbach Alpha test were subjected to factor analysis that resulted in four factors. The obtained factors with appropriate labels were presented in the Table 13a. Factor 1, Referent Power, was comprised of items eight (08) and nine (09). The item number six (06), contrary to the expectations, fell in the Factor 4, Economic Power. Further review of the research instrument indicated that the item number 6 was the only referent power item with reference to franchise representatives. A franchise representative is often strongly associated with the economic sources of power with the ability to reward and punish. Hence, it was logical to assume that the item 6 with reference to franchise representative could incidentally be a part of the Factor 4, Economic Sources of Power. The factor loadings were presented in the Table 13b. The factor loading values for 09 and 08 (referent power) were 0.9568 and 0.4482 respectively. 
Table 13a

\section{Factor Analysis of Sources of Power}

FACTOR 1

FACTOR 2

FACTOR 3

FACTOR 4
Referent Power

08,09

Noneconomic Power $015,016,017,018,019$

Legitimate Powe

$011,013,014$

Economic Power
Q3, 04, 05, (06)*

* = The item 6 was expected to be in the FACTOR 1 (Referent Power) 
Table 13b

Factor Loadings for Sources of Power

REFERENT

POWER

09

08

Q19

016

0.18

017

015

013

Q14

011

06

05

Q4

Q3
NON-ECONOMIC POWER

.14364

.15367

.73035

.65488

.64828

.56054

.50298

.12178

$-.14597$

$-.01455$

.19394

.09446

.06117

.04500

\section{LEGITIMATE POWER}

.00003

.10984

$-.09264$

.02114

$-.05363$

.09651

.14297

.72458

.69893

.44025

.08624

.04665

$-.05426$

.00661
ECONOMIC

POWER

.03062

$-.15357$

$-.55587$

$-.01698$

.11203

.21851

.28264

$-.02698$

$-.04156$

$-.00125$

$-.52847^{*}$

.39023

.22228

.13473 
Table 14

Factor Correlation Matrix

$\begin{array}{llll}\text { FACTOR } 1 & \text { FACTOR } 2 & \text { FACTOR } 3 & \text { FACTOR } 4\end{array}$

FACTOR 1

1.0000

FACTOR 2

.2645

1.0000

FACTOR 3

.2616

.1356

1.0000

FACTOR 4

$-.1998$

.1146

$-.0544$

1.0000 
Factor 2, Noneconomic Power, was comprised of items fifteen through nineteen. The factor loading values for items in the second factor, Noneconomic Power, were as follows: 019 (0.7304); $016(0.6549) ; 018(0.6483) ; 017(0.5605)$; 015 (0.5030). All the loading values were positive in nature. Factor 3, Legitimate Power, contained items 11, 13 and 14. The factor loading values for these items were Q13 (.7246); Q14 (.6499); and Q11 (.4402). Finally, Factor 4, Economic Power, included items Q3, 04, Q5 and 06. In contrast to the expectations, O6 loaded on Factor 4, Economic Power, instead of Referent Power. The factor loading values for items in the Factor 4, Economic Power, were Q6 (-0.5285); 05 (0.3902); 04 (0.2222); and Q3 (0.1347). Interestingly, all factor loadings were positive values except for the item 06 which was negative.

Independence of the obtained factors was further supported by the low interfactor correlational values noted in the correlational matrix (Table 14). Highest correlation value between any two factors was only 2645 between referent power and noneconomic power and it was insgnificant. Principal Component analysis resulted in four factors explaining a total variance of 55.4 percent (Table 15 ). Oblimin rotation, a nonorthogonal rotation, was selected in the present case. After the rotation, the obtained Eigen values ranged from 3.2696 for Factor 1 to 1.1375 for Factor 4 (Table 15).

\section{SATISFACTION}

One of the dependent variables, satisfaction, was measured with six items (Part IV, 05 through $\mathrm{Q10}$ ) on six point Likert-type scale. The question number ten was coded in reverse order to reflect the reverse nature of the question. A reliability coefficient of 0.78 was attained when the reverse order question, 010, was excluded from the analyses. 


\section{Table 15}

Factor Analysis: Eigen Values and Other Statistics

$\begin{array}{lccc}\text { FACTOR } & \text { EIGEN VALUE } & \begin{array}{c}\text { PERCENT OF CUMULATIVE } \\ \text { VARIANCE }\end{array} & \text { VARIANCE } \\ 1 & 3.2697 & 23.4 & 23.4 \\ 2 & 1.8034 & 12.9 & 36.2 \\ 3 & 1.5387 & 11.0 & 47.2 \\ 4 & 1.1375 & 8.1 & 55.4\end{array}$


In sum, all the obtained reliability coefficients were within the acceptable limits with a range of 0.52 to 0.78 . All the constructs were measured with multiple items enhancing the reliability of the research instrument. In exploratory studies such as the current study, Cronbach Alpha values of 0.60 or above were considered acceptable. Although the obtained alpha values were slightly lower they were within the norms of established research reported in marketing and hospitality literature (Slater and Narver 1994, p52).

\section{FINANCIAL PERFORMANCE}

Financial performance is often measured in terms of revenues, gross margin, net profit, market share, and or growth rate. Chakravarty (1986) listed fourteen most commonly used financial measures. In the current study, four different types of financial measures were employed to measure financial performance: gross sales per year; gross margin; income before fixed charges; and growth rate. Content validity of these measures was well established in the hospitality literature (Dev 1988; Tse 1988; West 1988).

The financial performance of the respondents was measured by four questions each measuring different aspects of firm performance. Item \# 1 in Part IV determines gross sales per year at the current unit. The respondents were requested to make a choice among eight predetermined categories. These categories were obtained from a rigorous pretesting process. The Nation's Restaurant News uses both unit sales per year and growth rate to rank restaurant firms in USA in its annual review of food service industry. 
The obtained responses were classified into three categories, high, medium, and low each representing one third of the responses from high to low respectively. In other words, the top one third of responses were considered as high performers, next one third were considered as medium performers, and the last one third were considered as low performers. Classification of responses into three categories (high, medium, and low) was based on numerical values as well as expert opinion wherever appropriate.

Gross sales per year reflects economic impact of QSR franchisees efforts through the year and it also captures any changes in franchisee and franchisor relationships. The sales per year was measured in eight categories. These categories were selected through the pretesting procedures.

The growth rate was measured by change in sales over the past year (Q3, Part IV) which could be either positive or negative. The respondents were given an opportunity to select one of the eight categories of sales down or up over past year. Because of inconsistencies in the responses this question was not considered for further analysis.

Profitability is essential for long term survival of any firm. It is even more critical for single unit franchisees who often do not have other sources of income to offset losses from current operations like multiunit operators do. Hence, the profitability was measured by two questions, 02 and $\mathrm{Q} 4$ in Part IV. The question number two measures average food and labor cost as percentage of sales. The food and labor costs were the largest contributors of the expenses in a restaurant. The value obtained by subtracting the total of food and labor cost percentages from one hundred was recognized as the percentage of gross margin. 
Measurement of gross margin in this form is common in the restaurant industry. Hence, it was chosen for the current study as one of the indicators of financial performance.

Net profit is the ultimate objective of any economic activity. Unfortunately, the OSR franchisees often are reluctant to disclose net profit figures out of concern for loss of confidentiality. In addition, different QSR franchisees follow different accounting procedures to arrive at the net profit figures thus complicating the selection process of a reliable and objective profit measure. Consequently, income before fixed charges(IBFC) was chosen in the current study as a substitute to the net profit. The selection of IBFC to measure financial performance has precedence in the hospitality literature (Dev 1988).

From the available four types of financial measures the sales per year and IBFC were considered for further analyses to test the research hypotheses.

\section{HYPOTHESES TESTS}

This study was undertaken to investigate the relationship between power perceptions, strategy implementation, and performance in QSR franchise systems. Two major types of power perceptions, economic power and noneconomic power, and a strategy implementation (Bourgeois and Brodwin's 1984) model were tested for their impact on single-unit OSR franchisees' satisfaction and financial performance. Earlier chapters have presented the theoretical relations among the research constructs. The observed theoretical relations were posited in ten research hypotheses. 
The current section of this chapter presents results of statistical analyses performed to test the research hypotheses. The empirical evidence of each hypothesis and its limitations were discussed. This section was concerned primarily with statistical inferences of the observed relationships, the broad theoretical implications were discussed later.

\section{HYPOTHESIS ONE:}

\section{"In QSR franchise systems, franchisees experience low level of satisfaction when they perceive their franchisors to possess economic sources power."}

The nature of franchisor-franchisee relations are affected by the power perceptions held by the franchise participants. In the present study, the perceptions of QSR franchisees on economic power were recorded by measuring legitimate power and coercive power. Analyses for correlation indicate that economic (coercive) power perceptions expressed by the franchisees were negatively correlated with the satisfaction (Table 16). The noted negative relation was statistically significant (at $p=.01$ level) with a correlation coefficient of -.2409 .

The observed negative relation between the coercive power and satisfaction indicates that OSR franchisees experience low satisfaction when high level of coercive power was perceived in the franchise systems. These results confirm the empirical conclusions of the earlier studies by Hunt and Nevin (1974) with the QSR industry during the growth stage of its life cycle. 
The mean values for satisfaction and economic power were presented in the Table 17. The mean value for satisfaction was 2.9603 , and the mean values for coercive power and legitimate power were 2.9178 and 2.8498 respectively.

Surprisingly, the relationship between satisfaction and legitimate power, one of the economic power sources, in the QSR franchise systems was positive in nature. The correlation coefficient between the legitimate power and satisfaction was 0.2341 and was significant at $p=.01$ level. The positive relation between the constructs under consideration was contrary to the preceding findings between coercive power, one of the economic power sources, and satisfaction. The relationship between legitimate power and satisfaction was not included in the study by Hunt and Nevin (1974).

Though the observed relationship between legitimate power and satisfaction was positive in nature it was much weaker than the relation between the satisfaction and noneconomic power sources (correlation coefficient $=0.6121$ and 0.5431 respectively) .

\section{HYPOTHESIS TWO}

"In QSR franchise systems, franchisees experience high level of satisfaction when they perceive their franchisors to possess noneconomic sources of power."

The franchisor-franchisee relations in the QSR industry are affected not only by economic power sources but also noneconomic power sources. In the current study, two noneconomic sources of power, referent power and information power, were included to study the franchise relations in the QSR industry during the maturity stage of its life cycle. The corre- 
Table - 16

Correlational Coefficient Values Between the Economic and Noneconomic Power Sources and Satisfaction

\begin{tabular}{||l|l||}
\hline \hline Independent Variables & SATISFACTION \\
\hline ECONOMIC POWER: & $-0.2409^{* *}$ \\
\hline Legitimate Power & $0.2341^{* *}$ \\
\hline NONECONOMIC POWER: & \\
Referent Power & $0.6121 * *$ \\
\hline Information Power & $0.5431 * *$ \\
\hline
\end{tabular}

** = Significant at 0.01 level 
Table - 17

Descriptive Statistics for Sources of Power and Satisfaction

\begin{tabular}{||l|l|l||}
\hline \hline Variable & Mean Value & Std. Deviation \\
\hline ECONOMIC POWER: & & \\
\hline Coercive Power & 2.9178 & 1.1003 \\
\hline Legitimate Power & 2.8498 & 0.9834 \\
\hline NoNECONOMIC POWER: & & 1.1803 \\
\hline Information Power & 3.0141 & 1.1466 \\
\hline SATISFACTION & 3.5123 & 0.9589 \\
\hline
\end{tabular}


lational analyses indicate a positive relationship between noneconomic power sources and QSR franchisee satisfaction.

The mean values for referent and information power sources were 3.0141 and 3.5123 respectively (Table 17). The correlation coefficient values between referent power and satisfaction was 0.6121 . A similar value was observed between information power and satisfaction 0.5431 . The observed relationships were significant statistically at $p=0.01$ level. The magnitude of the noted relations was relatively high. These observed relations were consistent with the earlier findings by Hunt and Nevin (1974).

In sum, the correlational analyses indicate that economic power sources correlate negatively with QSR franchisee satisfaction and noneconomic power sources correlate positively with QSR franchisee satisfaction. These results provide empirical evidence to the theoretical relations presented in the earlier chapters. The first two research hypotheses involving QSR franchisee satisfaction and sources of power have received an empirical support from the current study.

\section{HYPOTHESIS THREE}

"In OSR franchise systems, franchisees' performance is positively related to their perception of noneconomic Sources of power possessed by their franchisors.

The financial performance of OSR franchisees is affected by the nature of franchisorfranchisee relations. Correlation analyses conducted with the current data indicate that, in 
contrast to the expected direction, noneconomic power sources correlate negatively with financial performance measured as Income Before Fixed Charges (IBFC). The correlational coefficient values between referent and information power sources and financial performance (IBFC) were -0.2428 and -0.3803 respectively (Table 18 ). Both the correlational values were statistically significant at the $10 \%$ level $(p=.10)$. These results were contrary to the expected positive relationship between noneconomic power and financial performance. Explanation for these contrasting results will be presented in the discussion section later.

As stated earlier, in the current study, the financial performance of OSR franchisees was also measured in terms of unit sales per year. The correlation coefficient value between referent power sources and financial performance (sales per year per unit) was negative in nature with the value -0.1189 . This value was not statistically significant (Table 18).

The correlation coefficient value between information power and financial performance (sales per year) was -0.1863 and statistically significant at $5 \%$ level $(p=.05$ ) (Table 18 ). The coefficient value is considered meaningful when it is greater than or equal to .30 . In the present case the coefficient value of -0.1863 between information power and performance is not considered meaningful.

The correlation coefficient value between referent power and financial performance (sales per year) was negative $(-.1189)$ but not statistically significant. The obtained value was consistant with other correlational coefficients between noneconomic power sources and financial performance (sales per year) and (BFC). 
Table - 18

Correlational Coefficient Values Between the Economic and

Noneconomic Power Sources and Financial Performance

\begin{tabular}{||l|l|l||}
\hline Independent Variables & IBFC & SALES PER YEAR \\
\hline \hline $\begin{array}{l}\text { ECONOMIC POWER: } \\
\text { Coercive Power }\end{array}$ & $0.0614 \mathrm{~ns}$ & $-0.0419 \mathrm{~ns}$ \\
\hline Legitimate Power & $0.0017 \mathrm{~ns}$ & $-0.0163 \mathrm{~ns}$ \\
\hline NONECONOMIC POWER: & & $-0.1189 \mathrm{~ns}$ \\
\hline Referent Power & $-0.2428 \mathrm{~ns}$ & $-0.1863^{*}$ \\
\hline Information Power & $-0.3803 \mathrm{~ns}$ & \\
\hline
\end{tabular}

* $=$ significant at $5 \%$ level $(p=0.05)$

ns $=$ not significant 
In sum, the results from the current empirical study indicate that financial performance of the QSR franchisees, whether measured as gross margin or sales per year, have a negative relationship with noneconomic power sources. The noted negative relationship between the noneconomic power sources and the financial performance was not statistically significant.

The third hypothesis describing a positive relationship between noneconomic power sources and financial performance in OSR franchise systems was not supported by the results from the current study. Explanation for the contrasting results will be presented in the discussion section later.

HYPOTHESIS FOUR:

"In QSR franchise systems, franchisees' performance is negatively related to their perception of economic Sources of power possessed by their franchisors.

Earlier studies with the nonhospitality industries indicate that the economic power sources have negative affect on franchisees' financial performance. These conclusions were empirically tested with the QSR industry in the current study.

The relationship between sources of economic power (coercive power and legitimate power) and financial performance (sales per year) was tested with correlational studies. The correlation coefficient values between coercive power and financial performance (sales per year) was -0.0419 and between legitimate power and financial performance (sales per year) was - 
0.0163 respectively (Table 18). The correlational coefficient values are not statistically significant.

The obtained negative correlation coefficient values from the current study offer only directional support but not emperical support to the relationship stated in the hypothesis four. The results from the current study only indicate that, in the QSR franchise systems, the financial performance (sales per year) of OSR franchisees has negative relationship with the economic power sources.

The hypothesis four states that financial performance is negatively related to economic power. In the current study, the financial performance of OSR franchisee was also measured as IBFC. When financial performance was measured as IBFC the correlation coefficient was 0.0614 for coercive power and 0.0017 for legitimate power. The obtained values describing the relationship between economic power and financial performance were positive but extremely weak and statistically nonsignificant.

Incidence of contrasting results when financial performance is measured as sales per year and IBFC has precedence in the hospitality literature (Dev, 1988). Further explanation and theoretical implications will be presented later in the discussion section.

\section{HYPOTHESIS FIVE}

"In QSR franchise systems, there is no difference in the performance level of franchisees classified according to the type of implementation model." 
The hypothesis five examines the assumption that, in QSR franchise systems, all types of strategy implementation are equally effective in achieving the desired financial objectives. The strategy implementation methods were measured as categorical data in Section-III of the instrument. This section describes five types of strategy implementation in a paragraph format and the respondents were requested to select one method that best describes their preference. The described five methods of implementation (Bourgeois and Brodwin 1984) are mutually exclusive. Since the obtained data were categorical in nature, a one-way analysis of variance test was conducted using two different measures of financial performance, sales per year and IBFC. Since the means of more than two groups were compared, it is appropriate to use oneway analysis with $F$ ratio rather than a t-test (Kerlinger 1986, $p 209$ ). Selection of one-way analysis for categorical data has precedence in the hospitality literature (Dev 1988).

The primary objective of one-way analysis for variance is to compare the mean values of the groups under consideration. The process involves calculation of mean square values between groups and within groups. Statistical significance ( $F$ ratio) of the difference between the means under consideration was calculated by dividing between-group-variance with withingroup-variance (error variance).

$$
\begin{gathered}
F \text { ratio }=\text { Between Group variance } / \text { Within Group variance } \\
\qquad(F=M S b / M S w)
\end{gathered}
$$

It is obvious from the above equation that higher $F$ values are obtained when numerator is larger or denominator is smaller. Greater $\mathrm{F}$ values result in greater statistical significance with consideration to the degrees of freedom. 
In the present study, a review of data indicate that one of the types of strategy implementation, the Cultural Model, was used by fewer respondents $(n=8)$ than other groups with high standard error ( $S E=0.9717$ ) (Table 19a). The observed low respondent number and high standard error of the Cultural Model have lead to unusually high within group variance, thus artificially lowering the $F$ value. Consequently, to achieve more realistic comparison of mean values of strategy implementation models and financial performance, the Cultural Model group was deleted from further tests in one-way analysis of variance. Deletion of a small data $(n=8)$ of respondents should not affect the outcomes qualitatively.

Deletion of one of the groups from one-way analysis for its smaller ' $n$ ' value has precedence in the hospitality literature. Dev (1988) deleted the Reactor strategy group for its low ' $n$ ' value of six from further analyses relating strategy content and financial performance. Removal of a group that has a smaller sample size and a high within group variance from oneway analysis of variance increases the power of the test (Hair et al 1987). Obtained results with four strategy implementation models and financial performance were presented in the Table $19 b$.

To test the hypothesis five, the selected four strategy implementation models [Command; Change; Collaborative; and Crescive (Cultural model deleted)] were compared for financial performance, measured as sales per year with one-way analysis of variance test. The results indicate that the Collaborative Model has the highest mean value $($ mean $=3.2857$ ) compared to the other groups (Table 20 ). The difference was statistically significant at $10 \%$ level $(p=0.10)$. The Collaborative Model was followed by the Crescive Model (mean $=2.9706)$; the Command model (mean $=2.6667)$; and the Change Model (mean $=2.5116)$ respectively . 
Table - 19a

One-way Analysis of Variance:

Strategy Implementation and Financial Performance (IBFC) with

All Five Implementation Groups Included

\begin{tabular}{|l|l|l|l|l|}
\hline Group & Count & Mean & $\begin{array}{l}\text { Standard } \\
\text { Deviation }\end{array}$ & $\begin{array}{l}\text { Standard } \\
\text { Error }\end{array}$ \\
\hline Command Model & 32 & 4.0313 & 2.6456 & 0.4677 \\
\hline Change Model & 34 & 4.5000 & 2.7988 & 0.4800 \\
\hline Collaborative Model & 12 & 3.9167 & 2.6097 & 0.7534 \\
\hline Cultural Model & 8 & 4.8750 & 2.7484 & 0.9717 \\
\hline Crescive Model & 29 & 4.2414 & 2.3400 & 0.4345 \\
\hline
\end{tabular}


The QSR franchisees that prefer the Collaborative model in implementing a chosen strategy tend to have higher sales per year per unit compared to the QSR franchisees that prefer other types of strategy implementation. These results reject the hypothesis five stated in null form contenting that there was no difference in performance of OSR franchisees when grouped according to their type of strategy implementation.

In the current study, the financial performance was also measured as Income Before Fixed Charges (IBFC). The OSR franchisees with preference for different strategy implementation types were compared for financial performance measured as IBFC. The obtained results (Table 21) indicate that the Change model has the highest mean value (mean $=4.50$ ) compared to the other types. Mean values for the other implementation types were, in descending order, Crescive (mean $=4.2414)$; Commander $($ mean $=4.0313)$; and Collaborative (mean $=3.9167$ ). Even though the mean values for IBFC were different for the different implementation types they were not statistically significant. Lack of statistically significant difference among the strategy implementation types precludes us from rejecting the null hypothesis.

Discussion of the contrasting results with different performance measures, sales per year and IBFC, will be presented later in the discussion section. Similar situation was encountered by Dev (1988) in his studies with strategy content and performance.

\section{HYPOTHESIS SIX}

"In QSR franchise systems, there is no difference in the satisfaction level of franchisees classified accordingto the type of implementation selected." 
Table - 19b

One-way Analysis of Variance: Test for Homogeneity

Strategy Implementation and Financial Performance (Sales per Year)

\begin{tabular}{||l|l|l||}
\hline Tests & 5 Groups Included & 4 Groups Included \\
\hline Cochrans C. value & $\begin{array}{c}0.3143, \\
\mathrm{P}=0.085\end{array}$ & $\begin{array}{c}0.3618, \\
\mathrm{P}=0.108\end{array}$ \\
\hline Bartlett-Box F value & $\begin{array}{c}1.363, \\
\mathrm{P}=0.244\end{array}$ & $\begin{array}{c}1.611, \\
\mathrm{P}=0.185\end{array}$ \\
\hline Max. Varinace/Min. Variance & 2.396 & 1.924 \\
\hline
\end{tabular}


Table -20

One-way Analysis of Variance: Four Implementation

Models and Performance (Sales per Year)

Independent Variable: Four Implementation Models

Dependent Variable: Financial Performance (Sales per year)

\begin{tabular}{|c|c|c|c|c|}
\hline Source & DF & Sum of Squares & Mean Squares & F Value \\
\hline Implementation & 3 & 8.3415 & 2.7805 & 1.2018 \\
\hline Error & 123 & 284.5719 & 2.3136 & \\
\hline Total & 126 & 292.9134 & & \\
\hline
\end{tabular}

Duncan's Multiple Range Test for Variable: Sales per Year Alpha $=0.10, \quad D F=126, \quad M S E=2.3136$

$\begin{array}{ll}\text { Mean Values: Command Model } & =2.6667 \\ \text { Change Model } & =2.5116 \\ \text { Collaborative Model } & =3.2857^{*} \\ \text { Crescive Model } & =2.9706\end{array}$

* = Denotes significant difference at the 0.10 level 
Table - 21

One-way Analysis of Variance: Four Implementation

Models and Performance (IBFC)

Independent Variable: Four Implementation Models

Dependent Variable: Financial Performance (IBFC)

\begin{tabular}{lrcll} 
Source & DF & Sum of Squares & \multicolumn{2}{c}{ Mean Squares } \\
& & & & \\
Implementation & 3 & 4.9211 & 1.6404 & 0.2401 \\
Error & 103 & 703.6958 & 6.8320 & \\
Total & 106 & 708.6168 & &
\end{tabular}

Duncan's Multiple Range Test for Variable: IBFC

Alpha $=0.10, \quad D F=106, \quad M S E=6.8320$

Mean Values: Command Model $\quad=4.0313$

Change Model $\quad=4.5000$

Collaborative Model $=3.9167$

Crescive Model $\quad=4.2414$

No two groups are significantly different at the 0.10 level 
The hypothesis six was designed to examine the relationship between OSR franchisees' method of implementation and their satisfaction. The hypothesis six was stated in a null form. As stated earlier, strategy implementation was measured as a categorical data and satisfaction was measured on a 6-point Likert-type scale with multiple questions. Satisfaction was in the Section IV of the instrument. Since the independent variable was in categorical form, a one-way analysis of variance test was chosen for this hypothesis. The obtained results were included in the Table 22.

As stated earlier in the discussion for hypothesis five, the Cultural model of strategy implementation was not included in one-way analysis tests because of its high level of within group variance caused by high standard deviation, and low level of respondents ( $n=8$ ). Results will be presented with four strategy implementation types and satisfaction.

The obtained results indicate that the Collaborative model of strategy implementation has the highest mean value of satisfaction (mean $=3.1429$ ) compared to the other groups. It was followed by the Change model (mean $=2.9778)$; the Crescive model (mean $=2.9029$ ) and the Command model (mean $=2.8872$ ). Even though the mean values of different strategy implementation types are different the difference is not statistically significant.

The hypothesis six states that the QSR franchisees with different strategy implementation models are different from each other when measured for satisfaction. Since the obtained results indicate that the mean values for the strategy implementation models were not statistically significant, one would fail to reject the hypothesis six stated in null form. The hypothesis six was not supported. 


$$
\text { Table - } 22
$$

One-way Analysis of Variance: Four Implementation

\section{Models and Satisfaction}

$\begin{array}{lcccc}\text { Independent Variable: } & \text { Four Implementation Models } \\ \text { Dependent Variable: } & \text { Satisfaction } & & & \\ & & & & \\ & & & & \\ \text { Source } & \text { DF } & \text { Sum of Squares } & \text { Mean Squares } & \text { F Value } \\ \text { Implementation } & 3 & 0.7870 & 0.2623 & 0.2882 \\ \text { Error } & 129 & 117.4254 & 0.9103 & \\ \text { Total } & 132 & 118.2123 & & \end{array}$

Duncan's Multiple Range Test for Variable: IBFC

Alpha $=0.10, \quad D F=132, \quad M S E=0.9103$
Mean Values: Commander Model $=2.8872$
Change Model $\quad=2.9778$
Collaborative Model $=3.1429$
Crescive Model $\quad=2.9029$

No two groups are significantly different at the 0.10 level 


\title{
HYPOTHESIS SEVEN
}

\author{
"In QSR franchise systems, high performance franchisees are different from low \\ performers when grouped according to the nature of congruence between economic \\ sources of power and type of implementation selected."
}

The next four hypotheses $(\mathrm{H} 7, \mathrm{H} 8, \mathrm{H} 9$ and $\mathrm{H} 10)$ involve dependent variables which were categorical and independent variables that were continuous. The independent variables economic power, noneconomic power and strategy implementation have linear relationships with the dependent variables satisfaction and financial performance, as explained in the earlier chapters. Under such circumstances, according to Hair et al. (1987), Discriminant Analysis of variance is most appropriate. The discriminant analysis is based on the principle of maximizing the between-group variance relative to the within-group variance. The distance between group centroids is the discriminant function. The statistical significance of the discriminant function was computed by comparing the distribution scores for two or more groups.

According to Hair et al. (1987), the hit ratios (percentage of respondents properly classified) is analogous to R-square in multiple regression. The hit ratios reveal how well the respondents were classified by the discrminant function. Hence, hit ratios will be used for comparative purposes in this section.

The next four hypotheses $(\mathrm{H} 7, \mathrm{H} 8, \mathrm{H} 9$ and $\mathrm{H} 10)$ were considered together as a group. All the four hypotheses under consideration have three research variables each arranged in a linear form. All four hypotheses have strategy implementation as the intermediate variable. 
Since the variables under consideration have linear relationships and the dependent variable has priori defined groups (high and low) the Multiple Discriminant Analysis was considered as an appropriate test. When the dependent variable was categorical, as in the present case, the Multiple Discriminant Analysis more appropriate than regression analysis (Hair et al. 1987, p76).

The dependent variables satisfaction and performance (measured as sales per year and (BFC) were measured as continuous variables. The satisfaction was measured by multiple questions (five) on a 6-point scale. Aggregate of the five questions ( 030 to 034 ) was recoded as a new variable, SATISFAC.

In multiple discriminant analysis (MDA) the dependent variable is categorical in nature. In the present study, the dependent variables were classified as high and low performers (satisfaction) using frequency values. Classification of the dependent variable data into high and low can be accomplished several ways. More liberal way to perform MDA for comparing high and low performers is to compare the top 10 percent of respondents with the bottom ten percent. On the other hand, more conservative way to compare high and low performers is to select top fifty percent and bottom fifty percent of respondents. In the present study, both conservative and liberal methods of comparing the high and low performers with MDA were followed wherever they were appropriate.

The results from analysis of financial performance measured as sales per year will be presented first. When the respondents were classified as high and low performers using frequency distributions on sales per year the high performance groups had 78 respondents and low performance group has 55 respondents. The proportional percentage of the selected groups were $\mathbf{5 8 . 6 5}$ percentage for low performers and 41.35 percent for high performers. 
Interpretation of results from multiple discriminant analysis requires calculation of maximurn chance criterion and proportional chance criterion for the selected groups. The maximum chance criterion is the highest chance a respondent has to be classified correctly. It was calculated as a ratio of the largest single group over the total number of respondents. In the present case, the maximum chance criterion for a respondent to be classified correctly was 58.7 percent $(78 /(78+55)=58.7 \%)($ Table 23$)$.

The proportional chance criterion for a group is the proportional chance a respondent has to be classified correctly. The proportional chance criterion was obtained by calculating the squares of the percentage of each group and taking the total of the obtained squares. In the present case, the proportional chance criterion was 51.5 percent (Table 23).

When high performance QSR franchisees were discriminated from low performers (measured as sales per year) with coercive power and strategy implementation as independent variables the hit ratio was 57.5 percent. The obtained hit ratio was slightly higher than proportional chance criterion $(51.5 \%)$ and lower than the maximum chance criterion $(58.7 \%)$ (Table 23).

The analysis was continued with legitimate power, one of the economic power sources, strategy implementation and performance. The hit ratio for the selected model was 56.0 percent which was slightly higher than the proportional chance criterion $(51.5 \%)$ and lower than the maximum chance criterion (58.7\%). Again, the nature of the obtained hit ratios were consistent with the hit ratios attained with coercive power, strategy implementation and performance. There was no upward bias towards the selected groups as indicated by the higher hit ratios for the unselected groups. 
The obtained hit ratios for the selected models indicate that the selected models were effective in identifying the respondents within the dependent variable groups. The selected model with Economic Power (coercive power and legitimate power) and strategy implementation was effective in correctly grouping high performance QSR franchisees from low performers.

Consistencies in observed results with two different sources of economic power and their relationships with the research constructs, strategy implementation and financial performance, demonstrate the empirical validity of the research construct, economic power and the research instrument. They also indicate validity of sales per year as a reliable financial measure.

The analysis was continued with IBFC as a measure of financial performance. When analyzed with IBFC as a measure of performance the maximum chance criterion for a respondent to be classified correctly was 53.0 percent and the proportional chance criterion was 50.0 percent. The hit ratio for the model with coercive power, strategy implementation and financial performance (IBFC) was 53.9 percent. Identical hit ratio $(53.9 \%)$ was obtained for the model with legitimate power, strategy implementation and IBFC (Table 23). These ratios were higher than the maximum chance criterion and the proportional chance criterion. There was no upward bias towards the selected group as indicated by higher hit ratio for the unselected group. 
Table - 23

Results of Multiple Discriminant Analyses: Economic Power,

Financial Performance (IBFC and Sales per Year)

and Satisfaction

\begin{tabular}{|c|c|c|c|}
\hline Model & Hit Ratio & $\begin{array}{l}\text { Maximum } \\
\text { Chance } \\
\text { Criterion }\end{array}$ & $\begin{array}{l}\text { Proportional } \\
\text { Chance Criterion }\end{array}$ \\
\hline $\begin{array}{l}\text { ECONOMIC POWER: } \\
\text { Coercive power + } \\
\text { Implementation + } \\
\text { Sales per Year }\end{array}$ & $57.5 \%$ & $58.7 \%$ & $51.5 \%$ \\
\hline $\begin{array}{l}\text { Coercive power }+ \\
\text { Implementation }+ \\
\text { IBFC }\end{array}$ & $53.9 \%$ & $53.0 \%$ & $50.0 \%$ \\
\hline $\begin{array}{l}\text { Coercive power + } \\
\text { Implementation + } \\
\text { Satisfaction }\end{array}$ & $\begin{array}{l}60.7 \% \\
64.6 \%\end{array}$ & $64.4 \%$ & $54.2 \%$ \\
\hline $\begin{array}{l}\text { Legitimate power }+ \\
\text { Implementation }+ \\
\text { Sales per Year }\end{array}$ & $56.0 \%$ & $58.7 \%$ & $51.6 \%$ \\
\hline $\begin{array}{l}\text { Legitimate power }+ \\
\text { Implementaion }+ \\
\text { IBFC }\end{array}$ & $53.9 \%$ & $53 \%$ & $50.0 \%$ \\
\hline $\begin{array}{l}\text { Legitimate power + } \\
\text { Implementation + } \\
\text { Satisfaction }\end{array}$ & $68.8 \%$ & $64.4 \%$ & $54.2 \%$ \\
\hline & & & \\
\hline
\end{tabular}

$=$ Hit ratios obtained by comparing top and bottom ten percent of respondents 
The obtained results indicate validity of the model selected. The selected model with Economic Power (coercive power and legitimate power) and strategy implementation was effective in correctly grouping high performance QSR franchisees from low performers measured as IBFC. The results from the analysis of financial performance measured as IBFC were consistent with the results obtained with performance measured as sales per year.

Based on the results obtained from the multiple discriminant analysis we can state that the theoretical relationships stated in the hypothesis seven were empirically supported.

\section{HYPOTHESIS EIGHT:}

\footnotetext{
"In QSR franchise systems, franchisees with high level of satisfaction are different from those with low level of satisfaction when grouped according to the nature of congruence between economic sources of power and the type of implementation selected."
}

The hypothesis eight was tested, as stated earlier, with multiple discriminant analysis. The dependent variable, satisfaction, was measured on a Likert-type 6-point scale with multiple questions (030 through 034). The aggregated values from the five questions were employed in MDA analysis. The top fifty percent of respondents on satisfaction scale were compared with the bottom fifty percent.

The hypothesis eight states that the OSR franchisees with high satisfaction can be discriminated from the QSR franchisees with low level of satisfaction when compared on the 
variables economic power and strategy implementation. The economic power was represented by coercive power and legitimate power.

The maximum chance criterion for the model with economic power, strategy implementation and satisfaction was 64.4 percent and the proportional chance criterion was 54.2 percent. The hit ratio (comparing top fifty percent with bottom fifty percent) for the model with coercive power, strategy implementation and satisfaction was 60.7 percent (Table 23). It was higher than the proportional chance criterion and slightly lower than the maximum chance criterion.

The analysis was continued by comparing the top ten percent of respondents on satisfaction scale with the bottom ten percent. The resulting hit ratio for the model was 64.4 percent (Table 23) which was substantially higher than the proportional chance criterion and equivalent to the maximum chance criterion.

These results indicate that the relationships between economic power, strategy implementation and satisfaction presented in the hypothesis eight were empirically supported. The attained empirical support may not be as strong as could be expected.

The analyses continued with the model consisting of legitimate power, strategy implementation and satisfaction. The hit ratio was 68.8 percent which was substantially higher than proportional chance criterion $(54.2 \%)$ and higher the maximum chance criterion $(64.4 \%)$ (Table 23). These results were consistent with the earlier results with the coercive power. 
The consistency in results obtained with coercive and legitimate powers indicate that they were measuring the same thing, the economic power sources.

The theoretical relationships presented in the hypothesis eight were empirically supported. In other words, the model consisting of economic power sources, strategy implementation and satisfaction was effective in discriminating QSR franchisees with high satisfaction from those with low satisfaction.

\section{HYPOTHESIS NINE:}

"In QSR franchise systems, franchisees with high level of satisfaction are different from those with low level of satisfaction when grouped according to the nature of congruence between noneconomic sources of power and the type of implementation selected."

As stated earlier noneconomic power sources were represented by referent power and information power. The hypothesis nine states that OSR franchisees with high level of satisfaction can be discriminated from those with low level of satisfaction when grouped according to the noneconomic power sources and strategy implementation.

In the current analysis the top fifty percent respondents on satisfaction were compared to the bottom fifty percent. The maximum chance criterion for groups under consideration was 64.4 percent and the proportional chance criterion was 54.2 percent. The hit ratio for the model with information power, strategy implementation, and satisfaction was 63.6 percent 
which was higher than the proportional chance criterion and slightly lower than the maximum chance criterion (Table 24).

When the analysis was continued with top percent and bottom ten percent respondents the hit ratio was 84.4 percent. The attained hit ratio was substantially higher than the proportional chance criterion and maximum chance criterion. This clearly signifies that the research variables noneconomic power and strategy implementation were effective in discriminating high satisfaction OSR franchisees from those with low satisfaction. The theoretical relations stated in the hypothesis nine have received empirical support from the current study.

The analyses were extended to referent power. The model incorporating referent power, strategy implementation and satisfaction has a hit ratio of 72.1 percent which was substantially higher than the proportional chance criterion $(54.2 \%)$ and the maximum chance criterion (64.4\%) (Table 24).

The analyses were repeated with top and bottom ten percent respondents. The resulting hit ratio was 88.9 percent which was substantially higher than the proportional chance criterion (54.2\%) and maximum chance criterion (64.4\%). This clearly indicates that the stated theoretical relationships in the hypothesis nine were empirically validated (Table 24) .

Consistency in the direction of the results obtained from the models with information power and referent power shows that both power sources were measuring the same thing, the noneconomic power sources. These results also demonstrate the validity of satisfaction as a dependent variable in studying QSR franchisees. 
Table - 24

Results of Multiple Discriminant Analyses: Noneconomic

Power, Financial Performance (IBFC and Sales per Year) and

Satisfaction

\begin{tabular}{|c|c|c|c|}
\hline Model & Hit Ratio & $\begin{array}{l}\text { Maximum } \\
\text { Chance } \\
\text { Criterion }\end{array}$ & $\begin{array}{l}\text { Proportional } \\
\text { Chance Criterion }\end{array}$ \\
\hline $\begin{array}{l}\text { NONECONOMIC POWE } \\
\text { Information power + } \\
\text { Implementation + } \\
\text { Sales per Year }\end{array}$ & $\begin{array}{l}59.7 \% \\
62.5 \%\end{array}$ & $58.7 \%$ & $51.5 \%$ \\
\hline $\begin{array}{l}\text { Information power }+ \\
\text { Implementation }+ \\
\text { IBFC }\end{array}$ & $\begin{array}{l}62.6 \% \\
70.21 \% *\end{array}$ & $53.0 \%$ & $50.0 \%$ \\
\hline $\begin{array}{l}\text { Information power }+ \\
\text { Implementation }+ \\
\text { Satisfaction }\end{array}$ & $\begin{array}{l}63.6 \% \\
84.4 \% *\end{array}$ & $64.4 \%$ & $54.2 \%$ \\
\hline $\begin{array}{l}\text { Referent power }+ \\
\text { Implementation }+ \\
\text { Sales per Year }\end{array}$ & $\begin{array}{l}59.7 \% \\
62.5 \%\end{array}$ & $58.7 \%$ & $51.5 \%$ \\
\hline $\begin{array}{l}\text { Referent power }+ \\
\text { Implementaion + } \\
\text { IBFC }\end{array}$ & $\begin{array}{c}53.9 \% \\
68.8 \% *\end{array}$ & $53.0 \%$ & $50.0 \%$ \\
\hline $\begin{array}{l}\text { Referent power + } \\
\text { Implementation + } \\
\text { Satisfaction }\end{array}$ & $\begin{array}{l}72.1 \% \\
88.9 \%\end{array}$ & $64.4 \%$ & $54.2 \%$ \\
\hline & & & \\
\hline
\end{tabular}

* = Hit ratios obtained by comparing top and bottom ten percent of respondents 


\section{HYPOTHESIS TEN:}

"In QSR franchise systems, high performance franchisees are different from low performers when grouped according to the nature of congruence between noneconomic sources of power and the type of implementation selected."

The final hypothesis describes relationship between noneconomic power sources, strategy implementation and financial performance of the single-unit OSR franchisees. The financial performance was measured by sales per year and IBFC.

Results from the analysis of sales per year as the measure of financial performance will be presented first. The maximum chance criterion for the selected model (noneconomic power, strategy implementation and performance) was 58.7 percent with 78 respondents in the low performance group and 55 respondents in the high performance group. The proportional chance criterion was 51.5 percent (Table 24).

The hit ratio for the model with information power, strategy implementation and performance (sales per year) was 59.7 percent. When the analysis was repeated with top and bottom ten percent performers the hit ratio was 62.5 percent. It was substantially higher than the proportional chance criterion (51.5\%) and slightly better than the maximum chance criterion (58.7\%) (Table 24). Thus, we may state that the selected model was effective in discriminating the high performance QSR franchisees from the low performers.

The hit ratio for the model with referent power, strategy implementation and financial performance was 52.2 percent. The obtained hit ratio was slightly higher than proportional 
chance criterion and less than maximum chance criterion. Further analysis was conducted comparing top ten percent performers with bottom ten percent performers on sales per year. The hit ratio for the model with referent power, strategy implementation and performance (sales per year) was 62.2 percent which was substantially higher than the maximum chance criterion $(58.7 \%$ ) and the proportional chance criterion $(51.5 \%)$ (Table 24$)$.

These results were consistent with the earlier model with information power, strategy implementation and performance (sales per year). These results also provide empirical validity to the theoretical relationship presented in the hypothesis ten. In other words, a model that includes noneconomic power sources, strategy implementation and financial performance (sales per year) was capable of discriminating high performance OSR franchisees from low performers. Consistency of the obtained results indicate that measurement of noneconomic power sources with information and referent power was valid.

The analysis was continued with financial performance measured as IBFC. The maximum chance criterion was 53.0 percent and the proportional chance criterion was 50.0 percent. The hit ratio for the model with information power, strategy implementation and performance (IBFC) was 62.6 percent (Table 24). The achieved hit ratio $(62.6 \%$ ) was substantially higher than the maximum chance criterion $(53.0 \%)$ and the proportional chance criterion $(50.0 \%)$. This indicates support to the theoretical relationships presented in the hypothesis ten.

When the analysis was replicated with top and bottom ten percent performers the hit ratio was 70.2 percent (Table 24 ). The obtained results were substantially higher than the maximum chance criterion $(53.0 \%)$ and the proportional chance criterion $(50.0 \%)$. Thus, the 
theoretical relationships posited in the hypothesis ten were empirically supported. These results were consistent with the results obtained earlier when financial performance was measured with sales per year.

The hit ratio for the model with referent power, strategy implementation and performance (IBFC) was 53.91 percent. The attained hit ratio was slightly higher than the proportional chance criterion ( 50.0 percent) and marginally better than the maximum chance criterion $(53.0$ percent). The hit ratio for the model with referent power, strategy implementation and performance when top and bottom ten percent performers were compared was 63.8 percent (Table 24). The obtained hit ratio was substantially better than the maximum chance criterion $(53.0 \%)$ and the proportional chance criterion $(50.0 \%)$. This provides further evidence to the theoretical relationships stated in the hypothesis ten.

The consistency of the results obtained with the information power and the referent power support the rationale that they are an integral part of noneconomic power sources. These results also support the validity of noneconomic power sources in studying OSR franchise systems. 


\section{RESULTS FROM MULTIPLE REGRESSION ANALYSIS}

The current study has three independent variables (Economic Power, Noneconomic Power and Strategy Implementation) and two dependent variables (Satisfaction and Performance). Since, the obtained data on independent and dependent variables was metric (interval) in nature it was possible to reanalyze the data with multiple regression and confirm or deny the results obtained with multiple discriminant analysis. One of the independent variables, strategy implementation, was measured as a categorical data. For the current analysis, it was converted to metric data by creating dummy variables.

One of the advantages of multiple regression was to be able to predict changes in the dependent variables given the level of independent variable. Another benefit of multiple regression was the examination of strength of association between several independent variables and the dependent variable in a single equation. It also provides extent of specific contribution by each independent variable. When high and low performers (satisfaction) were compared using multiple discriminant analysis the midlevel performers were excluded from the analyses. consequently, some of the valuable information such as variance was lost. For above mentioned reasons, the collected data were reanalyzed using multiple regression method and the results were presented in Tables $25 a, b, c$.

First phase of multiple regression analysis included satisfaction as the dependent variable, and sources of power (referent, information, coercive, and legitimate) and strategy implementation (command, crescive, collaborative, culture) as the independent variables. A total of 52.32 percent of variance was explained with a $F$ value of 17.83 which was significant (Table 25a). 
Following abbreviations were adapted to present the results from multiple regression analyses.
$\mathbf{R}=$ Referent Power
1 = Information Power
$\mathrm{C}=$ Coercive Power
$\mathrm{L}=$ Legitimate Power
$\mathrm{Cr}=$ Crescive Model
$\mathrm{Cu}=$ Cultural Model
Co $=$ Collaborative Model
$\mathrm{Cm}=$ Command Model

Satisfaction $=1.21+.35 \mathrm{R}+.31 \mathrm{I}-.16 \mathrm{C}+05 \mathrm{~L}-.31 \mathrm{Co}-.19 \mathrm{Cm}-.17 \mathrm{Cr}-.12 \mathrm{Cu}$

The analysis was continued by eliminating one of the independent variables, strategy implementation. Purpose of this procedure was to evaluate the strength of relationship between the sources of power and satisfaction, and calculate the contribution of strategy implementation in explaining the variance in QSR franchisee satisfaction. The sources of power explained 51.27 percent of variance which was slightly lower (1.05 percent) than the combined effect of power sources and strategy implementation (52.32 percent). The $F$ value was 35.25 which was significant.

Satisfaction $=1.11+.35 \mathrm{R}+.30 \mathrm{I}-.14 \mathrm{C}+.05 \mathrm{~L}$

These results indicate that noneconomic sources power, referent and information, were more significant in explaining the variance in OSR franchisees' satisfaction. Together they explained 48.56 percent of variance. Strategy implementation was not very effective in explaining OSR franchisees' satisfaction since the $R$ square value has changed very slightly (.11) after it was removed from the equation. 
Table 25a

Results of Multiple Regression

Independent Variable: Sources of power (Coercive Power; Legitimate Power; Referent Power; Information Power)

Strategy Implementation (Command; Change; Collaborative; Crescive)

Dependent Variable: Satisfaction

Variables in Equation

$\begin{array}{lrlll}\text { Variable } & \text { Coefficient } & \text { R square } & F & \text { Significance } \\ & & & & \\ \text { Y-intercept } & 1.2123 & & & \\ \text { Referent Power } & .3530 & .3829 & 85.007 & .000 \\ \text { Nonecon Power } & .3148 & .4856 & 64.193 & .000 \\ \text { Econ Power } & -.1569 & .5104 & 46.904 & .000 \\ \text { Legitimate Power } & .0462 & & & \\ \text { Crescive } & -.1723 & & & \\ \text { Culture } & -.1237 & & & \\ \text { Collaborative } & -.3099 & & & \\ \text { Command } & -.1894 & .5232 & 17.829 & .000\end{array}$

Independent Variable: Sources of power (Coercive Power; Legitimate Power; Referent Power; Information Power)

Dependent Variable: Satisfaction

Variables in Equation

$\begin{array}{lrlll}\text { Variable } & \text { Coefficient } & \text { R square } & F & \text { Significance } \\ & & & & \\ \text { Y-intercept } & 1.1086 & & & \\ \text { Referent Power } & .3501 & .3829 & 85.007 & .000 \\ \text { Nonecon Power } & .3021 & .4856 & 64.193 & .000 \\ \text { Econ Power } & -.1424 & .5104 & 46.904 & .000 \\ \text { Legitimate Power } & .0507 & .5127 & 35.249 & .000\end{array}$


Table 25b

Results of Multiple Regression

Independent Variable: Sources of power (Coercive Power; Legitimate Power; Referent Power; Information Power)

Strategy Implementation (Command; Change; Collaborative; Crescive)

Dependent Variable: Income Before Fixed Charges (IBFC)

Variables in Equation

\begin{tabular}{|c|c|c|c|c|}
\hline Variable & Coefficient & $\mathrm{R}$ square & $\mathrm{F}$ & Significance \\
\hline Y-intercept & 6.8705 & & & \\
\hline Referent Power & -.3436 & & & \\
\hline Econ Power & .1112 & & & \\
\hline Legitimate Power & .2873 & & & \\
\hline Nonecon Power & -.7556 & .1446 & 19.102 & .000 \\
\hline Crescive & -.0646 & & & \\
\hline Culture & .7903 & & & \\
\hline Collaborative & .1622 & & & \\
\hline Command & -.2789 & $.1768 \quad 2.845$ & .007 & \\
\hline
\end{tabular}

Independent Variable: Sources of power (Coercive Power; Legitimate Power; Referent Power; Information Power)

Dependent Variable: Income Before Fixed Charges (IBFC)

Variables in Equation

$\begin{array}{lrlrl}\text { Variable } & \text { Coefficient } & \text { R square } & F & \text { Significance } \\ & & & & \\ \text { Y-intercept } & 6.9859 & & & \\ \text { Econ Power } & .0716 & & & \\ \text { Legitimate Power } & .2566 & & & \\ \text { Nonecon Power } & -.7734 & .1446 & 19.102 & .000 \\ \text { Referent Power } & -.3020 & .1672 & 5.523 & .000\end{array}$


Table 25c

Results of Multiple Regression

Independent Variable: Sources of power (Coercive Power; Legitimate Power; Referent Power; Information Power)

Strategy Implementation (Command Model; Change Model; Collaborative Model; Crescive Model)

Dependent Variable: Sales per year

Variables in Equation

$\begin{array}{lrlll}\text { Variable } & \text { Coefficient } & \text { R square } & F & \text { Significance } \\ & & & & \\ \text { Y-intercept } & 3.6111 & & & \\ \text { Referent Power } & -.1171 & & \\ \text { Nonecon Power } & -.2508 & & \\ \text { Econ Power } & -.0359 & & \\ \text { Legitimate Power } & .0671 & & \\ \text { Crescive } & .5128 & & \\ \text { Culture } & .5682 & & & \\ \text { Collaborative } & 1.1296 & & & \\ \text { Command } & .2958 & .0908 & 1.548 & .147\end{array}$

Independent Variable: Sources of power (Coercive Power; Legitimate Power; Referent Power; Information Power)

Dependent Variable: Sales per Year

Variables in Equation

$\begin{array}{lllll}\text { Variable } & \text { Coefficient } & \text { R square } & F & \text { Significance } \\ & & & & \\ \text { Y-intercept } & 3.9526 & & & \\ \text { Nonecon Power } & -.2225 & & & \\ \text { Econ Power } & -.0794 & & & \\ \text { Legitimate Power } & .0583 & & .211 \\ \text { Referent Power } & -.0968 & .0443 & 1.485 & .211\end{array}$


Negative nature of regression coefficient of the Coercive power indicates that higher the level of Coercive power lower the satisfaction experienced by the OSR franchisees. In contrast to the expectations, the Legitimate power, one of the economic sources of power, has positive but weak (.05) sign. Positive signs of Referent and Information sources of power indicate that higher the level of these sources of power greater will be the OSR franchisees' satisfaction. These results were consistent with other studies in marketing literature and earlier results obtained with the One-way Analysis of Variance.

In the second phase, the independent variables remained the same (sources of power and strategy implementation) but the dependent variable was changed to financial performance. In the current study, the financial performance was measured as Income Before the Fixed Charges (IBFC) and Sales per Year. Therefore, the second phase of multiple regression analysis was repeated with different measures of the dependent variable, IBFC and sales per year.

The multiple regression analysis was continued with IBFC as a measure of the dependent variable, financial performance. Obtained results (Table 25b) indicate that strategy implementation was a poor predictor of QSR franchisee performance, similar to the earlier results in the first phase. The sources of power explained 16.72 percent variance in financial performance measured as IBFC. Inclusion of strategy implementation in the regression equation increased the explained variance by only .96 percent to 17.68 percent. When Information power was included the $F$ value was 19.10 which was significant. The $F$ value for Referent power was 5.52 which was also significant.

$$
\begin{aligned}
& \text { IBFC }=6.87-.711-.34 \mathrm{R}+.29 \mathrm{~L}+11 \mathrm{C}+.79 \mathrm{Cu}-.29 \mathrm{Cm}+.16 \mathrm{Co}-.06 \mathrm{Cr} \\
& \text { IBFC }=6.99-.77 \mathrm{I}-.30 \mathrm{R}+.26 \mathrm{~L}+.07 \mathrm{C}
\end{aligned}
$$


Again, noneconomic sources of power (referent and information) were more effective than the economic sources of power (coercive and legitimate) in explaining observed variance in financial performance. Contrary to the expectations, the sign of noneconomic power sources was negative stating that greater the level of noneconomic power sources lower the financial performance. Economic power sources (coercive and legitimate) were ineffective in explaining variance in financial performance. These results confirm the earlier results with correlational studies.

For the last multiple regression analysis, the dependent variable was financial performance of OSR franchisees was measured as Sales per Year. The independent variables remained the same, sources of power and strategy implementation. As reported earlier with correlational studies, the results were slightly different when performance was measured as sales per year. The obtained regression equations were presented here (Table 25c).

$$
\begin{array}{ll}
\text { Sales per Year }=\quad & 3.61-.251-.12 \mathrm{R}+.07 \mathrm{~L}-.04 \mathrm{C}+1.13 \mathrm{Co} \\
& .57 \mathrm{Cu}+.51 \mathrm{Cr}+.30 \mathrm{Cm} \\
\text { Sales per Year }=\quad 3.95-.221-.10 \mathrm{R}-.08 \mathrm{C}+.06 \mathrm{~L}
\end{array}
$$

These equations indicate that three of the power sources ireferent, information, and coercive) have negative relationships with sales per year. In other words, when high level of power sources were perceived the OSR franchisees experience low level of sales per year. Interestingly, only the legitimate power has positive relationship with sales per year. Sources of power explained only 4 percent of variance in sales per year. Correlational studies also indicated nonsignificant relationships between sales per year and the power sources. The independent variables, sources of power and strategy implementation, together explained only 
9 percent of variance in sales per year. In sum, both the independent variables have failed as predictors of change in the dependent variable financial performance measured as sales per year.

\section{SUMMARY}

This chapter presents the results obtained from the statistical analyses of the data collected. Also presented are the nature of research data, a profile of the respondents and results from the statistical analyses. Rationale for the statistical tests selected was also included.

Three major statistical tests were used in this study: Correlational studies $(\mathrm{H} 1$ to $\mathrm{H} 4)$; One-way analysis of variance $(\mathrm{H} 5$ and $\mathrm{H} 6)$; and Multiple Discriminant Analysis $(\mathrm{H} 7$ to $\mathrm{H} 10)$. Significance of the obtained results were presented. Obtained results were further verified by using multiple regression analysis. Limitations in interpreting the results of the statistical analyses were also discussed.

Results indicate that majority of the hypotheses are supported empirically. The hypotheses one and two are strongly supported. The hypothesis three was not supported and four received only weak support. The hypothesis five stated in the null form was rejected, as preferred. The hypothesis six was not supported. The hypothesis seven and eight have received weak but positive support. The hypotheses nine and ten were strongly supported with high percentage hit ratios. 
Summary of the hypothesis tests is as follows:

\author{
Hypothesis 1: Supported \\ Hypothesis 2: Supported \\ Hypothesis 3: Not supported \\ Hypothesis 4: Not supported \\ Hypothesis 5: Supported (rejected the null form) \\ Hypothesis 6: Not supported (failed to reject the null form) \\ Hypothesis 7: Supported (weak) \\ Hypothesis 8: Supported (weak) \\ Hypothesis 9: Supported \\ Hypothesis 10: Supported
}

Significance of these results and implications for theory building will be presented in the next chapter, chapter 6 . The next chapter also includes possibilities for extending the test results to other industries. 


\section{Chapter 6}

\section{DISCUSSION}

\section{INTRODUCTION}

The preceding chapter included results of the statistical analyses performed on the data collected. The outcome of the research hypothesis tests were also presented in the previous chapter.

The current chapter discusses the implications of the results obtained, contributions of the current study to theory building in the hospitality and marketing literature, strengths and weaknesses of the research methodology adapted, and plausible suggestions for further studies wherever appropriate.

Before proceeding with discussion of the results, some of the outcomes from the statistical analyses are presented here: 
1. The response rate $(18.75 \%)$ was slightly lower than the expected $(22 \%)$.

2. Nonresponse bias was not present.

3. Substantial number of QSR franchisees were located in suburban areas $(38 \%)$.

4. Majority of the respondents have single-unit contracts $(66 \%)$.

5. Profile of the QSR franchisees participated in the current study may be described as: Male $(89.5 \%), 25-34$ years $(45.5 \%)$, some college education $(38.6 \%)$, annual salary between $\$ 25-34.9$ thousand $(31.5 \%)$, income from sources other than the franchise $(53.8 \%)$, tenure with the current franchise 2.67 years $(36.6 \%)$, no prior business experience $(24.3 \%)$ and with background in foodservice $(39.9 \%)$.

6. The Cronbach alpha values achieved for different variables in the current study were: coercive power 0.52 ; legitimate power 0.63 ; referent power 0.67 ; information power 0.78 ; and satisfaction 0.78 .

7. Statistically significant negative relationship was observed between the economic power sources (coercive and legitimate power) and QSR franchisee satisfaction.

8. Statistically significant positive relationship was noted between the noneconomic power sources (information and referent power) and OSR franchisee satisfaction. 
9. Te relationship between noneconomic powers sources (referent and information power) and financial performance (IBFC) was found to be negative and statistically significant. It was in contrast to the hypothesized direction of the relationship.

10. Proposed relationship between noneconomic power sources (information power) and performance (sales per year) was negative in nature and statistically significant. But the relationship between the referent power (noneconomic power source) and performance (sales per year) was not statistically insignificant although negative.

11. The relationship between economic power sources (coercive and legitimate power) and performance (sales per year) was negative in nature, as hypothesized, but statistically insignificant.

12. The relationship between economic power sources (coercive and legitimate power) and performance (IBFC) was positive in nature, in contrast to the hypothesized relations, and statistically insignificant.

13. When four different strategy implementation models were compared for financial performance (IBFC) the QSR franchisees with the Change model reported greater gross margins (IBFC) than other models. The difference was not statistically significant.

14. When four different strategy implementation models were compared for financial performance (sales per year) the Collaborative model franchisees were statistically significant from others with highest mean value of IBFC. 
15. When four different strategy implementation models were compared for franchisee satisfaction, the QSR franchisees with the Collaborative model have reported highest level of satisfaction over the others.

16. The following models were found to be effective in discriminating QSR franchisees with high level of satisfaction from those with low level of satisfaction:
A. Economic Power sources + Strategy Implementation (weak)
B. Noneconomic Power sources + Strategy Implementation

17. The following models were found to be statistically significant in discriminating high performance QSR franchisees from low performers when performance was measured as IBFC:
A. Economic Power sources + Strategy Implementation (weak)
B. Noneconomic Power sources + Strategy Implementation

18. In QSR franchise systems, the following models were found to be statistically significant in discriminating high performers from low performers when performance was measured as sales per year:
A. Noneconomic Power sources + Strategy Implementation
B. Economic Power sources + Strategy Implementation

The above mentioned eighteen points summarize the results obtained from the current study. These points were considered as the bases for further discussion of the results for theoretical contributions, methodological limitations and suggestions for further investigation. 


\section{DISCUSSION}

In the current study three major statistical procedures were followed: Correlational studies; One-way analysis; and Multiple Discriminant Analysis. By nature, any statistical technique do not support or indicate causal relationships. In fact, in social sciences, the causal relationships can only be established by theoretical means. Even though there was a tendency to speak in terms of causal relationships, the nature of correlational studies do not lend themselves well to such assumptions. For that matter, no data collected whether by experimental or non-experimental means could prove any causation (Pedhazur 1982, p579). In other words, strength of a theory combined with and the rigor of empirical evidence may represent the relationships that are closest to the causality.

\footnotetext{
"Causes are connected to effects; but this was because our theories connect them,......"
}

(Hanson 1958, p64)

"The law of causality ..... is a relic of bygone age, surviving, like the monarchy, only because it is erroneously supposed to do no harm."

(Russell 1953, p387)

Bagozzi (1980) noted that in naturalistic field surveys, as in the present case, it is not possible to infer causality with certainty. By the process of falsification of rival theories and reduction of error terms one can improve internal validity. Enhanced internal validity leads to confirmation of theoretical relationships leading to the development of generalizations. Hence, 
one cannot pretend to have established causal relations with empirical analysis from a single study. Considering the limitations, discussion of the empirical evidence to support the theoretical relationships posited in the research hypotheses was inluded here. Causal assumptions will be extended only when appropriate and meaningful.

\section{POWER PERCEPTIONS AND SATISFACTION}

In the OSR franchise systems, the franchisors and the franchisees are interdependent on each other for long term survival. Nature of the interdependency is affected by the level of conflict, degree of dependence, and sources of power present in the franchise systems. Satisfaction (performance) of the QSR franchisees is influenced by level of conflict, dependence, and power present in the system. The current study was limited to power perceptions and their impact on satisfaction and financial performance.

Hunt and Nevin (1974) explored the franchisors and franchisee relationships in the OSR industry. They noted that OSR franchisees' satisfaction is positively influenced by noneconomic power sources, and negatively influenced by the economic power sources. These results were later confirmed by several others (Etgar 1976a; Lusch 1977; Brown et al. 1983; Michie and Sibley 1985; Frazier and Summers 1984; and Lewis and Lambert 1991).

The QSR industry has entered the maturity stage of its industry life cycle during the late 1980s (West 1988; Tse 1988; Parsa and Khan 1992). During the past two decades, the OSR industry has experienced several significant changes. Parsa and Khan (1992) mentioned many of those changes in their review article. One of the changes is the franchise disclosure 
legislation of 1974. In 1992, Congressman John J. LaFalce of New York has introduced two bills in the U.S. Congress that could significantly affect franchise relations. The proposed congressional bills are expected to impact power balance in favor of franchisees. In light of these changes one would expect significant changes in franchise relations.

The first two hypotheses relate power, economic and noneconomic, perceptions to franchisee satisfaction. The results from the current study indicate that, during the maturity stage of industry life cycle, the franchisees satisfaction is significantly affected by the economic power sources. The results also indicate that high level of economic power sources are inversely related to franchisee satisfaction. This means that the OSR franchisees were less satisfied when they perceive high level of economic power sources by their franchisor. These findings are consistent with the earlier studies by Hunt and Nevin (1974) from the QSR industry during the growth stage of industry life cycle, and several authors from different industries.

The observed results also demonstrate that, during the maturity of industry life cycle, the QSR franchisees satisfaction is directly related to the noneconomic power sources. In other words, the OSR franchisees that participated in the current study are more satisfied when high level of noneconomic power sources are perceived in the franchise systems. Again, these results are consistent with the earlier studies by Hunt and Nevin (1974) with the QSR industry during the growth stage of QSR industry life cycle and Michie and Sibley (1985) with farm implement distribution systems.

In the current study, specific services provided by the franchisors were measured as information power sources llocal marketing support; field supervision; training; field supervision; and total marketing support). Lewis and Lambert (1991), in their study with OSR franchisees, 
noted that franchisees expressed increased overall satisfaction when satisfied with franchisors' performance with specific services. Results from the present study support Lewis and Lambert's (1991) earlier findings.

Some of major contributions of the results from the first two hypotheses include confirmation of earlier studies thus improving generalizability of the presented theoretical relations. Another major contribution is demonstration of stability of power perceptions in franchise systems during the various stages of industry lifecycle. The direction of the relationships between economic power, noneconomic power and satisfactions is found to be stable through the growth and maturity stages of lifecycle of the QSR industry.

\section{POWER PERCEPTIONS AND FINANCIAL PERFORMANCE}

Performance of a firm can be measured in several ways. It can be measured in financial terms (profitability ratios, liquidity ratios, revenues, return on assets, return on sales, return on investment, cash flow etc.), nonfinancial terms (market position, product quality, new product development, diversification etc.), and behavioral terms (resource dependence, conflict resolution mechanisms, human resource measures, employee satisfaction, goal satisfaction etc.). In the current study, the performance of OSR franchisees was measured in two financial terms as Income Before Fixed Costs (IBFC) and Sales per Year.

Selection of financial measures was based on the primary assumption that a firm is primarily an economic entity with financial health as one of the principal objectives. The third 
and fourth hypotheses relate sources of power (economic and noneconomic) to financial performance of the franchisees. It was hypothesized that economic power sources were inversely related to financial performance and noneconomic power sources directly related to financial performance.

Results from the current study indicate that economic power sources were inversely related to financial performance when it was measured in terms of sales per year. These results were not statistically significant. It means, the participating OSR franchisees could experience lower sales per year when high economic power sources were perceived in the franchise system. It was consistent with the theoretical relations posited. The relationship posited in the fourth hypothesis was supported with a negative correlation coefficient but not confirmed with a statistically significant value. Similar results were obtained by Sibley and Michie (1981) in their study with farm equipment manufacturers.

Surprisingly, contrasting results were observed when the financial performance was measured with IBFC. The relationship between economic power sources and financial performance found to be positive in direction. The obtained results were weak and statistically insignificant. The correlation coefficients were 0.0017 and 0.0614 for legitimate and coercive powers respectively. These low coefficient values are less than meaningful in establishing theoretical relationships.

The positive relationship between economic power sources and financial performance (IBFC) can be explained by the fact that single unit QSR franchisees are often required to become owner-operators thus limiting their potential to earn income from nonfranchise sources. Hence, when economic power is perceived the OSR franchisees may prefer to secure their 
franchise investment (livelihood) by focussing on gross margins rather than sales. Consequently, positive relation was observed between performance (gross margin) and economic powers. This can be confirmed by Etgar's (1977 p75) statement that during the maturity stage of lifecycle franchisors may tend to apply greater economic power to achieve higher financial results.

The third hypothesis states that noneconomic powers are directly related to financial performance. The statistical analyses indicate that noneconomic power sources were inversely related to financial performance whether measured as IBFC or sales per year. The obtained results were statistically significant. This demonstrates that the theoretical relations presented in the hypothesis three were not supported by the empirical evidence.

The contrasting results were surprising. In Sibley and Michie's (1981) study two of the noneconomic powers were directly related to performance and one was inversely related to performance. They also noted that during the economic recessionary times noneconomic power sources are less effective in achieving desired results. During the maturity stage of life cycle firms experience increased competition and decreasing demand for products and services. Hence, ineffectiveness of noneconomic power sources to improve financial performance is understandable.

\section{STRATEGY IMPLEMENTATION}

Importance of strategy implementation in achieving higher performance is well established (Stevens, Beyer and Trice 1980; Stonich 1980; Alexander 1981; Hrebiniak and 
Joyce 1984; Nutt 1986; Govindarajan 1988). The hypotheses five and six focus on strategy implementation, satisfaction, and performance. The hypotheses, five and six, state that there is no difference in QSR franchisees in performance and satisfaction when compared on the method of strategy implementation adapted.

Very limited information is available in the hospitality literature relating implementation and performance. Schmelzer (1992) investigated the role of organization design variables in strategy implementation using case study approach using six restaurant firms as research subjects. Satisfaction as a dependent variable is least explored in strategy implementation research. Hence, I consider the current study as an exploratory investigation.

Bourgeois and Brodwin (1984) stated that as sophistication in thinking about strategy implementation increases firms may prefer to adapt different implementation models. As firms adapt different implementation models their financial performance and outcome satisfaction must change accordingly. That means, different implementation models lead to varied levels of performance and satisfaction.

Results from the current study indicate that during the maturity stage of lifecyle the QSR franchisees with the Collaborative model of strategy implementation experience highest level of satisfaction compared to others. This refutes hypothesis six stated in null form.

In a single-unit restaurant franchise situations the owner-operator has very limited resources. The success of strategy implementation depends greatly on unit-level employees' participation and commitment. It is not surprising that QSR franchisees with Collaborative model expressed highest level of satisfaction. The Collaborative model franchisees are "closer to the 
front line of operations" (Bourgeois and Brodwin 1984) and involve front line employees in strategic management and team commitment is achieved at the expense of economic rationality. Consequently, higher level of satisfaction is achieved regardless of financial performance.

The results also indicate that the QSR franchisees that prefer Change model reported the highest level of financial performance measured as Income Before Fixed Income. In the Change model the CEO does not give up centralized control (Bourgeois and Brodwin 1984). Therefore, the QSR franchisees may possess greater control on economic mechanisms that are central to unit operations to achieve higher financial returns.

The results indicate that the direction of theoretical relations presented in the hypotheses five and six were weakly supported. The Collaborative model was significantly better than the other models in franchisee financial performance (sales per year) and performance.

Interestingly, when the financial performance was measured as sales per year, the OSR franchisee with the Change model achieved significantly better sales than others. Similar situation was experienced by Dev (1988) when he compared strategy content with performance. In his study, the Prospectors performed better with sales and the Defenders performed better with IBFC.

According to Bourgeois and Brodwin (1984), in the Change model "...the CEO applies behavioral science techniques to manipulate his organization into compliance....." The role of a CEO is to make the change happen. The CEO is an architect of administrative systems, 
compensation plans, and performance measures. In any QSR organization immediate effect of "change" is noted in profit increase and expected change in sales has time lag. Therefore, it is not surprising to expect OSR franchisees with the Change model to achieve higher levels of profits than othen implementation models.

The present study demonstrates that not all implementation model are equal. Major contribution of the results from the hypotheses five and six was the demonstration of Collaborative as a better alternative to achieve high satisfaction and higher sales. Another significant point is the recognition of the Change model as a high profit generator. These results indicate that different implementation models lead to different levels of financial performance and satisfaction.

POWER, IMPLEMENTATION, AND PERFORMANCE (SATISFACTION)

The earlier hypotheses (one through six) presented relationships between power and performance (satisfaction), and implementation and performance (satisfaction) independently. The next four hypotheses (seven through ten) consider the research variables in combination of three, presented in a sequential manner. All four hypotheses have strategy implementation as the intermediate variable.

The primary objective of the next set of four hypotheses was to identify a set of variables that are theoretically meaningful, and effective (statistically significant) in 
differentiating QSR franchisees with high level of performance (satisfaction) from those with low level of performance (satisfaction).

\section{ECONOMIC POWER AND IMPLEMENTATION}

Hypotheses seven and eight were discussed first since they both have a common independent variable economic power sources. It was followed by hypotheses nine and ten that have noneconomic power sources as the common independent variable.

The hypotheses seven and eight relate economic power sources, method of strategy implementation and level of QSR franchisees' satisfaction (performance). These hypotheses state that during the maturity stage of industry lifecycle, the OSR franchisees with high level of satisfaction (performance) can be differentiated from those with low level of satisfaction based on economic power sources and the method of implementation preferred.

Results from the Multiple Discriminant Analysis indicate that the model with economic power (coercive and legitimate) and implementation was effective in discriminating OSR franchisees on satisfaction. The highest hit ratio was 68.8 percent which was slightly better than the maximum chance $(64.4 \%)$ and substantially better than the proportional chance $(54.2 \%)$ criteria. The higher hit ratio for the legitimate power denotes that it was a better predictor than the coercive power.

Interpretation of results from Multiple Discriminant analysis will be incomplete without the discussion of loading weights. Results from discriminant analysis were interpreted either 
with discriminant coefficients or structural correlations (discriminant loadings). Discriminant weights were subject to considerable instability, and smaller weight of a variable indicates its irrelevance in determining relationship. Because of these limitations structural correlations (discriminant loadings) are preferred in interpreting the results from discriminant analysis. Discriminant loadings measure the simple linear correlation between each independent variable and the discriminant function. They also reflect the variance that the independent variables share with the discriminant function (Hair et al. 1987). Hence discriminant loadings are more effective than the discriminant weights.

In the current study, stability of the discriminant loadings was verified first. Discriminant analysis was conducted comparing top fifty percent respondents with the rest. The analysis was repeated using the top and the bottom ten percent of respondents. Consistancy of the results from both the analyses indicated stability of the discriminant loading. In interpreting discriminant loadings the variables with values greater than .30 were considered significant irrespective of sign $(+$ or -1 .

The results indicate that economic power sources (coercive and legitimate) were significant predictors of financial performance, measured as IBFC, with discriminating loadings 0.9738 for coercive power and 0.9220 for legitimate power. Contribution by strategy implementation $(-0.3389)$ was significant with legitimate power but not with coercive power (0.0510) (Table 26).

When financial performance was measured as Sales per Year the economic power sources (coercive and legitimate) again became significant predictors with discriminating loadings .9529 for coercive power and -.5516 for legitimate power. Contribution by strategy 
implementation was significant with legitimate power $(.7414)$ but not with coercive power (.2753) (Table 26). The economic power sources were effective in resulting higher profits and legitimate power was a better predictor of performance.

The hypothesis eight states that economic power and implementation were effective in predicting franchisees' satisfaction. The results indicate that economic power sources were significant in discriminating high satisfaction OSR franchisees from those with low level of satisfaction with discriminating loadings .9999 (coercive) and .9873 (legitimate). Implementation was not a significant contributor with either coercive (-.2093) or legitimate power $(.2179)$ in the equation.

The hit ratios for the model with economic power sources and implementation as independent variables, and satisfaction as the dependent variable were $64.4 \%$ (coercive) and $68.9 \%$ (legitimate). These ratios were slightly higher than maximum chance criterion and substantially better than proportional chance criterion. These results indicate that the model with economic power sources and implementation was effective in discriminating QSR franchisees on level of satisfaction.

Results from the hypotheses seven and eight indicate that coercive power was very effective in discriminating QSR franchisees on financial performance (IBFC and sales per year) and satisfaction. Another contribution of these hypotheses was that when legitimate power is included in the model, the strategy implementation also becomes a significant contributor along with the legitimate power. These two hypotheses were helpful in presenting that economic power sources could be used effectively in discriminating OSR franchisees' on satisfaction and finanical performance. 
Table - 26

Multiple Discriminant Analyses: Discriminant loadings for

Economic power, Implementation, Satisfaction and

Financial Performance

\begin{tabular}{||l|l|l|l|}
\hline Model & Sales per Year & IBFC & Satisfaction \\
\hline \begin{tabular}{|l} 
ECONOMIC POWER: \\
Coercive Power +
\end{tabular} & $0.9529^{*}$ & $0.9738^{*}$ & $0.9999^{*}$ \\
\hline $\begin{array}{c}\text { Coercive Power }+ \\
\text { Implementation }+\end{array}$ & $-0.2753 \mathrm{~ns}$ & $0.0510 \mathrm{~ns}$ & $-0.2093 \mathrm{~ns}$ \\
\hline $\begin{array}{c}\text { Legitimate Power }+ \\
\text { Legitimate Power }+ \\
\text { Implementation }+\end{array}$ & $-0.5516^{*}$ & $0.9220^{*}$ & $0.9873^{*}$ \\
\hline
\end{tabular}

* = Significant

ns $=$ Non significant 


\section{NONECONOMIC POWER AND IMPLEMENTATION}

The final two hypotheses, nine and ten, relate noneconomic power sources and implementation, and satisfaction (performance). The hypotheses state that QSR franchisees can be differentiated with a model including noneconomic power sources and implementation as independent variables, and satisfaction and financial performance as dependent variables.

Financial performance as the dependent variable will be discussed first. The discriminating weights indicate that noneconomic power sources were significant contributors to the discriminant function with values 0.9220 and 0.9946 (referent power) and .0 .9409 and 0.9990 (information power) (Table 27). These results indiate that noneconomic power sources were very effective in discriminating high performance OSR franchisees from low performers on financial performance measured as IBFC and sales per year.

Strategy implementation also became a significant discriminant when included in the model with noneconomic power sources and financial performance. The discriminant weights when performance measured as IBFC were -0.3389 (referent power, implementation and IBFC) and 0.2957 (information power, implementation, and IBFC). When performance was measured as sales per year the discriminant weights were -0.1351 (information power, implementation, and sales per year) and 0.0976 (referent power, implementation, and sales per year) (Table 27). The obtained results indicate that implementation becomes a better discriminant when financial performance measured as IBFC rather than sales per year. The hit ratio for the model with referent power, implementation and financial performance (IBFC) was 63.8 percent. The hit ratio was 62.2 percent when performance was measured as Sales per Year. These two values 
Table - 27

Multiple Discriminant Analyses: Discriminant loadings for

Noneconomic power, Implementation, Satisfaction and

Financial Performance

\begin{tabular}{||l|l|l|l||}
\hline Model & Sales per Year & IBFC & Satisfaction \\
\hline $\begin{array}{c}\text { NONECONOMIC POWER: } \\
\text { Information power }+\end{array}$ & $0.9990^{*}$ & $0.9409^{*}$ & $0.9999^{*}$ \\
\hline $\begin{array}{c}\text { Information power }+ \\
\text { Implementation }+\end{array}$ & -0.1351 & $-0.2957^{*}$ & $0.1109 \mathrm{~ns}$ \\
\hline $\begin{array}{c}\text { Referent power }+ \\
\text { Implementation }+\end{array}$ & $0.9946^{*}$ & $-0.9220^{*}$ & $0.9962^{*}$ \\
\hline $\begin{array}{l}\text { Referent power }+ \\
\text { Implemens }\end{array}$ & $-0.0976 \mathrm{~ns}$ & $-0.3389^{*}$ & $-0.0576 \mathrm{~ns}$ \\
\hline
\end{tabular}

* = Significant

$\mathrm{ns}=$ Non significant 
were substantially higher than the proportional chance criterion $(50.0 \%$ and $51.5 \%)$ and maximum chance criterion $(53.0 \%$ and $58.7 \%$ ) (Table 24$)$.

The hit ratios for information power, implementation and performance (IBFC and sales per year) model were 70.2 percent and 62.5 percent respectively. Both the hit ratios were substantially higher than maximum chance $(53.0 \%$ and $58.6 \%)$ and proportional chance $(50.0 \%$ and $51.5 \%)$ criterion. From these results one may conclude that noneconomic power sources (referent and information power) and implementation were very effective in differentiating high performance franchisees from low performers in financial performance measured as gross profit (IBFC) or sales per year. The hypothesis number nine was well supported.

Finally, when satisfaction was introduced as the dependent variable and noneconomic power as the independent variable the discriminating loadings were 0.9962 (referent power) and 0.9983 (information power) (Table 27). These results indicate that noneconomic power sources were significant discriminators when used in a model with satisfaction.

When noneconomic power sources and implementation were introduced as the independent variabes and satisfaction as the dependent variable the discriminant weights were 0.1109 and -0.0576 (Table 27). Neither of the discriminant loadings were significant. It means, implementation does not contribute much in enhancing the explanatory power of noneconomic power in explaining satisfaction.

The hit ratios for the model with noneconomic (referent and information power) power sources, implementation and satisfaction were $88.9 \%$ and 84.4 percent. Both the hit ratios 
were very substantially higher than the maximum chance $(64.4 \%)$ and proportional chance (54.2\%) criteria (Table 24). Hence, one may state that the hypothesis ten was empirically well supported.

Contributions of the hypotheses seven through ten are presented here. Results from these studies clearly indicate that, in OSR franchise systems during the maturity stage of lifecycle, power sources (economic and noneconomic) and strategy implementation were very effective in differentiating high performers (satisfaction) from low performers. The study also shows that franchisees satisfaction was dependent more on power sources (economic and noneconomic) than implementation. QSR franchisees also reported relatively higher satisfaction with noneconomic power sources than economic power sources.

Another contribution was measurement of financial performance. Contribution of strategy implementation towards performance was influenced by the nature of power. Financial performance measured either as IBFC or sales per year was effective in discrminanting high and low performers. In contrast, importance of implementation becomes significant whenever noneconomic power sources were dominant and performance was measured as sales per year. In other words, significant sales increase was realized by QSR franchisees when noneconomic power sources and implementation were pursued together.

Contribution by implementation towards financial performance and satisfaction becomes insignificant when economic power sources were dominant and performance was measured as IBFC. This shows that economic power sources were dominant enough to minimize the impact of implementation on performance and satisfaction. 
This study brings out the issue of performance measurement. Dev (1988) reported that different results are obtained when performance was measured with sales and profits. The current study supports Dev's (1988) conclusions that further studies are required to resolve this measurement issue. Hopefully, future researchers might consider this issue and answer it by using different techniques.

This study establishes, empirically, the importance of implementation in understanding performance and satisfaction differences among the hospitality franchisees. To confirm the current results and improve their generalizability further studies are required.

From methodological point of view, the current study makes a major contribution to instrument development. The rigorous pretesting procedures followed have resulted in a refined and valid research instrument. Maximum care was taken in developing the self-typing instrument for implantation. It was positioned specific enough to capture the essence of implementation process from QSR franchisees and general enough to duplicate for other industries.

Earlier Miles and Snow (1978) introduced a very successful self-typing instrument to measure strategy content. It was successfully adapted by several researchers in various industries (Coleman 1978; Dev 1988; Hambrick 1980). Snow and Hambrick (1980) stated that self-typing is a sound method for identifying intended strategies since organization executives are most up-to-date on the organization's directions. The present instrument, styled after Miles and Snow's (1978) instrument, can be adapted with little effort for other industries. Original research instruments of this nature are very few in hospitality and strategy implementation literature. 
Power as a research construct is pursued extensively in marketing channels literature. To the best of my knowledge, it is the first time power is measured during two different lifecycle stages (growth and maturity) of the same industry. Consequently, it became possible to study stability of power sources during various stages of lifecycle of a single industry.

Venkatraman and Ramanujam (1987) addressed several methodological issues and suggested that research design should include financial and nonfinancial measures to measure strategy effectiveness. As discussed in earlier chapters, financial performance and satisfaction are rarely pursued together either in marketing channels or strategy literature. The current study makes such an attempt considering the political-economy nature of the QSR franchise systems. Therefore, there is no precedence to compare the results. Concurring and contrasting results attained from this study, hopefully, raise more methodological and theoretical questions that contribute to further theory building.

The results also indicate that franchisees do not necessarily seek economic optimization, they also seek satisfaction. Hence, measurement of satisfaction along with financial measures must be considered in future studies.

\section{FRANCHISEE PROFILE}

This part will include a brief discussion of the respondents profile. Franchisees from six Quick Service Restaurant companies have participated in this study. Majority of the responses were from Dominos Pizza company. The respondents were predominantly male between the ages of 24 to 35 years with some college education. One may be surprised to note that the 
significantly low percentage of the respondents were females. Only further studies could reveal the causes of apparently discriminating practices in awarding OSR franchise contracts. Several respondents have college degrees and some reported graduate degrees. It is encouraging to see well educated franchisees in the hospitality industry. This trend might lead to further changes in franchise relations.

Majority of the respondents were single-unit contract holders and units were located predominantly in suburban sites. This clearly indicates that QSR franchisors prefer to franchise suburban locations. These results confirm the earlier results by Dev and Brown (1989) from hotel industry where highway locations were predominantly franchised.

Majority of the respondents have previous foodservice experience. It is very common in the restaurant industry for executives of franchisors becoming franchisees. Significant percentage of them have income from sources other the franchise contract. Nature of outside income was not explored here. Franchisees received average annual salaries ranging from $\$ 25$ to $\$ 34$ thousand as unit managers. The reported annual salaries are comparable to the restaurant industry averages thus indicating that the OSR franchisees were not using the restaurants as "cash cows".

\section{SUMMARY}

This chapter discussed the results obtained from the current study and their implications. Relationships between the research variables as noted from the statistical analyses 
were discussed for their significance. Suggestions for improvement were included wherever appropriate.

All the ten research hypotheses were discussed for their contribution to theory building. To simplify the discussion process the hypotheses were grouped together wherever necessary. The profile of the respondents was briefly considered.

The next chapter will present conclusions, limitations, and suggestions for further research. It also includes research propositions for further investigation. 


\section{Chapter 7}

\section{CONCLUSIONS}

Ansoff (1965) stated that strategic planning takes place in integral system with steps that range from formulation to implementation. Strategy content is not necessarily the ONLY deciding factor in determining organization performance as championed by the content researchers. Hence, the final and critical step in strategic management, strategy implementation process, was investigated here.

The current study demonstrates that implementation plays a significant role in determining performance (satisfaction) of an organization. It also shows that sources of power (economic and noneconomic) impact organizational performance (satisfaction) whether measured as revenues or profits.

Here some of the generalizations that could be drawn from the current study are presented: 
1. Satisfaction of franchisees is subject to the influence of power sources present in the franchise systems.

2. The choice of strategy implementation does affect financial performance. Some implementation models are more effective than others.

3. Different performance objectives demand different implementation models. The "match" between the outcome objectives and the implementation model is essential to achieve desired performance objectives.

4. Proper congruence between power sources and implementation models is critical to accomplish the desired financial and satisfaction objectives.

5. Different types of power (coercive, legitimate, referent, and information) have different effects on the contribution of implementation models in achieving desired objectives, financial and nonfinancial.

Nutt (1983), in his conceptual paper, presented that nature of power present in the environment influences the method of implementation selected. He considered four types of power legitimate, information, reward, and expert, and their impact on fifteen different implementation techniques. Importance of congruence between power and implementation model to achieve desired objectives is described by Nutt (1983). The current study presents an empirical evidence to support his contention using Borgeois and Brodwin's (1984) model. 
Strategy implementation is a complex, multidimensional concept. To capture the essence of implementation we have selected a self-typing instrument as recommended by Snow and Hambrick (1980). Positive and statistically significant results achieved in the current study offer the empirical validity to the instrument. Originality of the instrument is one of the major methodological contributions of the study.

The earlier chapters presented that, in implementing a chosen strategy, organizations do not have conceptually rich and empirically tested models to select. The current study presents Bourgeois and Brodwin's (1984) model as a viable alternative and demonstrates its relevance to the hospitality industry.

A primary conclusion of this study is the importance of implementation in achieving the desired results. QSR franchisees have an option to select an appropriate model to accomplish desired levels of revenues, profits, and satisfaction.

Another major contribution is the confirmation of earlier studies by several authors on relation between power and satisfaction, and power and performance using the hospitality industry setting.

From the results obtained here, one can state that for long term survival the OSR franchisees must consider alternative implementation models and their congruence with the nature of power present in the franchise system. 


\section{LIMITATIONS OF THE RESEARCH}

Every study has inherent limitations. As McGrath (1982) stated, every study is a compromise depending on the perspective. Generalizability cannot be maximized without compromising reality and vice versa. This study is no exception to the limitations that are ubiquitous in social science research. Some of the limitations are presented here:

1. One obvious limitation concerns the use of correlational data analysis. Correlation does not lend itself to the determination of causal relationships. Correlational studies may support the causalities established earlier in the theory building process.

2. The smaller sample size and low response rate have certain limitations in generalizing results to the total population. A word of caution is advised in interpreting and extending the conclusions.

3. This study is industry specific, hence limiting its generalizability to other populations. Generializability can only be established by repeated measures across different contexts.

4. Perception-based responses regarding implementation process could be subject to error, thus adding to the noise.

5. This study was designed as a cross sectional exploratory investigation. Therefore, the potential time-lag between the power perceptions, intended implementation models, and eventual organization outcomes was not considered here. Since, strategy is defined as 
a pattern in decision making process (Mitzberg 1978) the time-lag is conceptually integrated in perceptual measurement of independent and dependent variables.

6. Use of both financial and nonfinancial measures of performance has not been attempted in strategy literature earlier. Every novelty has its own risk in establishing reliability, validity and eventual acceptance.

7. Due to external and resource constraints several theoretically important and meaningful constructs are not included in the model. Some of the excluded strategic management variables are strategy content, environment, structure, and leadership. From marketing channels literature research constructs such as dependence, conflict, countervailing power, and transaction costs could be included in future research.

8. From methodology point of view, probably, the presented theoretical relations could be further explored with LISREL analyses. Resource constraints limited author's ability to pursue LISREL.

\section{SUGGESTIONS FOR FUTURE RESEARCH}

The suggestions will be presented from methodological point of view first. The first suggestion for future research is to overcome some of the limitations presented above. The reliability coefficient for some of the power sources could be enhanced. Higher levels of response rate and larger sample size are more desirable. The sample size could be enlarged by increasing the sample frame and including more OSR firms. The response rate could be improved by using a follow up letters method or providing incentives to the respondents. 
The research instrument deserves further refinement in measuring the dependent variables, especially the financial measures. Other measures such as market share, return on market value, Return On Value Added (Hofer 1983), asset turnover could be tested in the future. Inclusion of primary and secondary sources of performance measures is strongly suggested as recommended by Venkatraman and Ramanujam (1986). Convergence of the results from different sources enhance the explanatory power of the theoretical hypotheses.

Contextual suggestions include replication of the study with other non-QSR franchise systems such as hotels, resorts, institutional foodservice, and casual and fine dining. Understanding of contextual differences with respect to power and implementation may enhance our ability to apply theoretical knowledge more effectively to the hospitality industry. Some of the potential propositions are presented here:

P1: Relationship between power and performance of franchisees do not differ across the hospitality segments.

P2: Relationship between implementation and performance of franchisees do not differ across the hospitality segments.

Some of the theoretical suggestions comprise inclusion of other behavioral variables, such as, dependence and conflict in further studies. Impact of conflict and dependence on strategy content and implementation are not considered adequately in the marketing channels literature. 
P3: The level of conflict perceived by the franchisees has an effect on franchisee performance and satisfaction.

P4: The degree of dependence experienced by the franchisees has an effect on franchisee performance and satisfaction.

From the perspective of strategic management, investigation of relationship between strategy content and channel member satisfaction could further enhance our understanding of the franchise systems. Future studies on influence of environmental uncertainty and organizational scanning activities on firm performance will be extremely beneficial in expanding the body of knowledge on franchise systems. Finally, financial as well as nonfinancial measures could be included in measuring strategy effectiveness.

P5: High performance franchisees adapt different type of strategy than the low performers.

P6: Hospitality franchisee with high level of satisfaction adapt different type strategy than those with low level of satisfaction.

P7: In hospitality franchise systems, congruence between strategy content and environmental uncertainty may result in higher performance (satisfaction).

P8: Congruence between strategy content and environmental scanning activities may result in higher performance (satisfaction) in hospitality franchise systems. 
Theoretical and empirical relations between strategy content and performance, and between implementation and performance are well established. Unfortunately, impact of congruence between strategy content and implementation is least understood. Understanding of relationship between strategy content and implementation is the most important missing link in strategic management.

P9: The effectiveness of hospitality franchisees is influenced by the nature of congruence between strategy content and implementation.

From methodological point of view, further analyses of data with LISREL could be beneficial (Joreskog and Sorbom 1981, 1982). It could be followed by comparing results from LISREL, multiple regression and multiple discriminant analysis.

In sum, strategic management is one of the least explored aspects of franchise systems. Future researchers may consider this under investigated but most important topic for their empirical investigation and enrich the theoretical understandings of franchise systems.

\section{SUMMARY}

This research project has contributed to the understanding of franchise systems by exploring the relation between power perceptions, implementation and performance (satisfaction) (Appendix - IX). Understanding of strategic management in franchise systems is an endeavor in interdisciplinary research. In spite of rigorous pretesting procedure, careful 
research design and data collection, and powerful multivariate statistical analysis, some limitations are noted. Suggestions are discussed to overcome some of the limitations.

This study was designed to be industry specific, exploratory in nature. Hence, caution is advised in generalizing the results to other contexts. Considering the rigor of the methodology and statistical methods used one can be comfortable to state that these results could be replicated in other settings.

Several suggestions are presented for future studies. Propositions are extended to encourage further research in understanding strategic management in franchise systems. 


\section{REFERENCES}

Achrol, Ravi S. Torger Reve and Louis W. Stern (1983), "The Environment of Marketing Channel Dyads: A Framework for Comparative Analysis," Journal of Marketing, 47, (Fall) 55-67.

Adell, Derek F. (1978), "Strategic Windows," Journal of Marketing, July, 21-26.

Alexander, Larry D. (1985), "Successfully Implementing Strategic Decisions," Long Range Planning, 18, (3), 91-97.

--.-- (1990), "Strategy Implementation: Nature of The Problem," Unpublished paper, College of Business, Virginia Polytechnic Institute and State University, Blacksburg, VA.

Anderson, Paul F. (1982), "Marketing, Strategic Planning and the Theory of the Firm," Journal of Marketing, 46, (Spring), 15-26.

Andrews, K.R. (1971), The Concept of Corporate Strategy, New York, NY: Dow-Jones Irwin.

Ansoff, H.Igor (1965), Corporate Strategy: An Analytical Approach to Business Policy for Growth and Expansion, McGraw-Hill, New York, NY.

(1979), Strategic Management, London, England: MacMillan Press.

(1980), "Strategic Issue Management," Strategic Management Journal, 1, 131-148.

Aristotle, (357 BC), Politics, English translation by Rackham Harris (1957), Aristotle Politics, Cambridge, MA: Harvard University Press.

Arndt, John (1983), "The Political Economy Paradigm: Foundation for Theory Building in Marketing," Journal of Marketing 47 (Fall), 44-54.

Badovick, Gordon J. and Sharon E. Beatty (1987), "Shared Organizational Values: Measurement and Impact Upon Strategic Marketing Implementation," Journal of hte Academy of Marketing Science, 15 (1) p19-26.

Bagozzi, Richard P. (1980), Performance and Satisfaction in an Industrial sales Force: An Examination of Their Antecedents and Simultaneity," Journal of Marketing, 44 (Spring) p65-77.

Baumol, W.J. (1958), "On the Theory of Oligopoly," Economica reported by Hawkins (1973) in Theory of the Firm, New York, NY: Macmillan

and M. Steward (1964), "On The Behavioral Theory of the Firm," in R.Marris and A. Wood (eds), The Corporate Economy, London, UK: Macmillan 
Bedian, A.G. (1986), "Contemporary Challenges in the Study of Organizations," in J.D. Hunt and J.D. Blair (eds), Yearly Review of Management of the Journal of Management, 12, p185-201.

Beier, Frederick J. and Louis W. Stern (1969), "Power in the Channel of Distribution," in Distribution Channels: Behavioral Dimensions, Louis W. Stern (ed) Boston, MA: Houghton Mifflin, p92-116.

Benson, Kenneth J. (1975), "The Interorganizational Network as a Political Economy," Administrative Science Quarterly, 20, (June) p.229-249.

Bourgeois III, L.J. and David R. Brodwin (1984), "Strategic Implementation: Five Approaches to an Elusive Phenomenon," Strategic Management Journal, 5, p241-264.

-, (1980), "Strategy and Environment: A Conceptual Integration," Academy of Management Review, 5 (1), p25-39.

Bracker, Jeffrey (1980), "The Historical Development of the Strategic Management Concept, Academy of Management Review, 5 (2), p219-224.

Brinberg, David and Joseph E. McGrath (1985), Validity and The Research Process, Newbury Park, CA: SAGE publications. p. 29-57.

Brown, F. E. (1980), Marketing Research: A Structure for Decision Making, Reading, MA: Addison-Wesley Publishing Company.

Brown, James R. and Chekitan Dev (1991).

, Robert F. Lusch, and Darrel D.Muehling (1983), "Conflict and Power-Dependence Relations in Retailer- Supplier Relations", Journal of Retailing, 59, (4), 53-80.

, and Gary L. Frazier (1978), "The Application of Channel Power: Its Effects and Connotations," in Research Frontiers in Marketing Dialogues and Directions, Subhash C. Jain (ed), Chicago, IL: American Marketing Association, p266-270.

(1981), "A Cross-Channel Comparison of Supplier-Retailer Relations," Journal of Retailing, 57 (4), p3-17.

, Jean L. Johnson and Young K. Lim (1986), "Behavioral Relations in Marketing Channels: A Review of Cross-Channel Comparisons," working paper, University of Nebraska, Lincoln, NE.

Buchanan, J.A. (1964), "What Should Economists Do?" Southern Economic Journal, 30, p213222.

Buzzell, Robert D., Bradley T. Gale and Ralph G.M. Sultan (1975), "Market Share -- A Key Profitability," Harvard Business Review, (January/February). 
Carman, James M. and Thomas A. Klein (1986), "Power, Property, and Performance in Franchising: A Review and Integration of Theory," in Research in Marketing (Vol. 8), Louis P. Bucklin and James M. Carman (guest ed) and Jagdish Sheth (senior ed), Greenwich, CT: JAI Press Inc. p71-130.

Carmines, Edward G. and Richard A. Zelier (1979), Reliability and Validity Assessment, Newbury Park, CA: Sage Publications.

Cartwright, Dorwin (1959), "A Field Theoretical Conception of Power," in Studies in Social Power, Dorwin Cartwright (ed), Ann Arbor, Ml: University of Michigan Press.

(1965), "Influence, Leadership and Control," in Handbook of Organizations, James G. March (ed), Chicago, IL: Rand McNally.

Cavanaugh, Mary S. (1984), "A Typology of Social Power," in Power, Politics and Organizations: A Behavioral Science View, Andrew Kakabadse and Christopher Parker (eds) New York, NW: John Wiley and Sons, p3-21.

Chakravarty, B.S. (1984), "Strategic Self-Renewal: A Planning Framework for Today," Academy of Management Review, 536-547

(1986), "Measuring Strategic Performance", Strategic Management Journal, 7, 437 458.

Chamberlin, E.H. (1953), "Elasticities, Cross-Elasticities and Market Relationships: Comment," American Economic Review

Chandler, Alfred D. (1962), Strategy and Structure, New York: MIT Press.

Chon, Kye-Sung (1990), "Consumer Satisfaction and Dissatisfaction in Tourism as Related to Destination Image Perception," Doctoral dissertation submitted to Virginia Polytechnic Institute and State University (VPI \& SU), Blacksburg, VA.

Coase, Ronald H. (1937), "The Nature of the Firm," Economica, 4, 386-405, reprinted in "Readings in Price Theory," George J. Stigler and Kenneth E. Boulding (eds), Homewood, IL.: Irwin Publications (1952).

Cohen, K.J. and R.M.Cyert (1965), The Theory of the Firm: Resource Allocation in a Market Economy, Englewood Cliffs, NJ: Prentice-Hall.

Coleman, $\mathrm{H}$ and Gaetan (1985), "Perceived Environmental Uncertainty, Investment Strategy, and Reasons for Business Failure in the Apparel Industry," Proceedings of the conference on Apparel Manufacturing, Clemson University: Clemson, SC

Cooper, Arnold C. and Dan E. Schendel (1976), "Strategic Response to Technological Threat", Business Horizons, (Feb.).

Crocker, Linda and James Algina (1990), Introduction to Classical and Modern Test Theory, New York, NY: Holt, Rinehart and Winston, Inc. 
Crozier, M. (1964), "The Bureaucratic Phenomenon," Chicago, IL: The University of Chicago Press.

Cyert, Richard M. and James G. March (1963), A Behavioral Theory of the Firm, Englewood Cliffs, NJ: Prentice-Hall.

Dahl, Robert A. (1957), "The Concept of Power," Behavioral Science, 2 (July), p201-218.

Day, George S. (1981), "Strategic Market Analysis and Definition," Strategic Management Journal, 2, 281-299.

and Liam Fahey (1988), "Valuing Market Strategies," Journal of Marketing, 52, 45-57. and Robin Wensley (1983), "Marketing Theory with a Strategic Orientation," Journal of Marketing, 47 (Fall), p79-89.

Dev, Chekitan S. (1988), "Environmental Uncertainty, Business Strategy, and Financial Performance: A Study of the Lodging Industry," Ph.D. dissertation, Virginia Polytechnic Institute and State University (VPI \& SU), Blacksburg, VA.

and Brown (1991), "Franchising and Other Operating Arrangements in the Lodging Industry: Astrategic Comparison," The Society of Franchising Annual Conference Proceedings, Bal Harbour, Florida.

Demsetz, H. (1983), "The Structure of Ownership and the Theory of the Firm, " Journal of Law and Economics, $11,275-300$.

Donald, M.N. (1960), "Implications of Nonresponse for the Interpretation of Mail Questionnaire Data," Public Opinion Quarterly, 24, p99-114.^R

Dwyer, Robert F. (1980), "Channel Member Satisfaction: Laboratory Insights," Journal of Retailing, 56 (Summer), p45-65.

and M. Ann Welsh (1983), "Environmental Relationships of the Internal Political Economy of Marketing Channels," Journal of Marketing Research, (November) 397414.

(1984), "Are Two Better Than One? Bargaining Behavior and Outcomes in an Asymmetrical Power Relationships," Journal of Consumer Research, 11 (September), p680-693.

and Sejo Oh (1987), "A Transaction Cost Perspective on Vertical Contractual Structure and Interchannel Competitive Strategies," Journal of Marketing, (April), 21 34.

El-Ansary, Adel I. and Louis W. Stern (1972), "Power Measurement in Distribution Channels," Journal of Marketing Research, 16 (February) p47-52. 
and Robert A. Robicheux (1974), "A Theory of Channel Control," Journal of Marketing, 38 (January), p2-7.

Emerson, Richard M. (1962), "Power-Dependence Relations," American Sociological Review, 27 (February) p31-41.

Emerson, Robert L. (1990), The New Economics of Fast Food, New York, NY: Van Nostrand Reinhold.

Etgar, Michael (1976a), "Effects of Administrative Control on Efficiency of Vertical Marketing Systems," Journal of Marketing Research, 13 (February), p12-24.

(1976b), "Channel Domination and Countervailing Power in Distributive Channels," Journal of Marketing Research, 13 (August), p254-264.

(1977), "Channel Environment and Channel Leadership," Journal of Marketing Research, 14 (February).

(1978), "Differences in the Use Manufacture Power in Conventional and Contractual Channels," Journal of Retailing, 54 (Winter), p412-460.

Evans, Mike R. and Chekitan Dev (1987), "Pre-opening Investment Study of Hotels and Motels," Center for Hospitality Research and Service: Research Report 1. Virginia Polytchnic Institute and State University, Blacksburg, VA.

Fama, Eugene and Merton H. Miller (1972), The Theory of Finance, Hinsdale, IL: Dryden Press.

Fortune, James (1990), personal communication, Department of Educational Research, Evaluation, and Policy Studies, Virginia Polytechnic Institute and State University, Blacksburg, VA.

Fowler Jr., Floyd J. (1988), Survey Research Methods, Newbury Park, CA: Sage Publications.

Frazier, Gary L. and John O. Summers (1984), "Interfirm Influence Strategies and Their Application within Distribution Channels, ${ }^{\prime}$ Journal of Marketing, 48 (Summer), p43-55.

French, John R.P. Jr. and Bertram Raven (1959), "The Bases of Social Power", in Studies in Social Power, Dorwin Cartwright (ed), Ann Arbor: University of Michigan, Institute for Social Research, 1959, 150-167; reprinted in Studies in Managerial Process and Organizational Behavior, John H. Turner, Alan C. Filley, and Robert J. House (eds), Glenview, IL: Scott Foresman and Co. 72-81.

Galbraith, John and Daniel A. Nathanson (1978), Strategy Implementation: The Role of Structure and Process, New York, NY: West Publishing Co.

and R.K. Kazanjian (1986), Strategy Implementation, Structure, systems, and Process, New York, NY: West Publishing Company. 
Gale, B.T., (1972), "Market Share and Rate of Return", Review of Economics and Statistics, p. 412-423.

Gaski, John F. (1984), "The Theory of Power and Conflict in Channels of Distribution," Journal of Marketing, 48 (Summer), p9-29.

(1986), "Interrelations Among A Channel Entity's Power Sources: Impact of the Exercise of Reward and Coercion on Expert, Referent, and Legitimate Power Sources," Journal of Marketing Research, 23 (February), p62-77.

Ginsberg, H. (1984), "Operationalizing Organization Strategy: Toward an Integrative Framework," Academy of Management Review, 9, p548-557.

Govindarajan, Vijay (1988), "A Contingency Approach to Strategy Implementation at The Business Unit Level: Integrating Administrative Mechanisms with Strategy،" Academy of Management Journal, 31 (4), p828-853).

Hair, Joseph F., Rolph E. Anderson and Ronald L. Tathum (1987), Multivariate Data Analysis, New York, NY: Macmillan.

Hambrick, Donald C. (1980), "Operationalizing the Concept of Business-level Strategy in Research," Academy of Management Review, 5, p565-575.

(1983), "Some Tests of the Effectiveness and Functional Attributes of Miles and Snow's Strategic Types," Academy of Management Journal, 26, p. 5-26.

Hanson, N.R. (1958), Patterns of Discovery, Cambridge University Press, Cambridge, UK.

Hatten, K.D., Dan E. Schendel and A.C. Cooper (1978), "A Strategic Model of the U.S. Brewing Industry: 1952-1971," Academy of Management Journal, 21 (December), p592-610.

Hawkins, C.J. (1973), Theory of the Firm, New York, NY: Macmillan Company.

Heide, Jan B. and George John (1988), "The Role of Dependence Balancing in Safeguarding Transaction-Specific Assets in Conventional Channels," Journal of Marketing, 52 (January), p20-35.

Hickson, D.J., C.R.Hinnings, C.A.Lee, R.E.Schneck, and J.M. Pennings (1971), "A Strategic Contingencies Theory of Intraorganizational Power," Administrative Science Quarterly, $16,(2), 216-227$.

Hill, Charles W. and W. Chan Kim (1988), "Searching for a Dynamic Theory of the Multinational Enterprise: A Transaction Cost Model," Strategic Management Journal, 9, p93-104.

Hofer, Charles (1983), "ROVA: A New Measure for Assessing Performance," Advances in Strategic Management, Volume 2, p43-55.

Hofer, Charles W. and Dan Schendel (1978), Strategy Formulation: Analytical Concepts, New York, NY: West Publishing Co. 
Hrebiniak, L.G. and Joyce, W.F. (1984), Implementation Strategy, New York, NY: Macmillan Publishing Co..

Hunt, Shelby D. and John R. Nevin (1974), "Power in a Channel of Distribution: Sources and

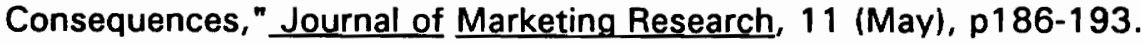

Hunt, Shelby D., Nina M. Ray and Van R. Wood (1985), "Behavioral Dimensions of Channels of Distribution: Review and Synthesis, " Journal of the Academy of Marketing Science, 13 (3) p1.24.

Hutt, Michael D.,Michael P. Mokwa and Stanley J.Shapiro (1986), "The Politics of Marketing: Analyzing the Parallel Political Market Place," Journal of Marketing, 50 (January), p4051.

Jensen, Michael C. and William H. Meckling (1976), "Theory of the Firm: Managerial Theory, Agency Costs, and Ownership Structure," Journal of Financial Economics, 3, 305-360.

John, George and Torger Reve (1982), "The Reliability and Validity of Key Informant Data from Dyadic Relationships in Marketing Channels," Journal of Marketing Research, 19 (November), 517-524.

Johnson, Jean L., Harold F. Koenig and James R. Brown (1985), "The Bases of Marketing Channel Power: An Exploration and Confirmation of Their Underlying Dimensions," in Robert F. Lusch et. al. (eds), American Marketing Association Educator's Proceedings, Chicago: American Marketing Association, p160-5.

Joreskog, Karl G. and Dag Sorbom (1981), LISREL V: Analysis of Linear Structural Relationships by Maximum Likelihood and Least Square Methods, Chicago, IL: National Educational Resources, Inc.

Joreskog, Karl G. and Dag Sorbom (1982), "Recent Developments in Structural Equation Modeling," Journal of Marketing Research, 19 (November) p404-416.

Justis, Robert and Richard Judd (1989), Franchising, Cincinnati, OH: South-Wetern Publishing Co.

International Franchise Association (1990), "Franchising in the Economy,"

Kasulis, J.J., R.E.Speckman and Richard P. Bagozzi (1979), "A Taxonomy of Channel Influence: A Theoretical-Operational Framework, " in Future Directions for Marketing: Proceedings of Two European Colloguia, George Fisk et.al. (eds), Cambridge, MA: Marketing Science Institute, p165-184.

Kalton, Graham (1983), Introduction to Survey Sampling, Newbury Park, CA: Sage Publications.

Kerlinger, Fred N. (1986), Foundations of Behavioral Research, Holt, Rinehart and Winston Inc., Chicago, IL. 
Khan, Mahmood A. (1991), Restaurant Franchising, New York, NY: Van Nostrand Reinhold.

Khandwalla, P.N. (1976), "The Techno-economic Ecology of Corporate Strategy", Journal of Management Studies, 13, (2), 62-75.

LaFalce, John J. (1991), Franchising in the U.S. Economy: Prospects and Problems, a report by the Committee on Small Business, House of Representatives, 101 st U.S. Congess, Second Session.

Lawrence, Paul R. and Jay W. Lorsch (1967), Organizations and Environment, Boston: Harvard University Press.

Le Breton, P. (1965), General Administration: Planning and Implementation, New York, NY: Holt, Rinehard and Winston.

Lederhaus, Mary Ann (1984), "Improving Marketing Channel Control through Power and Exchange," Journal of the Academy of Marketing Science, 12 (3), p18-34.

Lewis, Christine M. and Douglas M. Lambert (1991), "A Model of Channel Member Performance, Dependence, and Satisfaction, " Journal of Retailing, 67 (2) p205-225.

Lillis, Charles M. Chem L. Narayana and John L. Gilman (1976), "Competitive Advantage Variation Over the Life Cycle of a Franchise, ${ }^{n}$ Journal of Marketing, (October), p77-80.

Little, Robert W. (1970), "The Marketing Channel: Who Should Lead This Extra-Corporate Organization?," Journal of Marketing, 34 (January)

Lorange, P., M.F. Morton and S. Ghoshal (1986), Strategic Control Systems, St. Paul, MN: West Publications

Lowe, Larry S. and Kevin F. McCrohan (1979), "Power in Channel Dyad by Relative Firm Size and Type of Relationship," in Contemporary Issues in Marketing Channels, Robert F. Lusch and Paul H. Zinszer (eds), University of Oklahoma, Norman, OK: University Printing Services, P77-85.

Lusch, Robert F. (1976a), "Sources of Power: Their Impact on Intrachannel Conflict," Journal of Marketing Research, 13 (November) p382-390.

(1976b), "Channel Conflict: Its Impact on Retailer Operating Performance," Journal of Retailing, 52 (Summer), p3-12, 89-90.

(1977), "Franchise Satisfaction: Causes and Consequences," International Journal of Physical Distribution, 7 (February), p128-140.

and James R. Brown (1982), "A Modified Model of Power in the Marketing Channel," Journal of Marketing Research, 19 (August), p312-323. 
and Gene R. Laczniak (1989), "Macroenvironmental Forces, Marketing Strategy and Business Performance: A Futures Research Approach," Journal of the Academy of Marketing Science, 17 (4), p283-295.

and Robert H. Ross (1985), "The Nature of Power in Marketing Channel," The Journal of the Academy Marketing Science, 13 (3), p39-56.

Machlup, F. (1967), "Theories of the Firm: Marginalist, Behavioral, Managerial," American Economic Review (March)

Marshall, Alfred (1936), (1) Principles of Economics, New York, NY: The Macmillan Company, Chap 3-5. (2) Principles of Economics, in Readings in Labor Economics and Labor Relations (1974), Lloyd G. Reynolds et. al. (eds), Englewood Cliffs, NJ: Prentice-Hall.

McDaniel, Stephen W. and James W. Kolari (1987), "Marketing Strategy Implications of the Miles and Snow Strategic Typology," Journal of Marketing, 53, 21-35.

McGrath, Joseph E. (1982), Dillemmatics: The Study of Research Choices and Dilemmas, in Judgement Calls in Research, Beverly Hills, CA: Sage Publications.

McGuire, J.W. (1962), "Executive Incomes, Sales and Profits," American Economic Review (September).

McKee, Daryl P., P. Rajan Varadarajan and William M. Pride (1989), "Strategic Adaptability and Firm Performance: A Market Contingent Perspective," Journal of Marketing, 53, (July), 21-35.

Michie, Donald A. (1978), "Managerial Tactics: An Alternative Explanation of Warranty Satisfaction in a Channel Distribution," Research Frontiers in Marketing: Dialogues and Directions, Subhash S. Jain (ed), Chicago, IL: American Marketing Association, p260265.

and Stanley D. Sibley (1985), "Channel Member Satisfaction: Controversy Resolved," Journal of the Academy of Marketing Science, 13 (2) p188-205.

Miles, R. and Snow, C. 1978), "Organizational Strategy, Structure, and Process", McGraw-Hill Book Co. N.Y.

Charles C. Snow, Alan D. Meyer, and Henry J. Coleman (1977), "Organizational Strategy, Structure, and Process", Academy of Management Review, July, 546-562.

Mintzberg, H. (1978), Patterns in Strategy Management, Management Science, 24, p934-948. (1979), The Structure of Organizations, Englewood Cliffs, NJ: Prentice Hall.

Morgan, Gareth (1986), Images of Organizations, Newbury Park, CA: Sage Publications. 
Murray, Jeff B. (1987), "The Critical Source of Uncertainty and The Dominant Sentiments of Marketing Channel Dyads: A Bargaining Simulation," Doctoral dissertation submitted to the Department of Marketing, VPI \& SU., Blacksburg, VA.

Nachmias, David and Chava Nachmias (1981) Research Methods in Social Sciences, New York, NY: St. Martin's Press

Nationa's Restaurant News (1991), "Top 100 Chains", August 5th, Vol. 20 (30) p1.

Nutt, Paul C. (1983), "Implementation Approaches for Project Planning," Academy of Management Review, 8 (4), p600-611.

- (1986), Tactics of Implementation," Academy of Management Journal, 29 (2) p230261.

, (1987), "Identifying and Appraising How Managers Install Strategy," Strategic Management Journal, 8, p1-14.

Ouchi, William G. (1980), "Markets, Bureaucracies and Clans," Administrative Science Quarterly, 25 (March), 129-141

Palamountain, J.C.Jr. (1955), The Politics of Distribution, Cambridge, MA: Harvard University Press.

Papandreou, A. (1952), "Some Basic Problems in the Theory of the Firm," in B.F. Haley (ed) A Survey of Contemporary Economics Vol II, Homewood, IL: Irwin.

Parsa, H.G. and Mahmood A. Khan (1989a), "Menu Trends Analysis," Council on Hotel, Restaurant and Institutional Education (CHRIE) Annual Conference Proceedings, Las Vegas, NE.

, Mary L. Gustin, and Mahmood A. Khan (1989b), "Potential Conflict Points in Franchisor-Franchisee Relations: An Exploratory Study of Fast Franchise Systems," CHRIE Annual Conference Proceedings, Las Vegas, NE.

and Francis A. Kwansa (1990), "Performance of Hospitality Franchise Firms: An Institutional economics Perspective," Association of Hospitality Financial Management Educators Annual Conference, New York, NY.

and -.---.- (1991), "Financial Performance and Strategic Options in Hospitality

Franchise Systems: A Franchisee Perspective," Society of Franchising Annual Conference, Miami, FL.

and Mahmood A. Khan (1991), "Comparative Analysis of Trends in Quick Service Restaurant Industry," working paper. Department of Hotel, Restaurant, and Institutional Management, VPI \& SU, Blacksburg, VA.

and (1992), "Menu Trends in Quick Service Restaurant Industry During the Various Stages Of Industry Life Cycle 1919-1988," Hospitality Research Journal 
Pedhazur, Elazar J. (1982), Multiple Regression in Behavioral Research, Holt, Rinehart and Winston: New York, NY.

Pettigrew, A.M. (1973), The Politics of Organizational Decision-Making, London, UK: Travistock.

Pfeffer, J. and Salancik, G.R. (1978), "The External Control of Organizations: A Resource Dependence Perspective," Harper and Row Publishers, New York, N.Y.

Philipps, Lynn W. (1981), "Assessing Measurement Error in Key Informant Reports: A Methodological Notes on Organizational Analysis in Marketing," Journal of Marketing Research, 18 (November) p395-415.

Porter, Michael E. (1974), "Consumer Behavior, Retailer Power and Market Performance in Consumer Goods Industries," The Review of Economics and Statistcis, Vol. LVI (4) p419-436.

(1985), "Competitive Strategy", The Free Press, a division of Macmillon Publishing Co. Inc., 866 Third Ave, New York, N.Y. 10022. p.8-191.

Pressman, J.L. and A. Wildavsky (1973), Implementation: How Great Expectations in Washington are Dashed In Oakland, Berkeley, CA: University of California.

Quinn, James Brian (1978), 'Strategic Change: "Logical Incrementalism,"' Sloan Management Review, 20 (1) p7-21.

(1980), Strategies for Change: Logical Incrementalism, Homewood, IL: Irwin.

Ramanujam, Vasudevan and N. Venkatraman (1987), "Planning System Characteristics and Planning Effectiveness," Strategic Management Journal, 8, p453-468.

Roberts, D.R. (1959), Executive Compensation, Glencoe, IL: Free Press.

Robinson, J. (1933), The Economics of Imperfect Competition, New York, NY: Macmillan.

Rosenthal, Robert and Ralph L. Rosnow (1984), Essentials of Behavioral Research: Methods and Data Analysis, New York, NY: McGraw-Hill Book Company.

Ross, Robert H., Robert F. Lusch and James R. Brown (1982), "Power and Dependency in the Market Channel: A Methodological Note, " in An Assessment of Marketing Thought and Practice, Educators Proceedings, Series No. 48, Bruce J. Walker (ed), American Marketing Association, 194-198.

Rubin, Paul H. (1978), "The Theory of the Firm and the Structure of Franchise Contract," Journal of Law and Economics, 21, 23-233.

Ruekert, Robert W. and Gilbert A. Churchill (1984), "Reliability and Validity of Alternative Measures of Channel Member Satisfaction," Journal Of Marketing Research, 21 (May). p226-233. 
, Orville C. Walker Jr. and Kenneth J. Roering (1985), "The Organization of Marketing Activities: A Contingency Theory of Structure and Performance," Journal of Marketing, 49, (Winter), 13-25.

Rumelt, R. (1974), Strategy, Structure and Economic Performance, Cambridge, MA: Harvard University Press.

Runkel, P.J. and J.E.McGrath (1972), Research on Human Behavior: A Systematic Guide to Method, New York, NY: Holt, Rinchart \& Winston.

Russell, Bertrand (1953), "On The Notion of Cause, With Applications to Free-Will Problem," in H. Fiegl and M. Brodbeck (eds), Readings in the Philosophy of Science, Appleton, New York, NY: p387.

Sasser, Earl W., R.P. Olsen and D.D. Wycoff (1978), Management of Service Operations, Boston, MA: Allyn and Bacon.

Schaffer, Jeffrey D. (1986), "Competitive Strategy, Organization Structure and Performance in the Lodging Industry: An Empirical Assessment of Miles and Snow's (1978) Perspective of Organizations," Ph.D. dissertation, School of Business Management, VPI \& SU, Blacksburg, VA.

Schendel, Dan E. and Charles W. Hofer (1979), Strategic Management: A View of Business Policy and Planning," Boston, MA: Little, Brown and Company.

and R. Patton (1978), "A Simultaneous Equation Model of Corporate Strategy," Management Science, (November), p1611-1621.

Schmelzer, Claire D. (1992), "An Exploratory Study InvestigatingThe Tole of Organization Design Variables in Implementing Strategy in a Restaurant Firm," unpublished doctoral dissertation submitted to VPI \& SU, Blacksburg, VA.

Shrader, Charles B., Lew Taylor and Dan R. Dalton (1984), "Strategic Planning and Organizational Performance: A Critical Appraisal, " Journal of Management, 10 (2) p149171.

Sibley, Stanley D. and Donald A. Michie (1981), "Distribution Performance and Power Sources," Industrial Marketing Management, 10, p59-65.

Simon, Herbert A. (1955), "A Behavioral Model of Rational Choice," Quarterly Journal of Economics, (February)

(1959), "Theories of Decision Making in economics and Behavioral Science," American Economic Review; reprinted in G.P.E. Clarkson (ed) Managerial Economics, (1968) Harmondsworth, UK: Penguin Books

(1964), "On the Concept of Organization Goal," Administrative Science Quarterly, 9 (June), P1-22. 
Sirkis, R. L. and Race S. M. (1982), "Strategic Planning for the Food Service Industry", The Practice of Food Service Management, March, p. 37-42.

Slater, Stanley F. and John C. Narver (1994), "Does Competitive Environment Moderate the Market Orientation-Performance Relationship," Journal of Marketing, January, 58, p4655.

Smith, Adam (1976), (1) The Wealth of Nations, London, UK: Stratton and Cadell. (2) The Wealth of Nations in Readings in Labor Economics and Labor Relations (1974), Lloyd G. Reynolds et. al. (eds), Englewwod Cliffs, NJ: Prentice-Hall.

Smith, Ken G., Terence R. Mitchel and Charles E. Summer (1977), "Top Level Management Priorities in Different Stages of the Organizational Life Cycle," Academy of Management Journal, 28 (4) p799-820.

Snow, Charles C. and L.G. Hrebiniak (1980), "Strategy, Distinctive Competence, and Organization Performance," Administrative Science Quarterly, 25, p317-366.

, and Donald C. Hambrick (1980), "Measuring Organizational Strategies: Some Theoretical and Methodological Problems," Academy of Management Review, 5 (4) p527-538.

Steiner, G. and Miner, J. (1977), "Management Policy and Strategy: Text, Readings, and Cases," New York, NY: Maccmillan Publishing Co.

Stern, Louis W. and Torger Reve (1980), "Distribution Channels as Political Economies: A Framework for Comparative Analysis," Journal of Marketing, 44 (Summer), 52-64.

Stevens, James (1986), Applied Multivariate Statistics for the Social Sciences, Hillsdale, NJ: Lawrence Earlbaum Associates, Publishers.

Stevens, S.S. (1946), "On The Theory of Scales of Measurement," Science, 103, p677-680.

Stevens, J.M., Janice M. Beyer and Harrison M. Trice (1980), " Managerial Receptivity and Implementation of Policies," Journal of Management, 6 (1) p33-54.

Stonich, Paul J. (1982), Implementing Strategy: Making Strategy Happen, Cambridge, MA: Ballinger Publishing Co.

Tannenbaum, Arnold S. (1968), Control in Organizations, New York, NY: McGraw-Hill.

Thibaut, J.W. and H.H. Kelley (1959), The Social Psychology of Groups, New York, NY: Wiley

Thomas, K.W. (1976), "Conflict and Conflict Management," in M.D.Dunette (ed) Handbook of Industrial and Organizational Psychology, Chicago, IL: Rand McNally.

Thompson, James D. and William J. McEwen (1958), "Organizational Goals and Environment," American Sociological Review, 23, p.23-31. 
(1967), Organizations in Action, New York: McGraw-Hill Book Co.

Thompson, A.A. and A.J. Strickland (1987), Strategic Management, Plano, TX: Business Publications Inc.

and (1991), Strategic Management: Formulation, Implementation and Control, Fourth edition, Homewood, IL: Irwin.

Tregoe, B.B. and Tobia P.M. (1990), " An Action-oriented Approach to Strategy," The Journal of Businee Strategy, p16-21.

Tse, Eliza Ching-Yick (1988), "The Impact of Strategy and Structure on the Organizational Performance in the Restaurant Firms," Ph.D. dissertation, VPI \& SU Blacksburg, VA.

Tushman, Michael L. (1977), "A Political Approach to Organizations: A Review and Rationale," Academy of Management Review, (April) p206-216.

Venkatraman N. and Ramanujam V. (1987), "Measurement of Business Performance in Strategy Research: A Comparison of Approaches", Academy of Management Review, 11, 801814.

and J.H. Grant (1986), "Construct Measurement in Organizational Strategy Research: A Critique and Proposal, " Academy of Management Review, 11, p71-87.

(1989), "Strategic Orientation Of Business Enterprises: The Construct, Dimensionality and Measurement," Management Science, 35 (8), p942-962.

Wamsley, G.L. and M.N.Zald (1973), Political Economy of Public Organizations, Lexington, MA: Heath

Weaver, Pamela A., Esther Chiu and Ken W. McCleary (1991), "Can Choice of Letterhead Affect Your Mail Survey Response Rate," Hospitality and Tourism Educator, 3 (2), p1013.

West, Joseph J. (1988), "Environmental Scanning, Strategy Formulation and their Effect upon Firm Performance," unpublished doctoral dissertation submitted to VPI \& SU, Blacksburg, VA.

Wilemon, David L. (1972), "Power Negotiation Strategies in Marketing Channels," The Southern Journal of Business, 7 (February), p71-72.

Wilkinson, lan F. (1981), "Power, Conflict and Satisfaction in Distribution Channels," Foundations of Marketing Channels, Arch G. Woodside et.al. (eds), Austin, TX: Austin Press, p305-309.

Williamson, Oliver E. (1975), Markets and Hierarchies: Analysis and Antitrust Implications, New York: Free Press. 
(1979), "Transaction Cost Economics: The Governance of Contractual Relations," Journal of Law and Economics, 22 (October), p3-61.

-.---.--, and William G. Ouchi (1981), "The Markets and Hierarchies and Visible Hand Perspectives", in Perspectives in Organization Design and Behavior, ed.by Andrew H. Van De Ven and William F. Joyce, New York: John Wiley and Sons.

(1985), The Economic Institutions of Capitalism: Firms, Markets, Relational Contracting, New York, NY: The Free Press.

Wind, Y. and T.S. Robertson (1983), "Marketing Strategy: New Direction for Theory and Research," Journal of Marketing, 47, (Spring) 12-25.

Zald, Mayer N. (1971), "Political Economy: A Framework for Comparative Analysis," in Power in Organizations, Mayer N. Zald, ed., Nashville, TN: Vanderbilt University Press, p.221261. 
APPENDIX 1

DEFINITIONS OF KEY CONCEPTS IN THE POLITICAL ECONOMY FRAMEWORK

(Stern and Reve 1980, p61-62) 
Political economy - a collectivity comprises of an economic system (economy) and a sociopolitical system (polity) which jointly influence collective behavior and performance.

Internal political economy - the internal structuring and functioning of an organized collectivity (e.g., marketing channel) analyzed in terms of an internal economy and in internal polity and their interactions.

External political economy - the task environment of an organized collectivity (e.g., marketing channel) analyzed in terms of an external economy and an external polity and their interactions.

Internal economy - the internal economic allocation system analyzed in terms of the internal economic structure and processes.

External economy - the economic task environment of an organized collectivity (e.g., marketing channel) described by the nature of its vertical (input and output) and horizontal markets.

External polity - the sociopolitical task environment of an organized collectivity (e.g., marketing channel) described by the distribution and use of power resources among external actors and their prevailing sentiments.

Internal economic structure - the economic arrangements or transactional form within an organized collectivity (e.g., marketing channel) set up to complete internal exchanges.

Internal economic processes - the decision making processes within an organized collectivity (e.g., marketing channel) which determine the terms of trade and the division of labor functions, and activities among the internal actors.

Internal sociopolitical structure - the pattern of power/dependence relations within an organized collectivity (e.g., marketing channel).

Internal sociopolitical processes - the dominant sentiments and behaviors which characterize the interactions between actors within an organized collectivity (e.g., marketing channel).

Transactional form - internal economic arrangements ranging from markets to hierarchies (e.g., vertical integration).

Decision making processes - internal collective choice processes ranging from impersonal determination of terms of trade through the price mechanism, through bargaining processes, to centralized planning processes.

Power/dependence relations - internal power/dependence pattern ranging from minimal power (low dependence), through mixed power constellations of balanced and imbalanced power (mutual dependence), to centralized power (unilateral dependence).

Dominant sentiments and behaviors - internal sentiments and behaviors of cooperation and functional or dysfunctional conflict characterizing internal exchange, ranging from minimal cooperation, high dysfunctional conflict to maximal cooperation, functional conflict. 


\section{APPENDIX II}

INTEGRATIVE REVIEW OF POLITICAL ECONOMY LITERATURE

(adopted from Murray 1987) 


\begin{tabular}{|c|c|c|}
\hline Intellectual foundations & $\begin{array}{l}\text { "Institutional approach" to studying } \\
\text { society } \\
\text { Social system theory } \\
\text { sociology } \\
\text { Political science } \\
\text { Organizational theory }\end{array}$ & $\begin{array}{l}\text { System resource review of } \\
\text { organization } \\
\text { Social theory } \\
\text { Organization theory }\end{array}$ \\
\hline $\begin{array}{l}\text { Level of the conceptual } \\
\text { macrosctructure }\end{array}$ & $\begin{array}{l}\text { Integrative framework: "The framework } \\
\text { of the 'middle range' because it assumes } \\
\text { many of the assertions or concepts of } \\
\text { social-system analysis and the general } \\
\text { theory of action. Instead of dealing with } \\
\text { "universals and completely general } \\
\text { propositions, it attempts to develop } \\
\text { concepts, propositions, and variables } \\
\text { that will order a range of specific } \\
\text { organizational forms and processes" (p. } \\
222 \text { ) }\end{array}$ & $\begin{array}{l}\text { Framework: "The political- } \\
\text { economy perspective is } \\
\text { integrative in the sense that a } \\
\text { number of diverse concerns of } \\
\text { inter-organizational research are } \\
\text { brought together (p. 180). }\end{array}$ \\
\hline $\begin{array}{l}\text { Definition of "Political } \\
\text { Economy" }\end{array}$ & $\begin{array}{l}\text { "The political economy (framework is of } \\
\text { the 'middle range' focuses on the } \\
\text { intersection of the policy structure and } \\
\text { political life of organizations with the } \\
\text { economy and economic life within } \\
\text { organizations: (p. 121). } \\
\text { The overall framework is undergirded by } \\
\text { a very general assumption: "...processes } \\
\text { originating in any of the sectors may } \\
\text { impinge on in some organizational cases } \\
\text { of any of the other sector" (p. 230). }\end{array}$ & $\begin{array}{l}\text { The political economy perspective } \\
\text { proposes a framework for } \\
\text { analyzing inter-organizational } \\
\text { fields. This framework } \\
\text { emphasizes the distinction } \\
\text { between substructure. At the } \\
\text { level of substructure, differentially } \\
\text { powerful organizations interact in } \\
\text { pursuit of the scarce resources of } \\
\text { money (economic structure and } \\
\text { processes) and authority (political } \\
\text { structure and processes). At the } \\
\text { level of superstructure, dominant } \\
\text { sentiments emerge as firms } \\
\text { coordinate their activity. The } \\
\text { substructure (political-economy) } \\
\text { places constraints on the range of } \\
\text { potential variation in the } \\
\text { superstructure. }\end{array}$ \\
\hline Specific concerns utilized & $\begin{array}{l}\text { External policy } \\
\text { Economic environment } \\
\text { Internal policy } \\
\text { Internal economic structure and process }\end{array}$ & $\begin{array}{l}\text { Substructure } \\
\text { Superstructure } \\
\text { Equilibrium } \\
\text { Balance } \\
\text { Network environments }\end{array}$ \\
\hline
\end{tabular}




\begin{tabular}{|c|c|c|}
\hline Definition of concepts & $\begin{array}{l}\text { External policy - Two dimensions: } \\
\text { (1) ...political relations develop } \\
\text { 'horizontally' among organizations have } \\
\text { similar products. Horizontal relations } \\
\text { have two focuses: control of relations } \\
\text { among the similar units price-fixing, } \\
\text { establishing territories and control of } \\
\text { relations between the organizations as a } \\
\text { group and agents in the impinging } \\
\text { environment - government, unions, etc. } \\
\text { (p. 232); 2)...political relations develop } \\
\text { "vertically" among suppliers of } \\
\text { resources, distributors, and buyers of } \\
\text { products (Palamountain 1955). These } \\
\text { include suppliers of labor, raw materials } \\
\text { and facilities and capital. (p. 232). } \\
\text { Economic environment - Vertical } \\
\text { relations: On the input side, } \\
\text { organizations deal with a variety of } \\
\text { specific markets, each with its own } \\
\text { internal differentiation and supply- } \\
\text { demand characteristics. "On the output } \\
\text { side, organizations vary in the number of } \\
\text { products they offer and in the structural } \\
\text { characteristics of product markets" (p. } \\
234 \text { ). } \\
\text { Internal policy - Three aspects: } \\
\text { 1) Internal power structure; } \\
\text { 2) Processes of demand-aggregation and } \\
\text { conflict-resolution; } \\
\text { 3) Succession systems and processes. } \\
\text { Internal economic structure and process } \\
\text { - Three aspects: 1) The division of } \\
\text { labor, technologies, and under-unit } \\
\text { exchanges; 2) Resource allocation and } \\
\text { efficiency; } \\
3 \text { ) Incentive economics and their } \\
\text { consequences }\end{array}$ & $\begin{array}{l}\text { Substructure - The political } \\
\text { economy. } \\
\text { Superstructure - Dominant } \\
\text { sentiments: "Our analytical } \\
\text { dimensions were specified at this } \\
\text { level: 1) Domain consensus; } 2 \text { ) } \\
\text { Ideological consensus; } 3 \text { ) } \\
\text { Judgments between organizations } \\
\text { of the quality of work of each; } 4 \text { ) } \\
\text { Work coordinetion (p. 147). } \\
\text { Eguilibrium -- "An } \\
\text { inter-organizational rework is } \\
\text { equilibrated to the extent that } \\
\text { participant organizations are } \\
\text { engaged in highly coordinated } \\
\text { interactions based on normative } \\
\text { consensus and mutual respect." } \\
\text { (p. 135). } \\
\text { Balance - the relationship } \\
\text { between the four structural } \\
\text { dimensions. } \\
\text { Network environments - The } \\
\text { social context within which } \\
\text { network relations are negotiated. } \\
\text { Important dimensions of the } \\
\text { structured environment: 1) } \\
\text { Resource } \\
\text { concentration/dispersion; } \\
\text { 2) Power concentration/ } \\
\text { dispersion; } 3 \text { ) Network } \\
\text { autonomy/dependence; } \\
\text { 4) Resource abundance/ } \\
\text { scarcity; 5) Control mechanisms; } \\
\text { incentive versus authoritative. }\end{array}$ \\
\hline $\begin{array}{l}\text { Substantive domain of } \\
\text { application }\end{array}$ & Public and private organizations & $\begin{array}{l}\text { Human service agencies: } \\
\text { "Nevertheless, the focus on } \\
\text { resources should provide a basis } \\
\text { on which future extensions of the } \\
\text { scheme will be accomplished." (p. } \\
230 \text { ) }\end{array}$ \\
\hline
\end{tabular}


Theoretical bivariate relationships suggested in specific illustrative propositions
This approach postulates that economic and political forces, structures, pressures, and constraints:

1) Are among the most significant motivators of change;

2) Are the key factors shaping directions of change (p. 155-256).

Note: In the context of a research question, Bald states: "...the political economy approach can be used in describing enduring structural conflicts and their resolutions (p. 236).
The hypothesis of balance: It is argued that increases in the superstructural dimension tend to be associated with increases in the others. Similarly, decreases in one dimension tend to be associated with decreases in the others (p. 236). Superstructural dimensions may become balanced at varying structural levels. The political-economic base hypothesis: Sub-structural events place restrictive limits upon the potential range of variation of the equilibrium components (dimensions) (p. 236).
Were theoretical relationships empirically tested
No: "The political economy framework can be used to generate specific predictions...no claim is made, however, that this framework has reached an advanced state of development (p. 357).
No. 


\begin{tabular}{|c|c|c|}
\hline Intellectual foundations & $\begin{array}{l}\text { Organization theory } \\
\text { Public administration theory } \\
\text { Marketing theory } \\
\text { Sociology } \\
\text { Transaction cost analysis } \\
\text { Political science }\end{array}$ & $\begin{array}{l}\text { Social exchange theory } \\
\text { The behavioral theory of the firm } \\
\text { Transaction cost economics }\end{array}$ \\
\hline $\begin{array}{l}\text { Level of the conceptual } \\
\text { macrostructure }\end{array}$ & $\begin{array}{l}\text { Integrative framework: The political } \\
\text { economy perspective as an organizing } \\
\text { framework enables the generation of } \\
\text { significant research questions and, } \\
\text { therefore, has the potential for producing } \\
\text { new theoretical insights." (p. 53). }\end{array}$ & $\begin{array}{l}\text { Paradigm: paradigms are viewed } \\
\text { here as the foundations of } \\
\text { theory. They give theory } \\
\text { building in a field direction and } \\
\text { meaning. }\end{array}$ \\
\hline $\begin{array}{l}\text { Definition of "Political } \\
\text { Economy" }\end{array}$ & $\begin{array}{l}\text { "The political economy approach views a } \\
\text { social system as comprising and } \\
\text { sociopolitical forces which affect } \\
\text { collective behavior and performance" (p. } \\
\text { 53). }\end{array}$ & $\begin{array}{l}\text { This article builds on what may } \\
\text { be called the "organizational } \\
\text { approach to political economy" } \\
\text { ( } p .47 \text { ). This approach views } \\
\text { social systems...as "comprising } \\
\text { interacting sets of major } \\
\text { economic and socio-political } \\
\text { forces which affect collective } \\
\text { behavior and performance (Stern } \\
\text { and Reve 1980, p. 53). (p. 47). }\end{array}$ \\
\hline Specific concepts utilized & $\begin{array}{l}\text { Internal economic structure } \\
\text { Internal economic processes } \\
\text { Internal socio-political structure } \\
\text { Internal socio-political processes } \\
\text { External policy }\end{array}$ & $\begin{array}{l}\text { The environment } \\
\text { External political relations } \\
\text { External economic relations } \\
\text { Internal polity } \\
\text { Internal economy }\end{array}$ \\
\hline
\end{tabular}


Definition of concepts
Internal economic structure - The transactional form within an organized collectively set up to complete internal exchanges.

Internal economic processes - The decision making processes which determine the terms of trade, functions and activities among the internal actors. Internal socio-political structure - The pattern of dependence relations within an organized collectivity.

Internal socio-political processes - "The dominant sentiments and behaviors which characterize the interactions between actors within an organized collectivity" (p. 62).

External economics - "The economic task environment of an organized collectivity described by the nature of its vertical (input and output) and horizontal markets" (p. 62).

External policy - "The socio-political task environment of an organized collectivity described by the distribution and use of power resources among external actors and their prevailing sentiments" (p. 62).
The Environment - Political and economic organizations which are external to the unit of analysis. "The following five dimensions presented below are common to many attempts to develop inventories of environmental dimentsion:" (p. 49).

1) proximity to the focal unit 2) capacity (availabiality of resources)

3) differentiation (heterogeniency of complexity)

4) concentration or dispersion 5) turbulence (rate of change) "... a superordinance dimension in environmental uncertainty or predictability, which is a function of dimensions (2) to (5) above" (p. 49).

External political relations Involves organizational efficiency that is "...the normal use of the transactional arrangements or the decision-making modes" 9p. 49).

Internal polity - Refers to the power system of the social unit. "...the way authority is distributed, mobilized, utilized, and limited" (p. 50).

Internal economy - Refers to the coordination of behavior and the allocation of resources to produce an output of "sufficient interest for external cexchange partners: (p. 50).

General application: micromarket as well as macromarketing contexts. 
Theoretical bivariate relationships suggested in specific illustrative propositions.
P1: Centralized planning processes are related to channel efficiency and effectiveness.

P2: Centralized planing proceesses are related negatively to quick reaction to external threats.

P3: "Market transactions in olizopsonistic situations are likely to lead to information imbalances, opportunistic behavior, and high transaction costs" (p.56).

P4: As power becomes increasingly balanced, both cooperation, and the potential for conflict will tend to increase.

P5: The use of coerecive power will produce a dysfunctional level conflict.

P6: The use of coercive power willproduce instability, resulting in decreased competitive viability.

P7: Minimal power will lead to low levels of cooperation.

P8: When power is centralized and market transactions predominate, centralized planning processes will emerge.

P9: Under the conditions specified by $P 9$, both conflict and cooperation will be high. Such channels will tend to be more competitively effective.

P10: A channel characterized by hierarchial transactions and centralized power will effectively mediate conflict, produce superordinate goals, and will be more likely to achieve efficiency.

P1 1: Cooperation is positively related to efficiency.

P12: Individual power is positively related to individual profits.
No specific propositions were stated. However, the following statement was made in the context of formulations: "A common pattern is that the internal polity is affected by its relation to the external polity (and to some extent to the relations to the external economh)" (p. 50). 
Were theretical relationships specifically tested?
No.

No.
No..." to get from such a general recognition of the external control of organizations to a theoretically meaningful and

operational framework is a vast navigational task in still mostly uncharted waters. (p.48). 


\begin{tabular}{lll}
\hline Intellectual foundations & $\begin{array}{l}\text { Organization theory } \\
\text { Marketing theory } \\
\text { Sociology }\end{array}$ & $\begin{array}{l}\text { Orgniazational theory } \\
\text { Sociology } \\
\text { Marketing theory }\end{array}$ \\
\hline $\begin{array}{l}\text { Level of the conceptual } \\
\text { macrostructure }\end{array}$ & $\begin{array}{l}\text { Integrative framework: "As such a } \\
\text { framework makes no pretension of being } \\
\text { a theory. Rather, its prpose is to help } \\
\text { position individual researchers so that } \\
\text { they can proceed in a systematic and } \\
\text { methodical fashion toward the } \\
\text { emergence of a dominant theoretical } \\
\text { pradigm" (p. 56). }\end{array}$ & $\begin{array}{l}\text { Framework: A "road map" } \\
\text { designed to facilitate the } \\
\text { comparative analysis of } \\
\text { productive exchange systems. }\end{array}$ \\
& $\begin{array}{l}\text { "The political economy approach views a } \\
\text { social ystem as cmprising interacting } \\
\text { sets or major economic and sociopolitical } \\
\text { forces which affect collective behavior } \\
\text { and performance" (Stern and Reve } \\
\text { 1980). (p.58). }\end{array}$ & $\begin{array}{l}\text { A system characterized by } \\
\text { interdependence among four } \\
\text { basic elements: the external } \\
\text { polity, external economy, internal } \\
\text { polity, and internal economy. }\end{array}$ \\
\hline $\begin{array}{l}\text { Definition of "Political } \\
\text { Economy" }\end{array}$ & $\begin{array}{l}\text { Focal dvad } \\
\text { Macro environment } \\
\text { Primary task environment } \\
\text { Secondary task environment }\end{array}$ & $\begin{array}{l}\text { Environmental characteristics } \\
\text { Channel configuration }\end{array}$ \\
& & $\begin{array}{l}\text { Internal political structure and } \\
\text { process. }\end{array}$ \\
\hline Specified concepts utilized & &
\end{tabular}


Focal dvad - And two-year exchange relationship under investigation. "Wherever direct, goal-oriented social interaction occurs between actors in a channel, a channel dvad exists" (p. 48). Macro environment - Composed of social, economic, political, and technological forces which interact with activities in the primary and secondary environments.

Primary and secondary task environments - The suppliers and customers of the dvad. The ladder is comprised of suppliers to the immediate suppliers, customers to the immediate customers, regulatory agents, and competitors. These environments are divided into four sectors:

1) Input: suppliers to the dvad.

2) Output: customers of the dvad.

3) Competitive - actual and potential horizontal competitors of the dvad.

4) Regulatory - public agencies who directly or potentially effect the political economic structure or processes of the dvad.

The secondary task environment is best characterized by five qualitative dimensions:

1) Environmental capacity.

2) Environmental homogeneity heterogeneity

3) Environmental stability instability

4) Environmental concentration instability

5) Environmental turbulence
Environmental characteristics "Decision makers typically focus on either (1) a source of information or (2) a stock of resources. This classification of environmental impact reflects the two fundamental problems the environment poses for decision makers: uncertainty and dependence" (p. 199).

"...we consider only one environmental attribute representing uncertainty, the degree of heterogeneity in the task environment (p. 199).

"... we consider oniy one dimension of dependence, the variability of the channel output environment: (p.199).

Channel configuration - Channel structure as defined by the division of labor. Cannel configur-ation reflects environmental conditions (contingency apporach) and acts as a filtering mechanism for environ-mental information.

Internal political structure and process - This is defined as the decision influence patterns of the unit of analysis. The decision structure of a channel has 4 primary dimensions:

1) centralization (concentration of decision making

2) participation (degree of in decision making

3) formalization (the extent to which decision making is regulated)

Decision influence patterns represent the relative control of channel members over marketing decisions. 
4) specialization (the amount of task differentiation)

Decision influence patterns

represent the relative control of channel members over marketing decisions. 
Theoretical bivariate relationships suggested in specific illustrated propositions
$P_{1}:$ There is a positive relation ship between vertical uncertainty (inpust-output) and conflict.

$P_{2}$ :There is a positive relationship between vertical uncertainty and efforts to vertically coordinate.

$P_{3}$ : The direction of change in the power belance is determined by which member is able to absorb uncertainty. The direction of change in power also deternines the direction of centrarlization of planning, coordination, and decision process.

$P_{4}$ : Vertical uncertainty may lead to backward or forward integration.

$P_{b}$ : As vertical undertainty, and therefore conflict increases, the dvad is likely to move to a "looser" relationship.

$P_{B}$ : There is a positive relation. ship between uncertainty in competitive sector and cooperation.

$P_{7}$ : If uncertainty from the competition sector cannot be absorbed by verticul coordination, closer linkages are established with competitors.

$P_{B}$ : "The more certain the regulatory environment, the more cooperative, coordinated and integrated dvad behavior becomes in response to regulatory demands" (p. 65).

$P_{0}$ : Under regulatory uncertainty, channel dvads tend to enter into interest coalitions with actors in the input, output, and com petitive sectors.

$P_{10}$ : If regulatory uncertainty cannot be absorbed by coalition behavior, closer linkeges will be established with the regulatory agents.
"Were theoretical relotionships empirically tested.
No: "In this article, the original framework is extended to account for the impact of environmental forces on dvadic structure and processes. To date, the letter topic has largely been ignored, especially in empiricel studies" (p. 65).
"At its most general level, the proposed model suggesis that environmental differences will be associated with differences in the internal politics of marketing channels: (p. 100).

Specific propositions:

$H_{1}$ : "Compared with
homogeneous channel
environments will be
associated with: (1)
complex channel
configuration; (b)
decentralized decision
structures; (c) high
participation in
decision making: (d)
less formalization in
procedures; (e)
specialization of
function; (f) more
retailer control over
marketing decisions:
(p. 401 ).
$H_{2}:$ "Compared with
steadfast channel
environments will be
associated with: (a)
less complex channel
configurations; (b)
centralized decision
making: (d) formalized
procedures; (e) less
specializetion in
function; (f) less
retailer control over
marketing decisions"
(p. 401 ).
(p. 401).

\footnotetext{
Yes. "Given the primal status of research under the proposed paradigm, ultiveriate stalistical support for the three of 12 specilic hypotheses - and localized support for three more. should be greeted with sanguinity" (p. 409 ).
} 
APPENDIX III

INTEGRATIVE REVIEW OF POWER IN MARKETING CHANNEL LITERATURE 


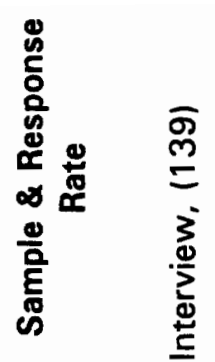
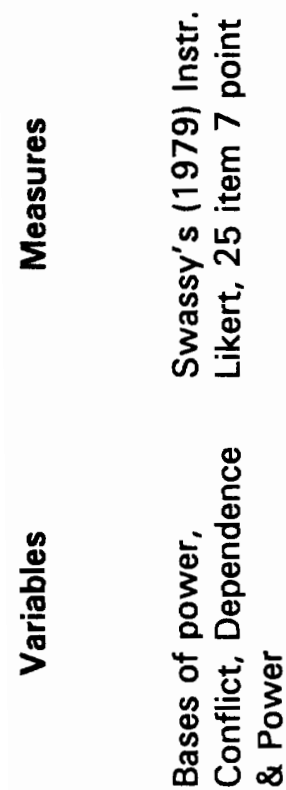

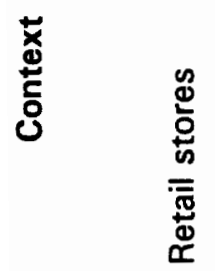

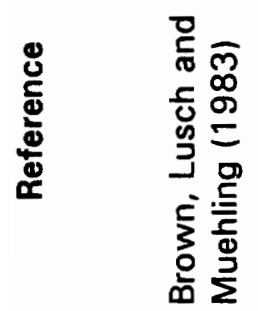

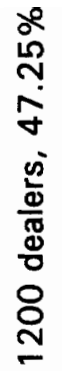

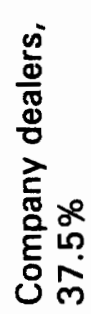

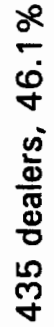

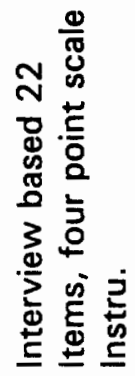

กั.

: ․ㅡㅁ

范范

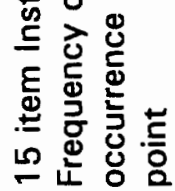

$\infty$

芯

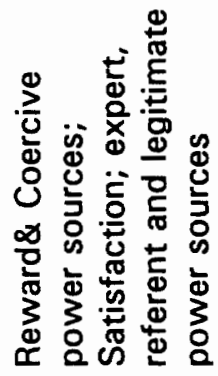

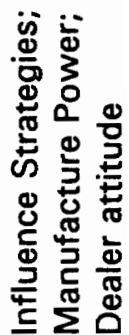

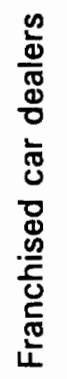

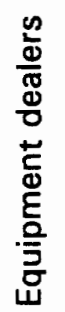

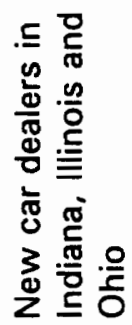

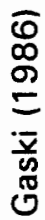

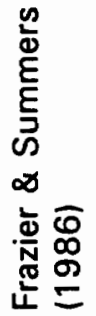



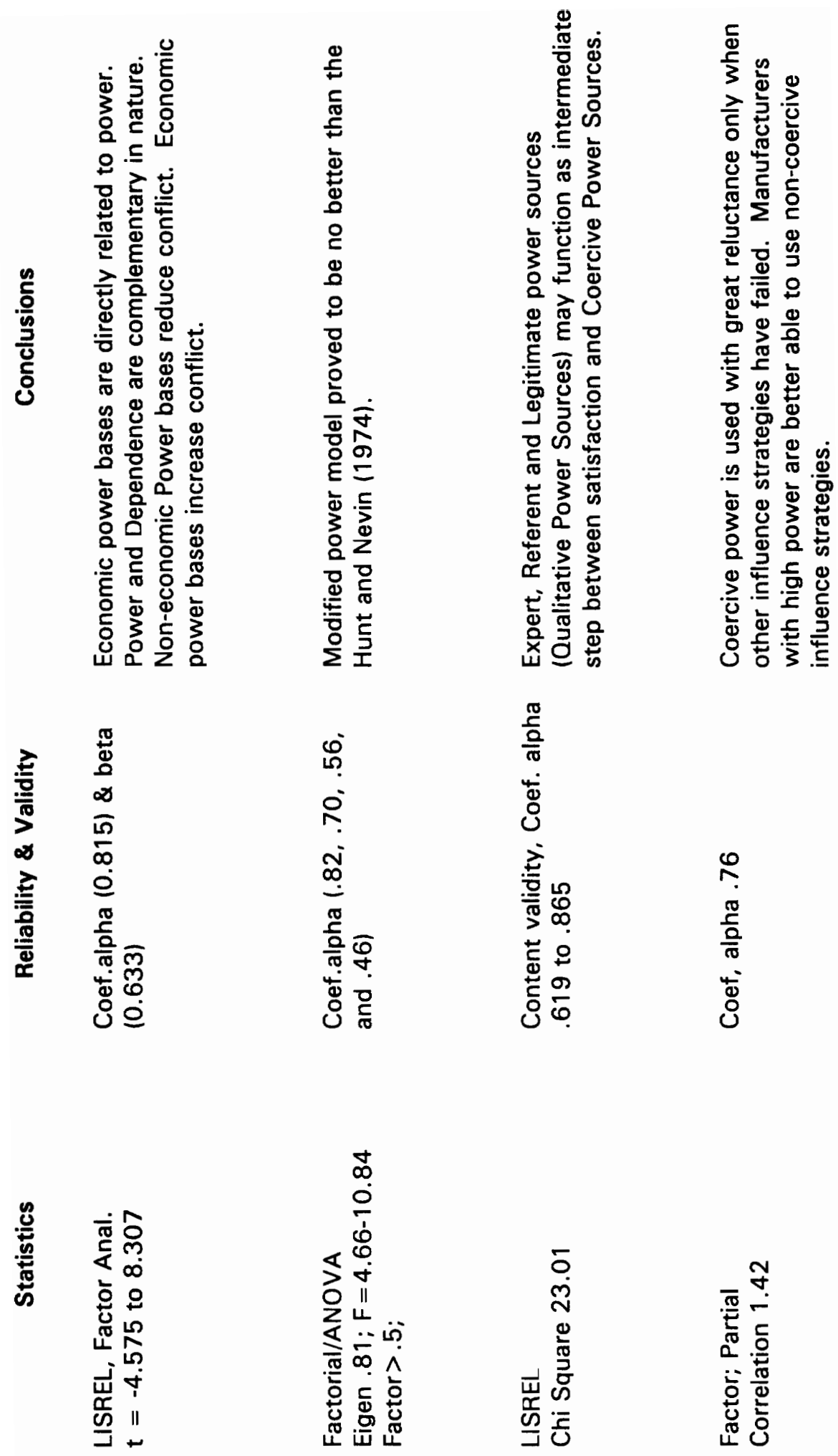

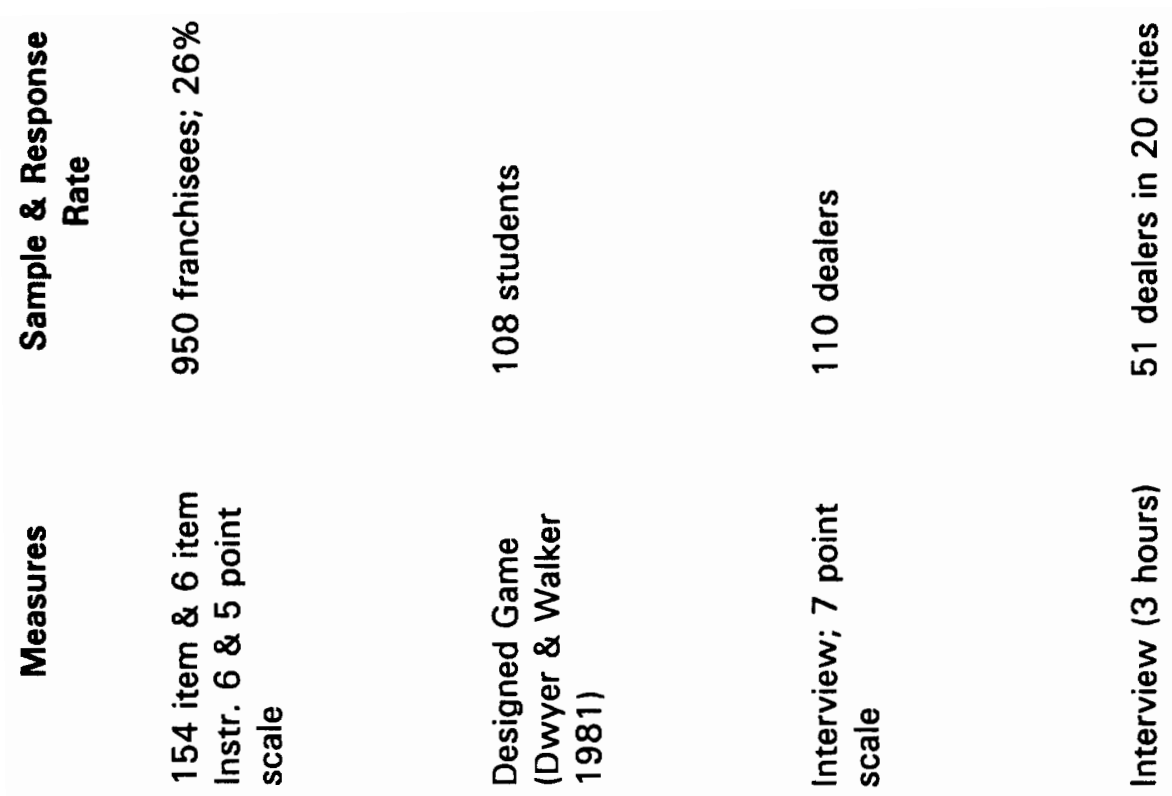

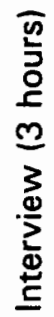
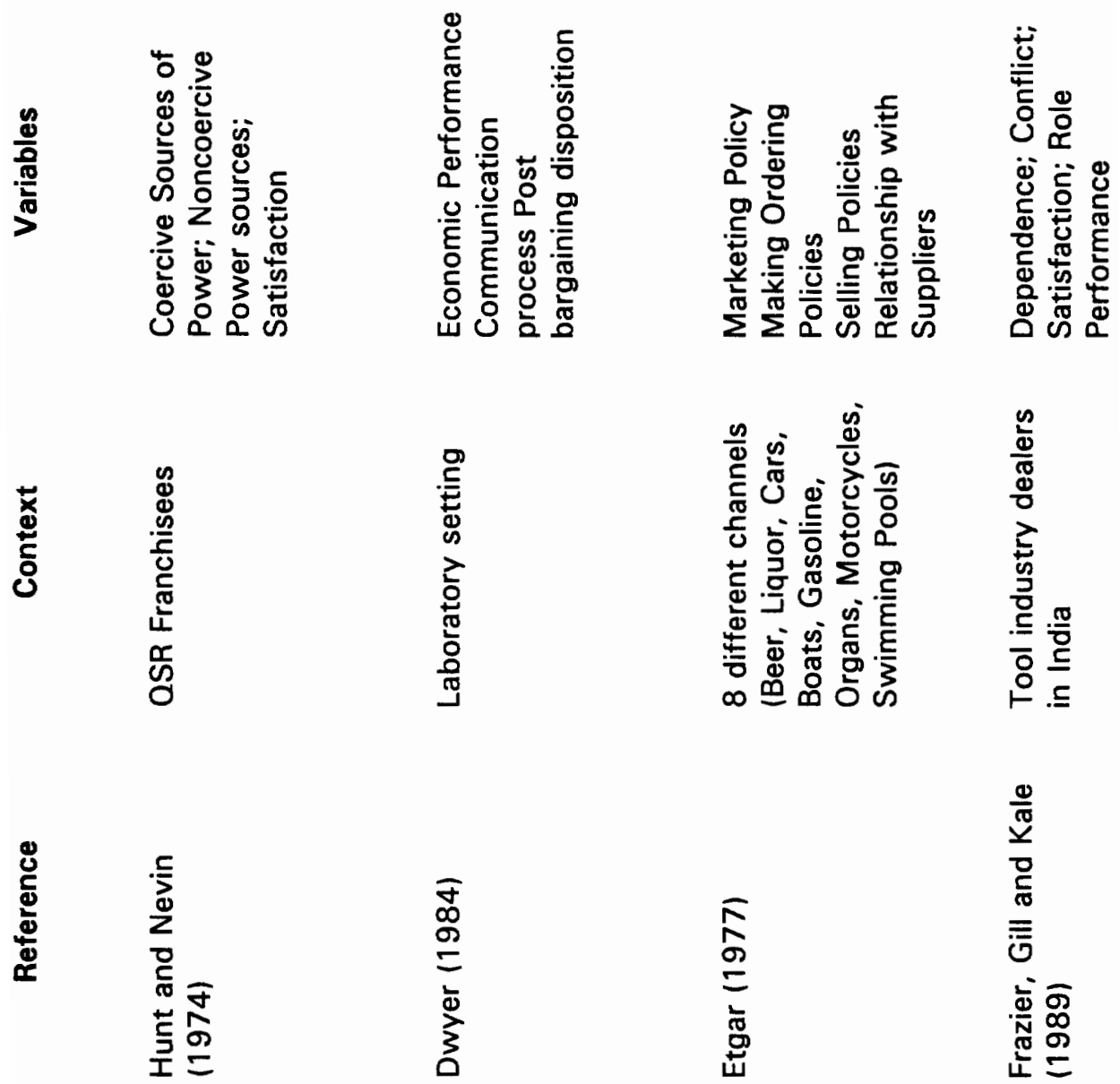

す
0
$=$
$\vdots$
$\vdots$
$\vdots$

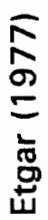

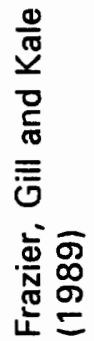



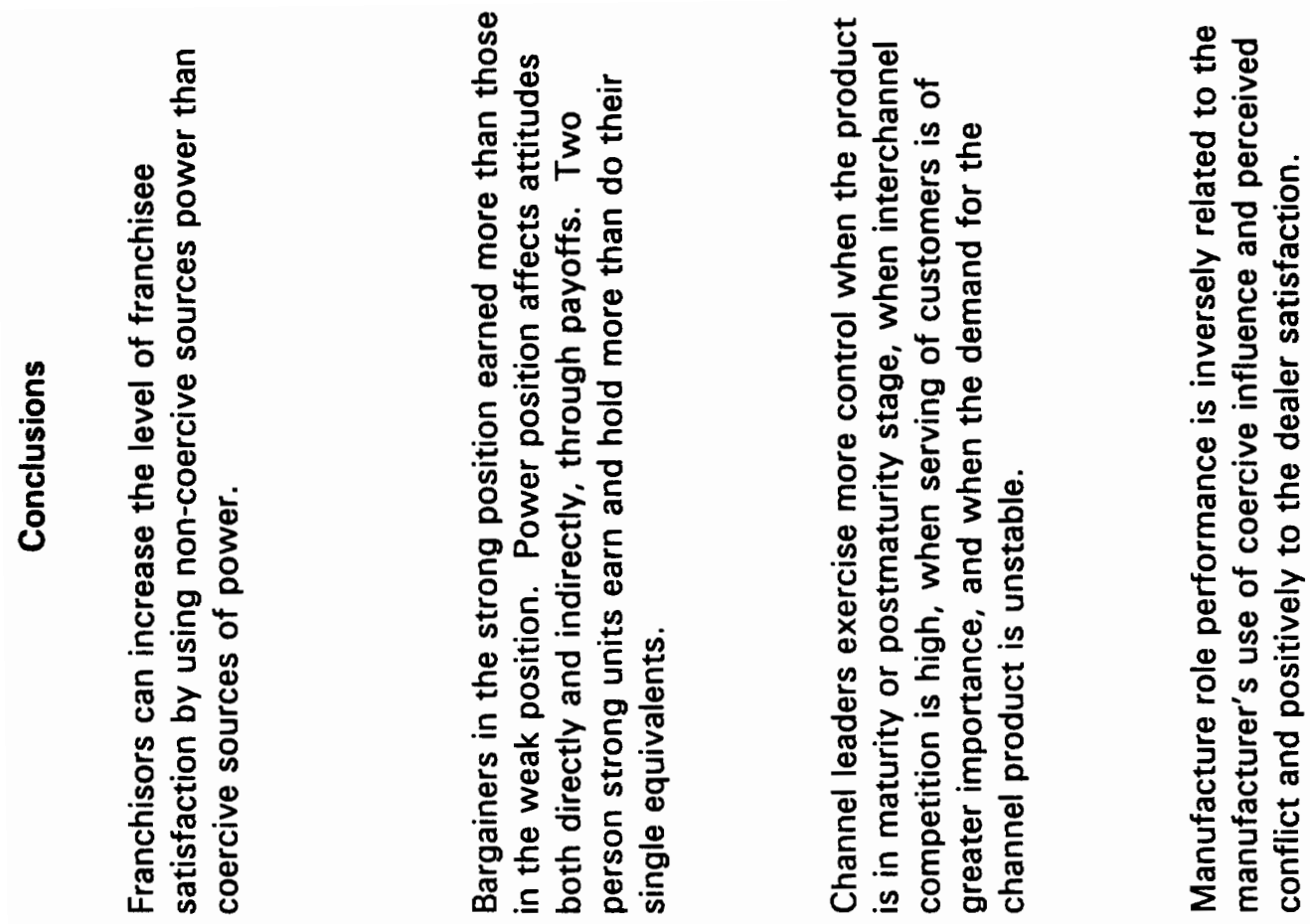

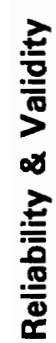

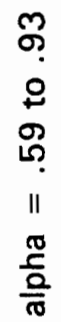
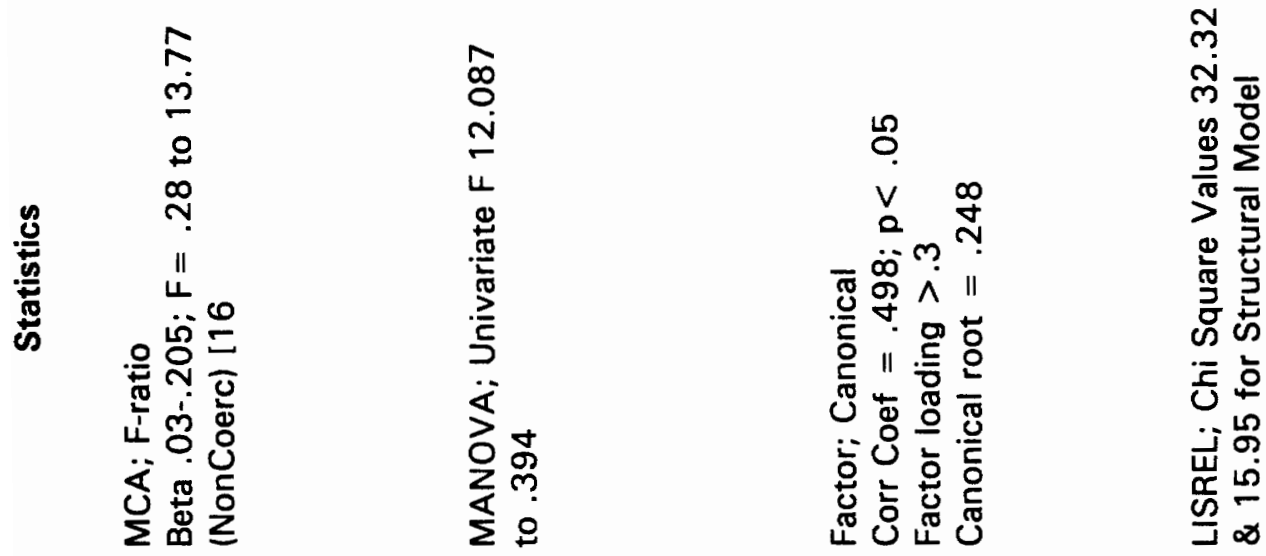

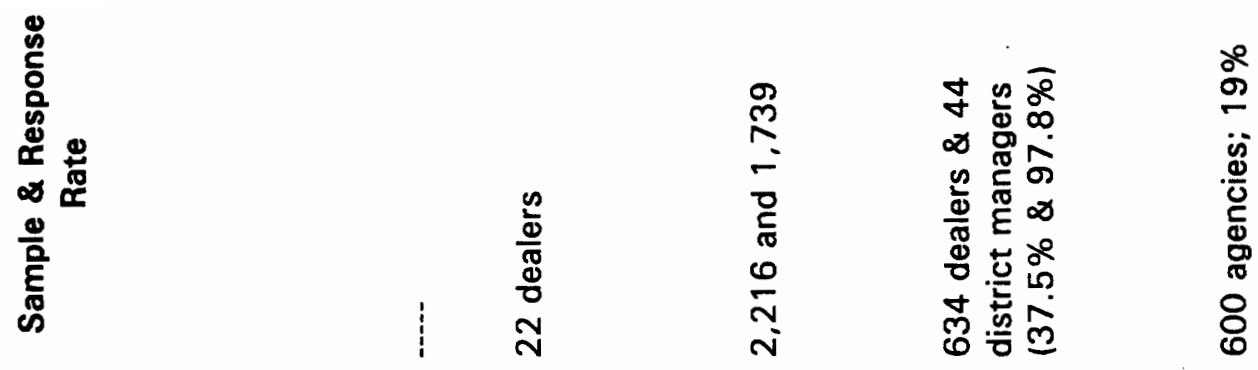

$y$
5
5
0
0

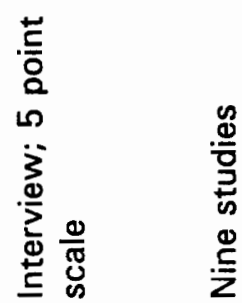

号 焉

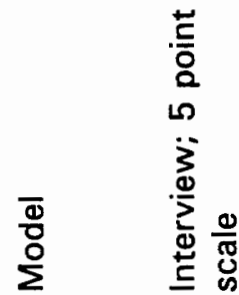

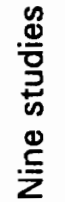

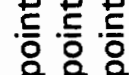

ת

Ё

느는

E.

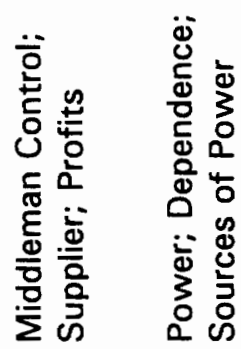

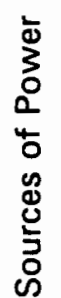

¿

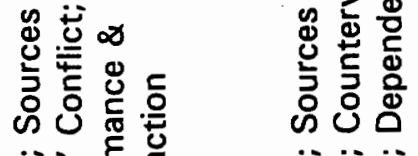

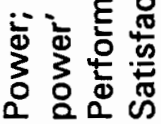

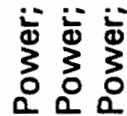

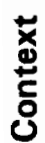
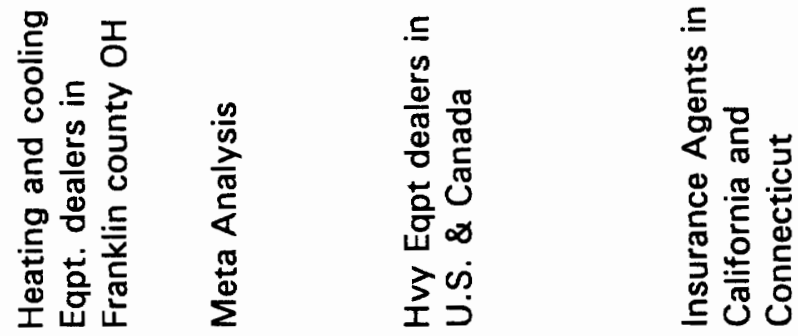

怘

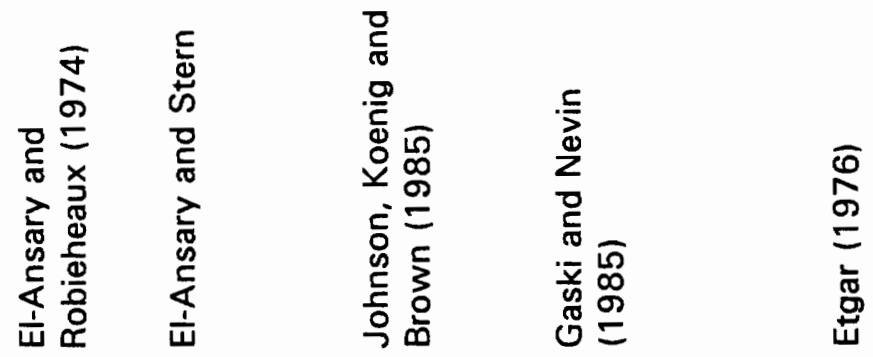



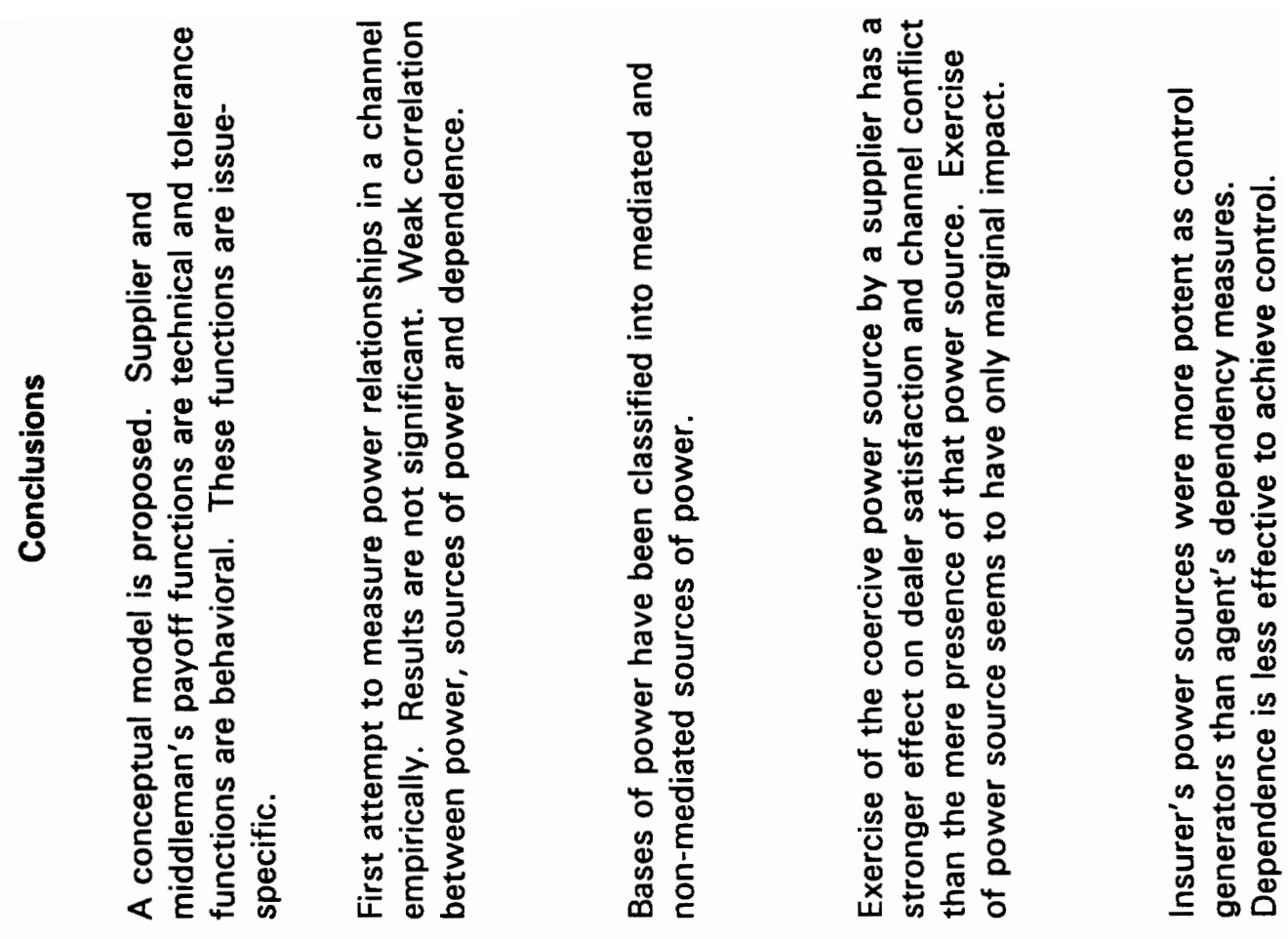

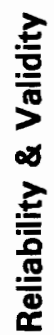

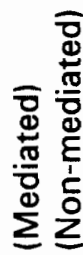

मू

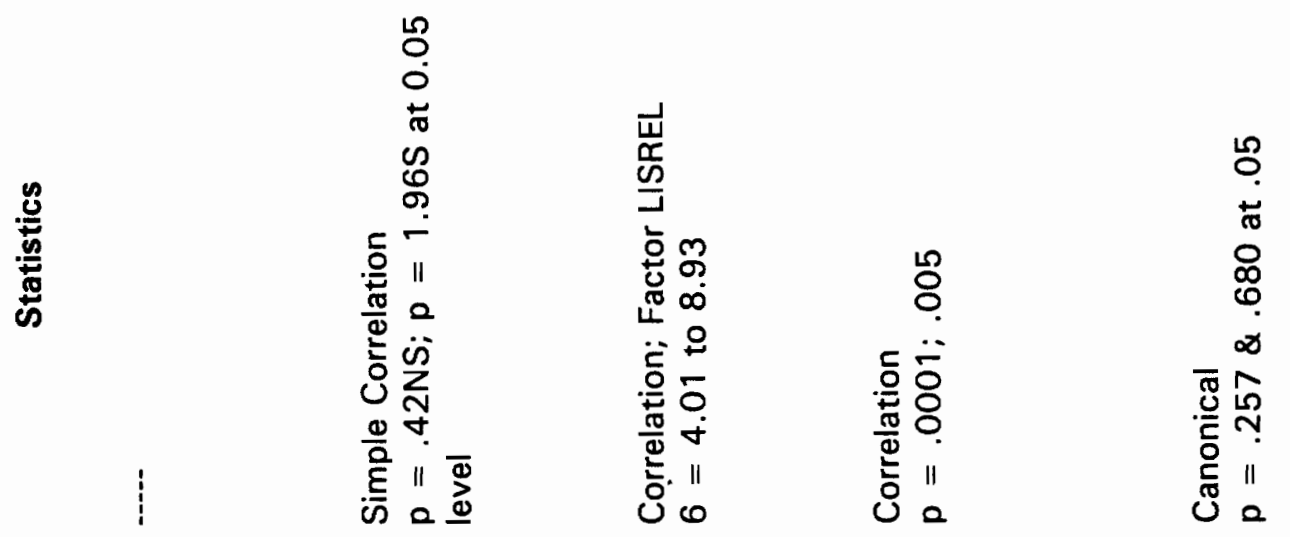




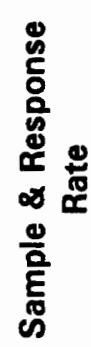

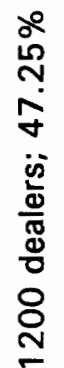

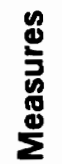

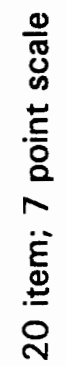

to

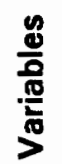

\$

ผ

苍

J્ّ

$\frac{2}{0}$
$\frac{0}{10}$
$\frac{8}{0}$
0
$\frac{0}{3}$
4

:

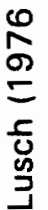




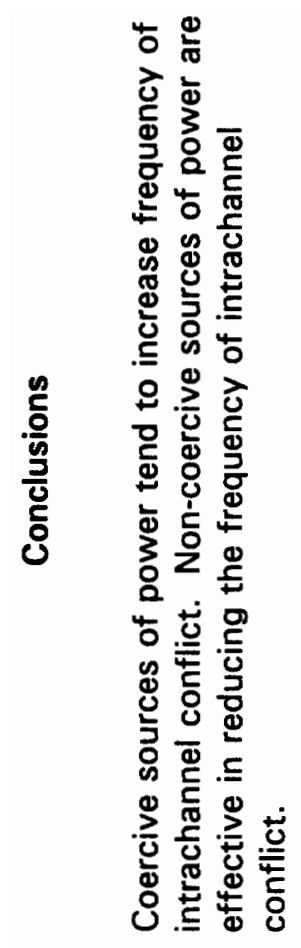

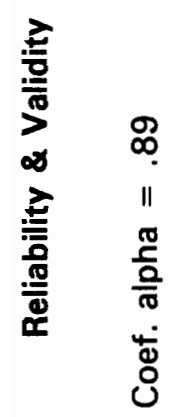

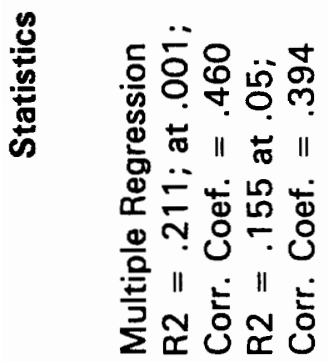


APPENDIX IV

LIST OF THEORETICAL PROPOSITIONS (RESEARCH) 


\section{Appendix - IV}

\section{PROPOSITIONS}

P1. In QSR franchise systems, during the maturity stage of industry life cycle, franchisees experience use of economic and noneconomic power sources by the franchisors, and consequent change in their satisfaction levels.

P2: In QSR franchise systems, during the maturity stage of industry life cycle, the nature of power sources held by the franchisors affects a franchisees' business performance.

P3: In OSR franchise systems, a firm's performance is contingent upon the type of implementation model it selects.

P4 In OSR franchise systems, the nature of firm performance can be better understood by determining the impact of organization power on the strategy implementation process. 
APPENDIX V

LIST OF HYPOTHESES 


\section{APPENDIX V \\ LIST OF HYPOTHESES}

H1: In QSR franchise systems, franchisees experience low level of satisfaction when they perceive their franchisor to possess high level of economic sources of power.

H2: In OSR franchise systems, franchisees experience high level of satisfaction when they perceive their franchisors to possess high level of noneconomic sources of power.

H3: In QSR franchise systems, franchisees' performance is positively related to their perception of noneconomic sources of power possessed by their franchisors.

H4: In QSR franchise systems, franchisees' performance is negatively related to their perception of economic sources of power possessed by their franchisors.

H5: In OSR franchise systems, there is no difference in the performance level of franchisees classified according to the type of implementation model.

H6: In OSR franchise systems, there is no difference in the satisfaction level of franchisees classified according to the type of implementation selected. 
H7: In OSR franchise systems, high performance franchisees are different from low performers when grouped according to the level of congruence between economic sources of power and the type of implementation process.

H8: In QSR franchise systems, franchisees with high level of satisfaction are different from those with low level of satisfaction when grouped according to the level $f$ congruence between economic sources of power and the type of implementation process.

H9: In QSR franchise systems, franchisees with high level of satisfaction are different from those with low level of satisfaction when grouped according to the level of congruence between noneconomic sources of power and the type of implementation process.

H10: In OSR franchise systems, high performance franchisees are different from those with low level of performance when grouped according to the level of congruence between noneconomic sources of power and the type of implementation process. 
APPENDIX VI

LIST OF PARTICIPATING OSR FRANCHISES 
APPENDIX VI

\section{LIST OF PARTICIPATING OSR FRANCHISES}

* $\quad$ Chuck-E-Cheese

* Domino's

* Hardees

* Little Caesar's Pizza

Sizzlers

Subway 
APPENDIX VII

COVER LETTER 
$1 \sim 2 \sim$

$3 \sim$

Dear 4 :

I am a faculty member in Hospitality Management at State University of New York, College at Buffalo, New York. Prior to joining the university, I worked in the Quick Service Restaurant industry over 13 years as a Multiunit Manager. I am currently working towards my $\mathrm{Ph} . \mathrm{D}$. Your response is extremely important in completing my degree program.

Francishees are the backbone of the restaurant industry. High franchise satisfaction and financial health are essential for long term survival of the industry. Effective conflict resolution leads to successful franchise operations. Hence, we Undertook this research to explore the impact of franchise relations on franchisee satisfaction and financial performance.

We assure you that all the collected data will be kept in strictest confidence. Results will be reported ONLY in the form of combined summaries and no information will be available on individuals. In gratitude for your cooperation, we will be happy to share the results with you. Please include your business card or the current address.

If you need more information, please do not hesitate to call us: H.G. Parsa (716) 8785913 and Prof. Khan at (703) 231-5515.

We look forward to receiving your response in the next TWO weeks. A postage paid envelope is enclosed for your convenience. Thank you in advance for your time and cooperation.

Sincerely,

H.G. Parsa

Assistant Professor

Food Systems Management

103 Caudell Hall

(716) $878-5913 / 5714$
Dr. Mahmood A. Khan

Prof. \& Head of Dept.

Dept. of Hotel, Restaurant

Institutional Management

Virginia Tech

Blacksburg, VA 24061

(703) 231-5515 
APPENDIX VIII

SURVEY INSTRUMENT 


\section{TO BE COMPLETED BY THE OWNER/GENERAL MANAGER OF THE UNIT}

\section{PART I -}

\section{DEMOGRAPHIC INFORMATION}

1. Please indicate the ONE category that best describes the LOCATION of your restaurant. (Check ONLY one category).
TOURIST RESORT
$\square$ DOWNTOWN
SUBURBAN
$\square$ SHOPPING CENTER
D RURAL
$\square$ HIGHWAY

2. Please indicate the ONE category that best describes your FRANCHISE CONTRACT arrangement. (Check ONLY one category).
SINGLE UNIT
MULTIUNIT
REGIONAL

PART II BEHAVIORAL PERCEPTIONS

This section relates to your OPINIONS and PERCEPTIONS of franchisor - franchisee relations with YOUR FRANCHISOR. Please circle the number that best describes your opinions and perceptions.

\begin{tabular}{|c|c|c|c|c|c|c|c|}
\hline & & $\begin{array}{l}\text { STRONGLY } \\
\text { AGREE }\end{array}$ & & & & & $\begin{array}{l}\text { STRONGLY } \\
\text { DISAGREE }\end{array}$ \\
\hline 3. & $\begin{array}{c}\text { The franchise agreement greatly } \\
\text { favors the franchisor. }\end{array}$ & 1 & 2 & 3 & 4 & 5 & 0 \\
\hline 4. & $\begin{array}{l}\text { Federal govemment should } \\
\text { restrict franchisors' right to } \\
\text { terminate franchise contracts. }\end{array}$ & 1 & 2 & 3 & 4 & 5 & 0 \\
\hline 5. & $\begin{array}{l}\text { The Franchisor has too much } \\
\text { control over resale of } \\
\text { the franchise units. }\end{array}$ & 1 & 2 & 3 & 4 & 5 & 6 \\
\hline 0. & $\begin{array}{l}\text { I like the franchise representative } \\
\text { I deal with. }\end{array}$ & 1 & 2 & 3 & 4 & 5 & 6 \\
\hline 7 & $\begin{array}{l}\text { I couldn't care less what the } \\
\text { franchisor thinks of me. }\end{array}$ & 1 & 2 & 3 & 4 & 5 & 0 \\
\hline 8. & $\begin{array}{l}\text { The approval of the franchisor } \\
\text { people means a lot to me. }\end{array}$ & 1 & 2 & 3 & 4 & 5 & 0 \\
\hline
\end{tabular}


9. ladmire my tranchisor and act to ment their respect.

10. I consider my franchisor an ideal company to be affilioted with.

11. The franchisor has a right to my cooperation.

12. The franchisor should stay out of my business.

13. The franchisor has the right to tell me what to do

14. The franchisor has the right to expect franchisees to follow instructions.

$\begin{array}{ll}\text { VERY } & \text { VERY } \\ \text { GOOD } & \text { POOR }\end{array}$

15. The quality of the TOTAL MARKETING $\quad 1 \quad 2 \quad \begin{array}{llllll}3 & 4 & 5 & 6\end{array}$ support provided by the franchisor is . .

16. The quality of the IRAINING support $\quad 1 \quad 2 \quad \begin{array}{llllll} & 3 & 4 & 5 & 6\end{array}$ provided by the fronchisor is ...

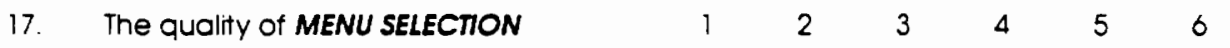
provided by the franchisor is...

18. The quality of the LOCAL MARKETING $\quad 1 \quad 2 \quad 3 \quad 4 \quad 5 \quad 6$ provided by the franchisor is . .

19. The quality of the FIELD SUPERVISION provided by the tranchisor is . .

20. My restaurant building is owned or controlled by the franchisor.

21. My franchisor has threatened to terminate the franchise contract

\section{PART III IMPLEMENTATION PROCESS}

This section refers to your METHODS FOR IMPLEMENTING chosen strategies. Please CHECK THE ONE category that BEST DESCRIBES YOu. All types are considered equally effective.

๑ 1 I have access to more information than anyone else in the restaurant; hold greater authority than any one else: make a majority of the decisions: has the final word in all decistons.

2. I believe in a systematic and methodical approach: possess good people skills: lead by example: believe in planning: emphasize meeting budget goals: profits are just as important as development of subordinates. 
1 often conduct "brainstorm" sessions: always emphasze team work and commitment: clearly explain organizational of goals to all participants: believe that all critical decisions should be made by the top management.

4. I let subordinates develop their own long-term plans: encourage long-term employment for all subordinates: encourage openess: upholding company traditions and customs is the major part of my job

I am willing to share or give up a significant part of responsibilities and controls would rather guide than lead: depend greatly on subordinates for ldeas strategies. execution, and results: occasional failures by subordinates are expected. tolerated, and not penolized.

\section{PART IV} FIRM PERFORMANCE

Finally, we REQUEST that you provide us some information on the operating results of your UNIT. You have our assurance that this information will be held in the strictest confidence. Please check the most appropriate number for the calendar year (January-December 1991).

1. Please check ONE of the following categories which best describes your TOTAL ANNUAL SALES PER UNIT for 1991. (Unit = a restaurant)

\section{$\square$ Less than $\$ 249$ thousand \\ $\square \$ 250$ to $\$ 499$ thousand \\ $\square \$ 500$ TO $\$ 749$ thousand \\ $\square \$ 750$ to $\$ 999$ thousand}

$\square \$ 1.00$ to $\$ 1.24$ million

$\square \$ 1.25$ to $\$ 1.49$ million

$\square \$ 1.50$ to $\$ 1.74$ million

$\square$ more than $\$ 1.75$ million

Please indicote your average Food Cost Percentage at this unit

Please indicate your average Labor Cost Percentage at this unit

Please indicate the PERCENTAGE of SALES change over last year

$\square$ DOWN by
$\square$
$\square$
$\square$
$\square$
$\square$
$\square$
$\square$
$\square$

\footnotetext{
$0 \% 10-1.9 \%$

$-2.0 \%$ to $-3.9 \%$

$-4.0 \% 10 \cdot 5.9 \%$

$-6.0 \%$ to $-7.9 \%$

$-8.0 \%$ to $-9.9 \%$

$-10.0 \%$ to $-11.9 \%$

$-12.0 \%$ 10 $-13.9 \%$

$-14.0 \%$ to $-15.9 \%$

Greater than $-16 \%$
}
$\square$

( IBFC = Gross Margin - Operating Expenses/Net Sales )

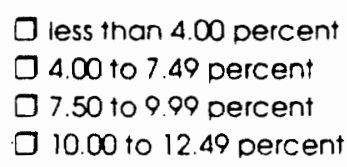

$\checkmark 12.50$ to 14.99 percent

[ 15.00 to 17.49 percent

D 17.50 to 19.99 percent

$\square$ more than 20.0 percent 


$\begin{array}{lr}\text { STRONGLY } & \text { STRONGLY } \\ \text { AGREE } & \text { DISAGREE }\end{array}$

5. In general, I am pretty satisfied in dealings with my Franchisor.

6. My Franchisor is a good company to do business with.

7. I am satisfied with the products and services I get from my Franchisor.

8. I am satisfied in my relations with the field representative.

9. I am satisfied with the franchise contract.

10. If I have an opportunity to do it over again. I would not do business with the current Franchisor.

\section{PERSONAL DATA:}

11. Number of years with current franchisor?

12. Years of business experience prior to this franchise?

13. Nature of experience prior to this franchise:

14. GENDER: Male Female

AGE: _ Under 24 yrs _ 25 to 34 yrs _ 35 to 44 yrs _ 45 to 54 yrs _ greater than 55 yrs

EDUCATION: _ High School _ Some College _ College Degree _ Graduate School or Highe!

15. Annual Salary as the General Manager (check ONE): Less than $S 14.9$ thousand

$S 15$ to 24.9 thousand

S 25 to 34.9 thousand

— 35 to 44.9 thousand

$S 45$ to 54.9 thousand

$S 65$ to 74.9 thousand

- Greater than $\$ 75$ thousand

INCOME (from sources other than the current franchise): Less than $\$ 24.9$ thousand $\$ 50$ to 74.9 thousand S 100 to 124.9 thousand 25 to 49.9 thousand

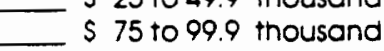
S 150 to 174.9 thousand

Please add below any comments you wish to make.

To receive a copy of research results, please enclose your business card. Postace poidenvelope is enclosed for your convenience. THANK YOU VERY MUCH! 
APPENDIX IX

RESEARCH SUMMARY TABLE 


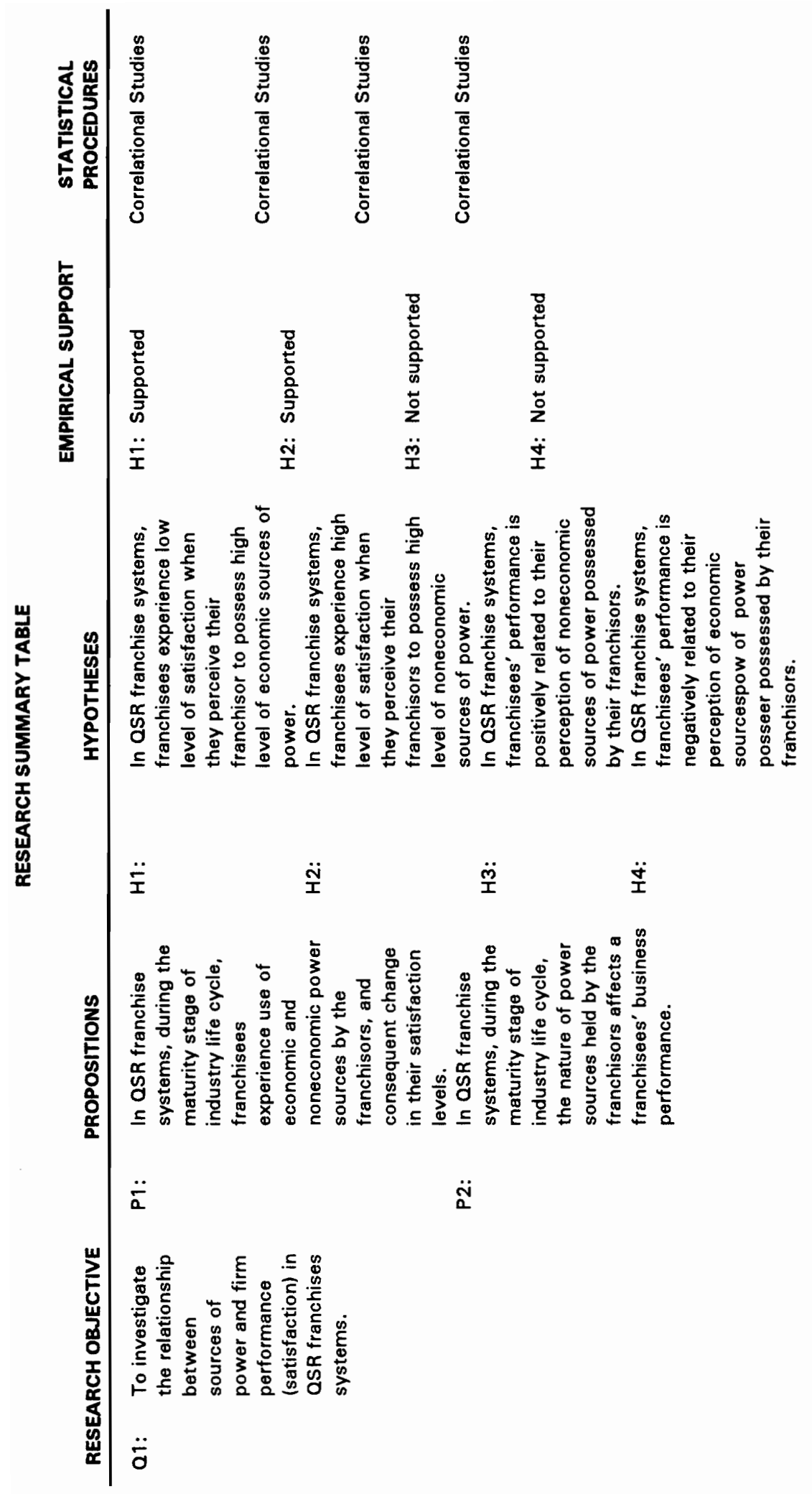




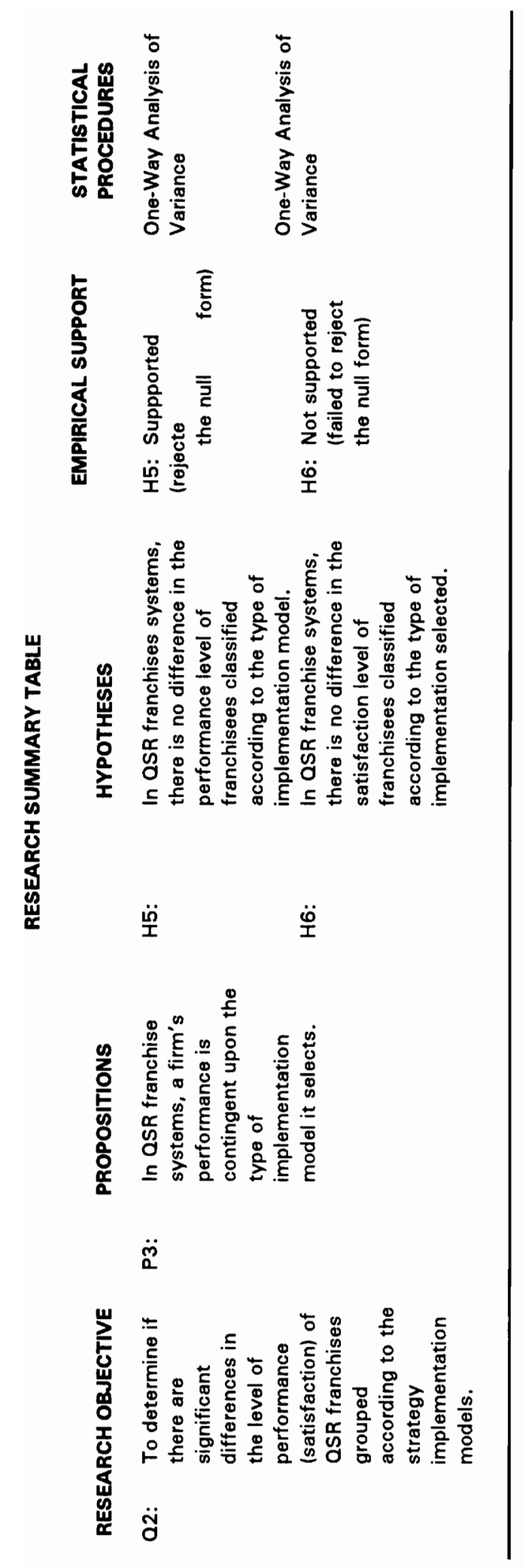




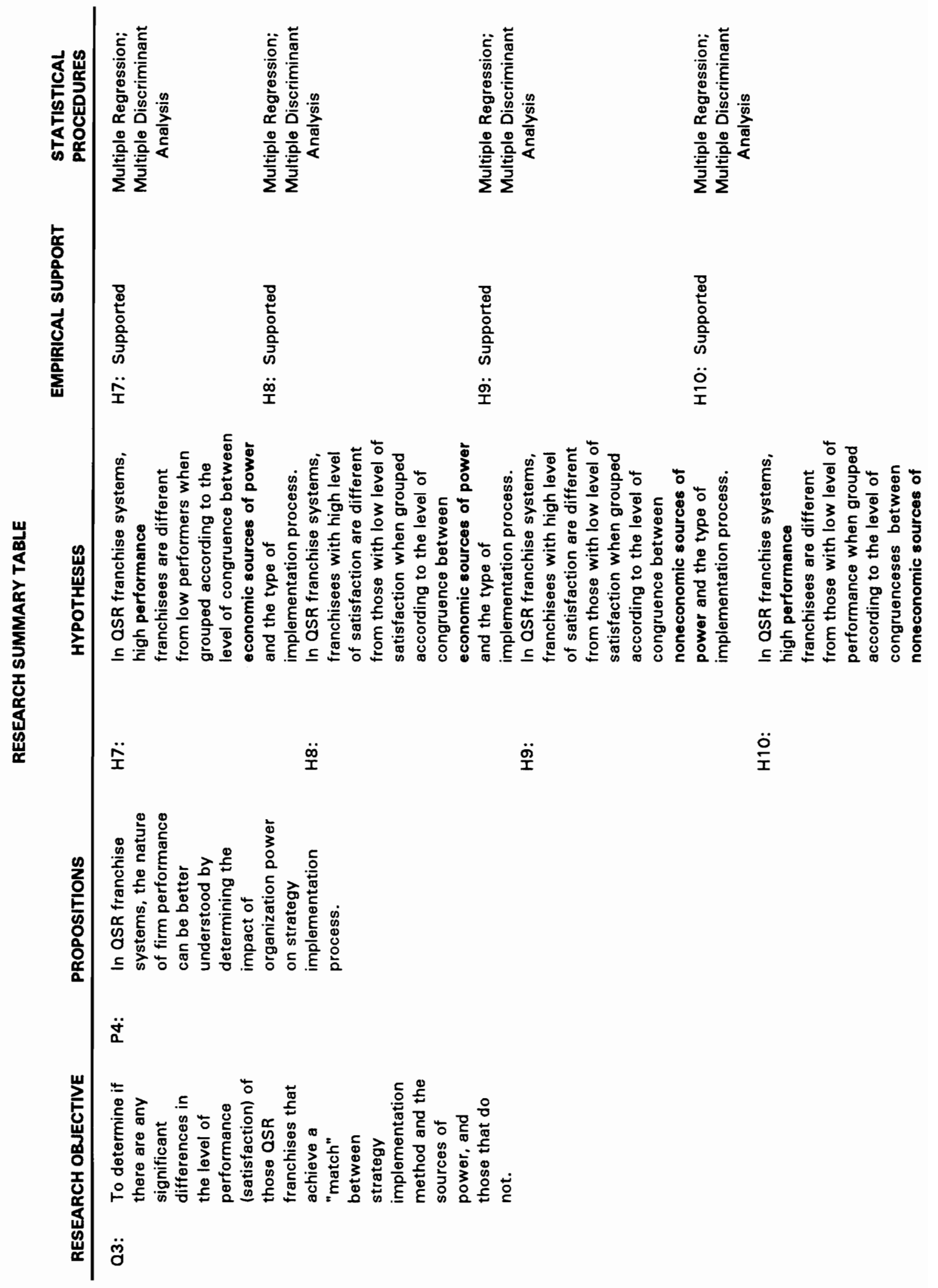


H. G. PARSA

Assistant Professor

103 Caudell Hall

Dept. of Nutrition, Hospitality \& Fashion

State University College at Buffalo (SUNY)

1300 Elmwood Ave, Buffalo, NY 14222

(716) $878-5714$

\section{EDUCATION}

Ph.D. Virginia Polytechnic Institute \& State University

Blacksburg, VA. January 1994.

(Hospitality and Tourism Management)

Central State University \& Rose State College

Oklahoma City, OK. 1986-1988

Accounting/Management Courses (36 hours)

M.S. University of Arkansas

Fayetteville, AR. 1978

(Food Science)

M.S. Osmania University

India 1974

(Biology)

B.S.(Honors) Osmania University

India 1972

(Chemistry)

\section{PROFESSIONAL EXPERIENCE}

1992-present State University of New York - College at Buffalo Buffalo, NY.

Assistant Professor. Responsible for teaching (three courses per semester), research, advisement, curriculum development, committee assignments, relevant administrative duties and service to the college and the community. Responsible for the following courses: Quantity Food Production \& Purchasing (NFS 300); Hospitality Marketing (NFS 390); Cases in Strategic Management in Hospitality (NFS 460); Advanced Human Resource Management (NFS 450); Computer Applications in Hospitality (NFS 350); Hotel Operations (NFS 389); Franchising \& Entrepreneurship in Hospitality (NFS 420) 


\section{Maior Accomplishments:}

Introduced four new hospitality courses and revised one existing course.

- Successfully coordinated the hospitality curriculum revision which received approval of the college senate and accreditation by ACPHA (August 1993).

- $\quad$ Participated in student recruitment activities that resulted in 36 percent increase between Spring 1992 and Fall 1993.

- Developed a hotel and tourism administration track to complement the current Food Systems Management program.

Proposed and developed an "Internal Quality Assurance Program for Hospitality Administration".

Initiated and Chaired the first strategic planning committee for the NHF department.

Contributed to the development of the Multicultural Food Experience (NFS 100) course.

Designed and developed a Capstone Course (NFS 480) for hospitality administration.

Initiated and implemented expansion of the Hospitality Advisory Board at SUNYC Buffalo from sixteen to twenty two members.

Organized and advised the Association of Hospitality Students.

1991-1992 Concord College

Athens, WV.

Visiting Assistant Professor. Responsible for student advisement, participation in curriculum] development, and teaching of the following courses including labs: Food and Beverage Management \& Lab (two sections); and Hospitality Marketing

Major Accomplishments:

- Redesigned the Food \& Beverage Management Lab to maximize the available on-campus foodservice facilities managed by the ARA Corporation.

- Developed plans for a new food service lab.

- Proposed a new course titled "Computer Applications in Hospitality Industry".

1988-1991 Virginia Polytechnic Institute \& State University

Blacksburg, VA.

Graduate Teaching Assistant. Responsible for teaching following undergraduate classes: Food and Beverage Management Lab (HNF 3414); The Capstone Course Lab (HNF 4414); Marketing part of the Capstone Course (HNF 4414). Frequent Guest Lecturer for the following courses: Introduction to Hotel, Restaurant and Institutional Management; and Food Purchasing, Production and Management 
Maior Accomplishments:

- $\quad$ Contributed to the Capstone Course instruction manual.

- $\quad$ Participated in computerization of the HRIM 4414 course lab manual.

1975-1978 University of Arkansas

Fayetteville, Arkansas

Graduate Assistant. Assisted the major professor in teaching classes and arranging labs for the following courses: Food Microbiology Lab (graduate level); Dairy Bacteriology Lab graduate level); Dairy Product Judging Lab (senior level).

1974-1975 Osmania University

Hyderabad, India

Research Assistant. Responsible for assisting the major professor in research projects and teaching undergraduate labs in Biology (senior level).

\section{RESEARCH CONTRIBUTION}

\section{Research Interests}

Nature of strategic planning process and implementation methods in the hospitality industry.

Application of behavioral theories to evaluate organizational effectiveness in hospitality franchise systems.

Effectiveness of the financial ratios as dependent variables in measuring organizational performance.

\section{Doctoral Dissertation Title (1994)}

"Exploratory Investigation of Organization Power, and Its Impact on Strategy Implementation and Firm Performance: A Study of the Hospitality Franchise systems"

\section{Masters Thesis (1978)}

"Effects of Partial Hydrolysis of Lactose on the Growth of the Lactic Culture and Some Proximate Analysis of Frozen Yogurt"

\section{Journal Publications}

Parsa, H.G. and M.A. Khan, (1993), "Quick Service Restaurants of the 21 st Century: An Analytical Review of Macro Factors," Hospitality Research Journal, V.17 (1) p161-174.

Parsa, H.G. and Khan, M.A. (1992), "Trends in the Quick Service Restaurant Industry," FIU Hospitality Review, V.10 (1) p19-26. 
Parsa, H.G. and Khan, M.A. (1992), "Menu Trends in the Quick Service Restaurant Industry During the Various Stages of Industry Life Cycle (1919-1988)," Hospitality Research Journal, V.15 (1) p93-107

\section{Conference Presentations}

Parsa, H.G. and M.A. Khan, (1993), "Power Perceptions, Strategy Implementation and Political Economy Framework: A Conceptual Integration," Society of Franchising Conference Proceedings, February, San Francisco, CA.

Parsa, H.G., M.A. Khan, and V. Vashi (1991), "Assessment of Royalty Fee Structures in the Hospitality Franchise Systems: An Econometric Alternative," CHRIE Annual Conference Proceedings, Houston, TX.

Parsa, H.G. and A.F. Kwansa (1991), "Financial Performance and Strategic Options in Hospitality Franchise Systems: A Franchisee Perspective," Society of Franchising Annual Conference Proceedings, Miami, FL.

Kwansa, F.A. and H.G. Parsa, (1990), "Business Failure Analysis: An Events Approach," CHRIE Annual Conference Proceedings, Washington D.C.

Parsa, H.G. and M.A. Khan (1990), "Menu Trends, During Various Stages Of The Fast Food Franchise Industry's Life Cycle: Impact of Environmental Factors," Society of Franchising Annual Conference Proceedings, Phoenix, AZ.

Parsa, H.G., M. Gustin, and M.A. Khan (1990), "Potential Conflict Points In FranchisorFranchisee Relations: An Exploratory Study of Fast Food Franchise Systems," CHRIE Annual Conference, Washington D.C.

Parsa, H.G. and M.A. Khan (1989), "Menu Trend Analysis," CHRIE Annual Conference (poster), Las Vegas, NV.

Murrmann, S.K. and H.G.Parsa (1989), "Students' Attitude on Acquired Immune Deficiency Syndrome (AIDS) and its Implications for Hospitality Education," Southeast CHRIE Annual Conference Proceedings, Spring.

Invited Presentations

Parsa, H.G. and M.A. Khan (1993), "Strategic Management in Franchise Systems," Annual Conference of Franchise Association of Australia-New Zealand, Sydney, Australia, June 20-24.

Parsa H.G. (1993), "Environmental Scanning in Strategic Management," Leadership Clearing House Lecture Series, State University of New York College at Buffalo, Buffalo, NY., November 13.

Parsa, H.G. and K.M. O'Brien (1993), "Lab-based Instruction of Multicultural Management: A Pedagogical Innovation," Round Table Presentation, CHRIE Annual Conference, Chicago, IL. 
Parsa, H.G. and N.P. Mishra (1993), "The 'Concept of Space' in Restaurant Designs: Futuristic Restaurant Designs for the Twenty First Century," poster presentation, CHRIE Annual Conference, Chicago, IL.

Parsa, H.G., M.A. Khan, and N. Rastogi (1991), "New Concepts for the New Decade: A Franchise Prototype for the 1990s," CHRIE Annual Conference, Houston, TX.

Parsa, H.G. and F.A. Kwansa (1990), "Performance of Hospitality Franchise Firms: An Institutional Economics Perspective," Association of Hospitality Financial Management Educators' Annual Conference, New York, NY.

Parsa, H.G. and S.K. Murrmann (1990), "Evolutionary Trends in Functional Areas of the Quick Service Industry from 1919 to 1988 ," Poster Presentation CHRIE Annual Conference, Washington D.C.

\section{Research In-progress}

Parsa H.G. (1993)," Organizational Performance Measures in Hospitality Strategy Research: Analysis of Theoretical Limitations and Suggestions for Future Research" in preparation for CHRIE conference.

Parsa H.G. (1994), "An Empirical Investigation of Strategy Implementation in Marketing Channels," in preparation for American Marketing Association annual conference.

Parsa H.G. (1993), "Comparative Analysis of Power Perceptions in Hospitality Franchise Systems: An Empirical Investigation" targeted for Hospitality Research Journal.

\section{Research Grant Activity}

Received a Research grant from the Center for Development of Human Services (1992), Buffalo, NY.: "Strategy Implementation in Not-for-profit Organizations"

Received a Research grant from the Center for Development of Human Services (1993), Buffalo, NY.: "Modification of Employee Performance Evaluation Systems to Achieve Strategy Implementation Objectives"

Made a grant request presentation with the Statler Foundation of Buffalo, NY (1992). Major scholarship grant is promised.

Two major grant proposals are presented with the Statler Foundation, Buffalo, NY.: "Institute for Research, Service, and Training in Hospitality"

"Computer Training and Computer Aided Design (CAD) Center in Hospitality for Greater Buffalo"

Made a grant proposal entitled "Educational Technology Lab for Graduate Student/Faculty Research and Training" in collaboration with the faculty members from the Business, Psychology and Sociology Departments at SUCB $(\$ 148,000)$. 


\section{SERVICE CONTRIBUTION}

\section{Administrative Responsibilities}

- Member, Search Committee for Dean of Faculty of Applied Sciences and Education, SUCB (1993-94)

Chair, NHF Dept. Strategic Planning Committee (1993-94)

Member, College Research Committee (1993-94)

Member, Department Budget Committee (1992-94)

Member, Department Curriculum Committee (1993-94)

In-charge of new faculty search for hospitality (1993-94)

United University Professionals Representative (1992-94)

Legislative Contact for United University Professionals (1993-94)

Group leader, preparation of self-study report for hospitality program accreditation by ACPHA (1992-93)

Coordinator, NHF department computer lab

- $\quad$ Liaison between the NHF department and the Wood Company, on-campus foodservice contractor, for arranging Quantity Food Production Labs (1993-94)

- Coordinator, FSM Program Advisory Council Strategic Planning Committee (1993-94)

- $\quad$ Advisor to over 50 undergraduate students (1992-94)

- Co-advisor, Phi Upsilon Omicron honor society (1993-94)

- Co-advisor, Association of Hospitality Students (1992-94)

\section{Professional Responsibilities}

- $\quad$ Paper reviewer, Society of Franchising Annual Conference (1990 - 1993)

- Member, Food Service Management Special Interest Section (CHRIE)

- Member, Professional Development Special Interest Section(CHRIE)

- $\quad$ Member, HEMAR chapter of CHRIE

- $\quad$ Past Member, Southeast CHRIE

Academic Honors

- $\quad$ Outstanding Graduate Researcher of the Year (1991)

- Winner of International Franchise Association Scholarship (1990)

- $\quad$ Graduate Teaching Assistant (1988 to 1991)

- $\quad$ Summer Research Seminar Presentation (1990)

- $\quad$ Chairman, HRIM Graduate Students Association Academic Affairs Committee (19891990)

Graduate Student Seminar - A (1977-1978)

- Best Graduate Student Seminar (1974)

\section{Professional Organizations}

Member:

- $\quad$ Council on Hotel, Restaurant, and Institutional Education (CHRIE)

- American Marketing Association

- $\quad$ Society of Franchising

- $\quad$ Association of Hospitality Financial Educators 
Past Member:

- $\quad$ National Association of Accountants

- Institute of Food Technologists

- $\quad$ American Dairy Science Association

- $\quad$ Southeast CHRIE

\section{Social Organizations}

- $\quad$ Strategic Planning Committee, Sweethome School District Amherst, NY - Past member of HRIM graduate students association

Group Leader: Dale Carnegie Seminars 1980 - 1981

- $\quad$ Past Member, Toastmaster International

- $\quad$ Active participant in PTA activities

\section{INDUSTRY EXPERIENCE}

Thirteen years experience - including Family Restaurants, Ethnic Concepts, Institutional Food Service and Quick Service Industry.

1987-88 Vo-Tech School Marketing Education Program, Oklahoma City, OK.

Industry Advisor. Provided guidance to Vo-Tech teachers in developing hospitality management and marketing courses.

1986-88 Wendy's International Inc., Oklahoma City, OK.

New Store Opening Coordinator.

Training Manger. Responsible for developing unit management staff, and conducting classes in Profit/Loss Statement analysis, total unit operations, Quality Service and Cleanliness (OSC) inspections, community involvement and Local marketing. Regarded as the 'Best General Manager Training Program in the Western USA Region' (1988).

1985-86 Taco-Tico Inc., Wichita, KS.

Area Manager. Responsible for Northeast Oklahoma State with 5 units, \$3 MM sales and twelve management staff, new product roll out, total area $P / L$ performance and management recruitment. Closely worked with the owners in streamlining the operations. Exceeded budget goals in three out of four quarters.

$1978-85$

Wendy's Int'I. Inc., Tulsa, OK. \& Tacoma, WA.

Training Instructor, Coordinator \& Instructor of training workshops and classes, and Personnel Recruiter.

District Manager responsible for 4 units and eighteen management staff. Won numerous awards for sales and profit performance, and management 
development. Third Highest Profit Improvement Area in the USA (1984): Supervisor of the Year (1982); Most Improved Store of The Year (1980).

1976-78 Pizza Hut Franchisee (A \& M Foods), Fayetteville, AR.

Management Trainee. Started as a part time employee and promoted as a management trainee. Responsible for shift management, opening and closing a restaurant.

1975-76 University of Arkansas, Fayetteville, AR.

Part-time employee at 'Arkansas Union' Food Service.

\section{PERSONAL INFORMATION}

Citizen U.S.A.

Married, Children: 2 boys and a girl

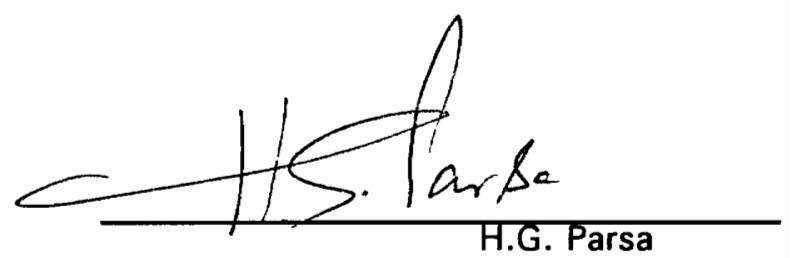

